\title{
UNCONSCIOUS MODULATION OF THE CONSCIOUS EXPERIENCE OF VOLUNTARY CONTROL
}

\section{DISSERTATIONSSCHRIFT}

zur Erlangung des akademischen Grades

Doctor rerum naturalium

(Dr. rer. nat.)

vorgelegt

DER FAKULTÄT MATHEMATIK UND NATURWISSENSCHAFTEN

DER TECHNISCHEN UNIVERSITÄT DRESDEN

von

Dipl. Psych. Katrin Linser,

geboren am 11. Februar 1974 in Wien (Österreich) 


\section{Contents}

1 Introduction $\quad 1$

2 Theoretical Background $\quad 5$

2.1 The philosophical debate on freedom of will 5

$\begin{array}{lll}2.2 & \text { Cognitive features of voluntary action } & 11\end{array}$

2.2.1 The role of effect-anticipation in voluntary action 11

2.2.2 Representational bases of controlled action 17

2.3 Unconscious processes in intentional action 22

2.3.1 The Libet-study 23

2.3.2 Unconscious modulation of forced-choice actions 27

2.3.3 Unconscious modulation of free-choice actions 33

2.4 The experience of voluntary control 36

2.4.1 Wegner's theory of apparent mental causation 36

2.4.2 The internal forward model theory and the sensory attenuation-hypothesis 40

2.5 Aim of the current work $\quad 45$

3 Experimental Part $\quad 47$

3.1 Introduction 47

3.2 Experiment 1 - Unconscious Modulation of experienced control in forced-choice action $\quad 49$

3.2.1 Methods 50

3.2.2 Data analyses and results $\quad 55$

3.2.3 Discussion 57

3.3 Experiment 2 - Unconscious modulation of experienced control in free-choice action $\quad 58$

3.3.1 Methods 58

3.3.2 Data analyses and results $\quad 62$

3.3.3 Discussion 64 
3.4 Experiment 3 - 'Reversed' unconscious modulation of experienced control

3.4.1 Pilot study: Forced choice priming task

68

3.4.1.1 Methods and procedure

3.4.1.2 Results and conclusion

3.4.2 Main study: Free-choice control-judgment task

3.4.2.1 Methods and procedure

3.4.2.2 Results

3.4.2.3 Discussion

3.5 Experiment 4- 'Reversed' unconscious modulation of

3.5.1 Methods experienced "effect" - predictability

3.5.2 Data analyses and results

3.5.3 Discussion

4.2 The present data in relation to earlier work

4.2.1 The present data and Wegner's theory of apparent mental causation-Unconscious processes in experienced control

4.2.2 Which mechanisms mediate the influence of unconscious effect-primes on conscious control? The present data and the internal forward model control

4.3 Voluntary action investigated in the lab

4.4 Is conscious will an illusion? 


\section{Figures}

\section{Theoretical Background}

1 Action control according to the ideomotor principle 14

2 Schematic view of the results obtained by Libet et al. (1983) 24

3 Unconscious activation of forced-choice action 29

4 Unconscious inhibition of forced-choice action - behavioral and electrophysiological evidence for the 'reversed' priming effect 31

5 Daniel Wegner's model of apparent mental causation 37

6 Action prediction and experienced control based on the forward model of motor control theory

\section{Experimental Part}

7 Experimental setup of the control-judgment task in Experiment 1

8 Control judgment scale used in Experiment 1

9 Experimental setup of the priming task in Experiment 1

10 Experimental setup of the prime-identification task in Experiment 1

11 Results of Experiment 1 57

12 Experimental setup of the control judgment task in Experiment $2 \quad 60$

13 Data of Experiment 2 for participants classified as 'non-detectors' and 'detectors' 64

14 Experimental setup of the 'reversed'-priming task $\begin{array}{ll}\text { Experiment } 3 \text { (pilot-study) } & 69\end{array}$

15 Experimental setup of the control-judgment task $\begin{array}{ll}\text { in Experiment } 3 \text { (main study) } & 73\end{array}$

16 Results of Experiment $3 \quad 74$

17 Judgment-scale of experienced "effect"-predictability
in Experiment 4

18 Results of Experiment $4 \quad 81$ 


\section{Chapter 1}

\section{Introduction}

Voluntary action represents a fundamental behavior in our daily life in which we constantly decide what to do next ${ }^{1}$. Are we getting to work by train or by car? Read a book or go to the gym in the evening? Work or visit a friend at the weekend? Human action is inseparably linked to decisions of this kind. The concept of volition tries to explain our past and future actions, to others as well as to ourselves.

Along with controlled action comes a specific conscious experience well known to each of us: the experience of conscious will and control, the characteristic feeling that $I$ am the author of the action. This experience of conscious will and voluntary control is a most central feature of human self-conception. However, the intuition that our intentions are the immediate causal triggers to our actions and their sensory consequences has been challenged by several findings. It has been shown that the processes which trigger intentional actions are often unconscious (e.g., Libet, Gleason, Wright, \& Pearl, 1983; Libet, 1985). Both, initiation and selection of our

\footnotetext{
1 In psychology, the term 'behavior' refers to the entirety of physical and psychological activities expressed by an individual with respect to his current environment (Dorsch Psychologisches Lexikon). In contrast to this rather inclusive concept of human activity, the term 'action' is defined more narrowly. 'Action' refers to a delimited unit of activity which is directed towards the realisation of a goal (e.g., Hacker, 1998; Hommel, 2002; Lewin, 1926; Rubinstein, 1984; Volpert, 1974). Action-goals are anticipated future effects which can be realized by an action (e.g., a particular event in the environment, a desired emotional state of an individual), (Prinz, 1998, 2000; Hommel, 2002). In the present work, the terms 'behavior' and 'action' will be used according to this differential understanding.
} 
voluntary actions are systematically affected by stimuli which are not consciously perceived by the actor (Neumann \& Klotz, 1994; Eimer \& Schlaghecken, 1998; Klapp \& Hinkley, 2002; Wendt-Kürschner, 2006). People often misjudge the extent to which outcomes are a result of their intentional behavior. Illusory control occurs when people overestimate the impact of their actions on events in the world (e.g., Langer, 1975; Langer \& Rodin, 1976; Wegner \& Wheately, 1999; Wegner, 2002). In every day life this happens for instance in superstitious action. In superstitions action people infer causality between their action and a subsequent event because they observed a repeated co-occurrence between a particular action (e.g., bring a talisman to an exam) and a subsequent event (e.g., get a good grade) even though, in fact, the relationship is not causal (Haggard, 2005). In a similar way the sense of authorship can go erroneously astray. Feelings of involuntariness for actions and effects which are actually self-caused are sometimes reported by people who are under hypnosis (e.g., Spanos, 1986; Lynn, Rhue \& Weekes, 1990; Kirsch \& Lynn, 1998; Haggard, Cartledge, Dafydd, \& Oakley, 2004) or by people who are engaged in spiritual games (e.g., table turning), (Carpenter, 1888; Janet, 1889; Solomons \& Stein, 1896). Moreover, such delusions of control are experienced by patients with specific psychiatric and neurological disorders such as schizophrenia, dissociative identity disorder, or the alien hand syndrome. It happens as a part of the clinical picture that some patients with these disorders misattribute self-caused actions to an external cause and feel their thoughts and actions to be controlled by external agents $^{2}$ or forces. Other patients, to the contrary, may erroneously feel in control over actions or events which are in reality externally caused such as other peoples' thoughts and actions or coincident events which they observe in the world. The mechanisms which underlie these dissociations have only begun to be understood (e.g., Frith, 1992, 2005; Frith, Blakemore, \& Wolpert, 2000; Spence, 2001; Jahanshahi \& Frith, 1998).

\footnotetext{
${ }^{2}$ In the current work, the term 'agent' refers to organisms, in particular humans, which constantly interact with their environment. This interaction is mutual, i.e., the interaction affects not only the sensors of the agent himself but also the environment he interacts with.
} 
The study of volition thus has to address at least two major questions: (1) what are the basic processes leading to action? (2) What are the processes generating the conscious experience of authorship and voluntary control? The current work is primarily dedicated to the latter issue.

According to a widely held view voluntary action is closely tied to our ability to mentally represent the future effects of our actions (cf., Lotze, 1852; James, 1890/1950; Michotte, 1954/1963; Elsner \& Hommel, 2001; Prinz, 1997, 1998, 2000; Goschke, 2003). Recent conceptions of voluntary action and experienced authorship have proposed that such mental representations or effect-anticipations also play a central role in the generation of the conscious experience of voluntary control. According to one concept accurate predictions or anticipations of action-effects lead to self-attribution of authorship and control because a match between actual and predicted consequences of an action produces an attenuation of the sensory representation of the perceived effects (e.g., Blakemore, Wolpert, \& Frith, 1998, 2000, 2002; Frith, 2005). According to the second concept correct previews of actioneffects lead to the retrospective perception of an apparent causal link between one's intention and action (e.g., Wegner, 2002, 2003, 2004; Wegner \& Wheateley, 1999). Based on the common core assumptions of these approaches the present work attempted to specify the role of effect-anticipation in the generation of the experience of voluntary control. The basic hypothesis was that the experience of control emerges from a comparison between anticipated and actual action-effects: if an event that follows an action as its potential effect is correctly anticipated before the action the event will be experienced as self-caused. Conversely if no or an incorrect effect-anticipation has occurred control will be attributed to an external cause rather than to the self. Specific consideration was given to the question of whether such effect anticipations must be available to consciousness or whether effect-anticipations can affect conscious control also on an unconscious level. In four 
experiments the effects of unconscious effect-anticipation on the experience of action control were investigated.

Chapter 2 provides an overview over theoretical approaches and empirical findings concerning the mechanisms which underlie action control and - in particular concerning the processes involved in generating experienced agency and control. Since obviously, voluntary action, conscious control and authorship-experience are not exclusively psychological issues, Chapter 2 will at first focus on the philosophical question of whether our voluntary actions are "free" or causally determined by external antecedents. The central positions taken in this debate on 'freedom of will' by libertarians, determinists and compatibilists will be outlined and discussed. Thereafter, the focus will shift on the cognitive features of voluntary action in general and the role of effect-anticipation in action control in particular. How do we acquire controlled action skills? What are the representational bases of action control? It will then be illuminated that actions are affected by effect-anticipations not only when they are conscious but even when they remain unavailable to awareness. The empirical findings on how unconscious effect-anticipations affect the control of forced- as well as freely chosen actions will be discussed with respect to our understanding of the role of conscious intention in action. The focus will then shift more narrowly on the question of the processes involved in generating the experience of voluntary control. Based on the hypothesis that effect-anticipations do not only affect the control of action but also experienced control, two recent theoretical approaches will be discussed: (1) Wegner's concept of apparent mental causation and (2) the 'sensory attenuation hypothesis' proposed by Frith and colleagues' internal forward model approach. Within this theoretical framework the aim of the current thesis, i.e., to investigate the influence of unconscious effectanticipations on the experience of voluntary control, will be elaborated. Thereafter, in Chapter 3, own experiments to investigate this question are described. 


\section{Chapter 2}

\section{Theoretical Background}

\subsection{The philosophical debate on freedom of will}

The subjective feeling of authorship and control is deeply embedded in our selfconceptualization as autonomous intentional agents as well as in our commonsense psychology (Goschke, 2003). As William James put it, “The whole sting and excitement of our voluntary life...depends on our sense that in it things are really being decided from one moment to another, and that it is not the dull rattling off of a chain that was forged innumerable ages ago" (1890/1950, Vol. 1, p. 453).

To an actor the conscious experience of will appears to testify a privileged introspective access towards the mental antecedents of his voluntary actions. This in turn generates the impression that as an autonomous agent one could - in principle - have decided and acted otherwise, even under identical conditions (Walter, 1998). When asked why at this very moment you are reading these pages instead of going to the gym, lying in the sun, or giving your best friend the long due call your answer - supposed you were under no external coercion - probably will be that you did so because you decided to do so. Could you have done otherwise? Of course you could, you might reply: if you had decided to go to the gym you would have done so (Goschke, 2003, 2004). 
What appears so evident from introspection is the central issue of an old and the same time very recent philosophical debate on the problem of the freedom of will which has been a principal topic of European philosophy and metaphysics since Descartes (1664) in general, and, since Kant (1788/1995) in the German philosophical tradition in particular. This debate is at its core a conflict between two contrary ideas. A so-called libertarian conception of free will is defended against a deterministic conception of voluntary action. The primary question of this classic dichotomy seems to be whether at least some of our actions are up to our free choice or whether they are determined by mechanisms beyond our conscious control (Wegner, 2002, 2004). An attempt to dissolve this antagonism has been made by compatibilists who have introduced a modified version of the traditional notion of freedom that is compatible with determinism (Walter, 1998; Bieri, 2001; Dennett, 2003; Goschke, 2003; Pauen, 2004).

In the last couple of years the subject of free will has become a major issue of a public scientific debate which is carried out via newspapers' feuilletons. Why is there so much concern? The way we account for the question of free will has profound practical and ethical implications because it is closely linked to the concept of moral responsibility, especially in the western cultures (Walter, 1998; Wegner, 2002; Goschke, 2003; Bieri, 2001). Our moral evaluation of an action depends crucially on whether we regard it as a willed action, or as an automatic response. Yet, would it make sense to disapprove a person for an act we despise and cherish another for an act we appreciate if, ultimately, these actions were determined by antecedents beyond the person's conscious control? In this respect the issue of conscious will is taken up in most civilized penal systems. Judgment is based on the principle of mens rea, 'a guilty mind' (Hart, 1968, p. 114) according to which the state of mind indicating the culpability of a delinquent is required as an element of crime. Conversely, criminal responsibility is dismissed in case of diagnosed "disturbances of consciousness in persons who retain the capacity to engage in goal-directed conduct based on prior learned responses" (Bonnie, 
Coughlin, Jeffries, \& Low, 1997, p. 107). Thus, we judge and punish someone when we believe that he decided consciously and could in principle have done otherwise - under identical conditions.

\section{Libertarianism}

The Libertarian concept of free will implies several premises which largely correspond to what most people refer to when intuitively speaking of free will and voluntary action. The first premise includes the belief that human behavior is not determined by external conditions. This implies the idea that even under completely identical conditions one could have decided otherwise. The second premise holds that the very origin of the causal chain leading to action resides in the actor himself in that his 'conscious self' generates the decisions and intentions leading to action. Third, the decisions made by an agent are intelligible and rational: actions are chosen for good reasons with respect to the agent's beliefs, desires and intentions (Walter, 1998, 2004).

The belief that human behavior is not determined by external causes, but is the result of conscious choices made by agents' conscious selves entails both dualism and mind-body causation: A conscious thought (intention) would need to activate the motor areas in the brain and set in motion the relevant muscles to realize an action. Mental-to-physical causation, however, contradicts the scientific assumption that the world is causally closed and determined. Such approaches are therefore incompatible with naturalistic conceptions of voluntary action which assume that intentions - as mental states in general - are realized in neural processes (e.g., Haggard, 2005; Goschke, 2003; see also Lautenbacher \& Gauggel, 2004).

\section{Determinism}

Determinism claims that all events - including intentions, decisions, actions and their effects - are inevitably set by past events. In the case of physical determinism, 
it is assumed that a current state of the world $A$ together with the laws of nature necessarily leads to a particular future state of the world B (Walter, 1998). According to deterministic conceptions of voluntary action, this principle applies to human action as well. Thus, it is supposed that actions are a causal consequence from distinct psychological states, such as for instance current constellations of desires and beliefs which themselves are results of factors like for instance genetics, experience, culture, and many more others. In concert with the given situational constraints, they bring forth just one particular intention and the corresponding action (Wegner, 2004). What prevents us from tracking back this causal chain and thus leads us to invent mental causation as an alternative explanation is in this view merely a consequence of our limited epistemic access (e.g., Singer, 2004; Markowitsch, 2004).

In conclusion, determinism implies that the causal chain of each action leads back to antecedents which have occurred in the remote past. This seems to entail that, ultimately, our intentions and actions are caused by mechanisms beyond our control (Van Inwagen, 1983). Clearly, it rules out that an actor could have decided otherwise under identical conditions. Accepting determinism in the context of willed action thus raises several questions: Can we hold on to the common conceptual differentiation between voluntary actions on the one hand and involuntary responses on the other? Is determinism at all reconcilable with an idea of free will and our common notion of moral responsibility? Or would we, as Benjamin Libet (1999) has portrayed it, be "...essentially sophisticated automata, with conscious feelings and intentions tacked on as epiphenomena with no causal power" (Libet, 1999, p. 47)?

\section{Indeterminism and agency - the libertarian dilemma}

Claiming that freedom must imply 'genuine' choice, that is, an actor must have the possibility to decide otherwise under identical conditions and constraints, the hard- 
line libertarian should reject the idea to reconcile 'freedom' with a deterministic concept of voluntary action. As it turns out, however, libertarian indeterminism raises a conceptual dilemma of its own. This dilemma refers to the fact that indeterministic events are random or arbitrary events (Bieri, 2001; Walter, 2004; Goschke, 2003; Wegner, 2002; Dennett, 1984). Yet, freedom of will is appreciated to guide actions with respect to the agent and thus in a non-random and rather systematic way. Undetermined will would be a mechanism unresponsive to past influences of any kind - at least not responsive in a systematic way. Action would then rely on arbitrary and unpredictable - ultimately random - decisions (Wegner, 2002). If actions were as such immune to past influence, how should they be intelligible? How should they relate to the personal 'self' of the actor including his experiences, basic beliefs and current desires?

The observation that, in fact, indeterminism subverts authorship rather than preserving it has been recognized as early as in 1910 by William James asking, "If a 'free act' be a sheer novelty, that comes not from me, the previous me, but ex nihilo, and simply tacks itself on to me, how can $I$, the previous I, be responsible?" (James, $1910 / 1963$, p. 53). As it turns out, indeterminism itself is irreconcilable with one basic libertarian intuition related to free will: agent-responsibility.

Apparently, this evokes the conclusion that freedom of will as we "feel" it exists neither in a deterministic nor in an indeterministic world. An alternative strategy, however, would be to redefine the notion of freedom reconciling it with causal determinism. This has been attempted by compatibilists.

\section{Compatibilism}

Compatibilists argue that determinism is a precondition rather than the barrier of personal authorship and control: voluntary actions are related to an actor in that they are causally determined by his beliefs, desires, and intentions (Beckermann, 2004; Walter, 1998, 2004; Bieri, 2001; Dennett, 1984; Goschke, 2003, 2004, 2006). 
According to Goschke intentions are "constraints" rather than "immediate triggering causes" of our voluntary actions which "modulate the readiness of responses to become activated by specific stimuli" (Goschke, 2003, pp. 50-51). In compatiblistic terms, voluntary actions differ from involuntary responses not because they are undetermined but because they are determined in a different way. As the philosopher Daniel Dennett has put it, "Determinism is the friend, not the foe, of those who dislike inevitability" (Dennett, 2003, p. 60; also Beckermann, 2004).

Admittedly, this weakened notion of freedom implies that we could not have acted differently under identical conditions and abandons thus one basic intuition related to 'free' will (Walter, 1998; Goschke, 2004). Besides, it is controversial whether compatibilism can resolve the problem of moral responsibility (Beckmann, 2004; see also Goschke \& Walter, 2005; Walter \& Goschke, 2006). However, the compatibilistic concept fits with the scientific purposes of experimental psychology and neuroscience because it implies that the causal antecedents of voluntary action are mechanisms that are open to empirical causal analysis (Prinz, 2000, 2004). Thus, given that we can specify how voluntary actions differ from involuntary responses 'objectively' compatibilism does permit us to maintain the concept of voluntariness in avoiding indeterministic dilemmata and dualism.

Accordingly, what the compatibilistic approach assigns to cognitive scientists is to specify the neuro-cognitive aspects which distinguish voluntary action from more basic categories of behavior such as automatic responses, reflexes or habits. To illustrate this point, consider the following example: To an actor, there is a marked experiential difference between the movement of his hand when he - reflexively pulls his hand back from, say, an electric fence compared to when he - voluntarily beckons the waiter in the restaurant to order the bill. To an external observer, however, this difference is not obvious. The following chapter will thus address to the cognitive features which characterize voluntary action. At the beginning of the chapter, different levels of action control will be discussed. From the cognitive 
features that characterize actions at lower levels of control such as reflexes and habitual responses the chapter focus will turn to voluntary action. In this respect it will be addressed that voluntary action which - at the highest level of action control - is to be distinguished from reflexes or habitual responses by the cognitive feature to anticipate the potential future effects (goals) of their actions.

\section{2 Cognitive features of voluntary action}

\section{2. 1 The role of effect-anticipation in voluntary action}

In the course of evolution organisms have developed different forms of action control. The progress in this development is characterized by a gradual increase in behavioral flexibility, i.e., in the degree to which behavior can be selected independent from a current external environment or a present internal state (Goschke, 2002, 2004, 2006).

At the most basic level innate reflexes constitute the least flexible form of behavior. Innate reflexes are controlled by predetermined response programs which are automatically and inevitably triggered in a fixed fashion by fixed external stimulus conditions. An example of a behavior which is controlled in this way is the patella reflex.

Another form of behavior is need-state-driven behavior. Different from reflexes, trigger stimuli are located not only in the environment but also 'within' the organism with respect to its current motivational- or need-state. The current need state of an organism, e.g., hunger, sets the respective response program, eat, in a state of readiness. Thus, need-states do not immediately trigger responses in a fixed way but when appropriate trigger stimuli are available the behavior is executed. For 
example, a food-deprived fruit fly will inevitably proceed to food when available. In humans need-states also set ready the need-correspondent action-program. For instance, when actions are merely need-state-controlled the desire for sugar would lead an organism to consume chocolate as soon as available.

A somewhat increased degree of behavioral flexibility becomes evident in habitual responsive behavior which is provided by procedural learning. Procedural learning enables organisms to modify or expand behavioral dispositions on the long run corresponding to individual experiences. However, the formation is slow and once a habit is formed modification possibilities and flexibility are limited.

The evolutionary step-stone to behavioral flexibility occurs in voluntary action which we know as humans. In contrast to innate reflexes, need-state-driven behavior, and habitual responses, voluntary action is - by definition - directed to goals (e.g., Hoffmann, 1993; Jeannerod, 1994; Goschke, 1996; Prinz, 1997, 1998, 2000; Jahanshahi \& Frith, 1998; Dörner, 1999; Elsner \& Hommel, 2001; Schall, 2001). In terms of a definition given by Prinz (1997) goals are intended future effects. Voluntary action thus invokes an essential cognitive ability: the ability to form internal representations of future action-effects (James, 1890/1950; Lotze, 1852; Michotte, 1954/1963; Hoffmann, 1993; Hommel, 1998, 2000, 2003; Elsner \& Hommel, 2001, 2004; Goschke, 2000, 2003). On the time scale such effect-anticipations vary from instant sensory experiences of a separate act, - e.g., the experience how splendid it tastes when I enter a piece of chocolate into my mouth, - to long term consequences of actions, - e.g., that I will feel sick within the next hour if I finish the whole bar or that I will gain weight within a few years if I eat chocolate every day. Importantly, the possibility to select action with respect to anticipated action effects liberates actors from both the current stimulus environment, e.g., chocolate available, and the present desire or need state, e.g., to consume sugar (Goschke, 1996, 2000, 2003). 
Thus, in contrast to reflexive responses which are triggered by currently available stimuli and mediated via fixed neuronal pathways voluntary actions are based on internal representations of future effects of actions and goals as well as on evaluations of these anticipated future states with respect to values, beliefs, intentions and desires of an individual actor (e.g., Rubinstein, 1984; Goschke, 2003, 2006). In this view an actor's hand-movement pulling it back from an electric fence differs from the superficially similar movement of beckoning the waiter to order the bill. The latter is selected in terms of its anticipated consequences, i.e., the intention to pay the bill and leave the restaurant.

This conclusion leads directly to the question of how we learn to control actions in terms of effect-anticipations and goals. It will be addressed in the next section.

\section{The acquisition of action control - The ideomotor principle}

The idea that effect-anticipations play a key role in the control of voluntary action has a long history. Inspired by his predecessors Lotze (1852) and Harleß (1861), William James was among the first to note that voluntary action is based on "...the anticipation of the movements' sensible effects, resident or remote..." (James, 1890/1950, Vol. 2, p. 521). Central to James' celebrated essay on the cognitive principles of 'will' is the proposal that action control relies on an ideo-motor principle. The ideo-motor principle holds that ideas - mental representations of intended actions and their effects - can evoke the actions which have been learned to produce them. According to the ideo-motor principle two processes are involved in the acquisition of controlled action. First, randomly produced movements lead to particular changes in the environment (perceptual effects); the respective motor pattern is then associated with its effect. Secondly, once such an action-effect association has been acquired, action control occurs because actions are automatically activated by anticipating their consequences (see Figure 1). 


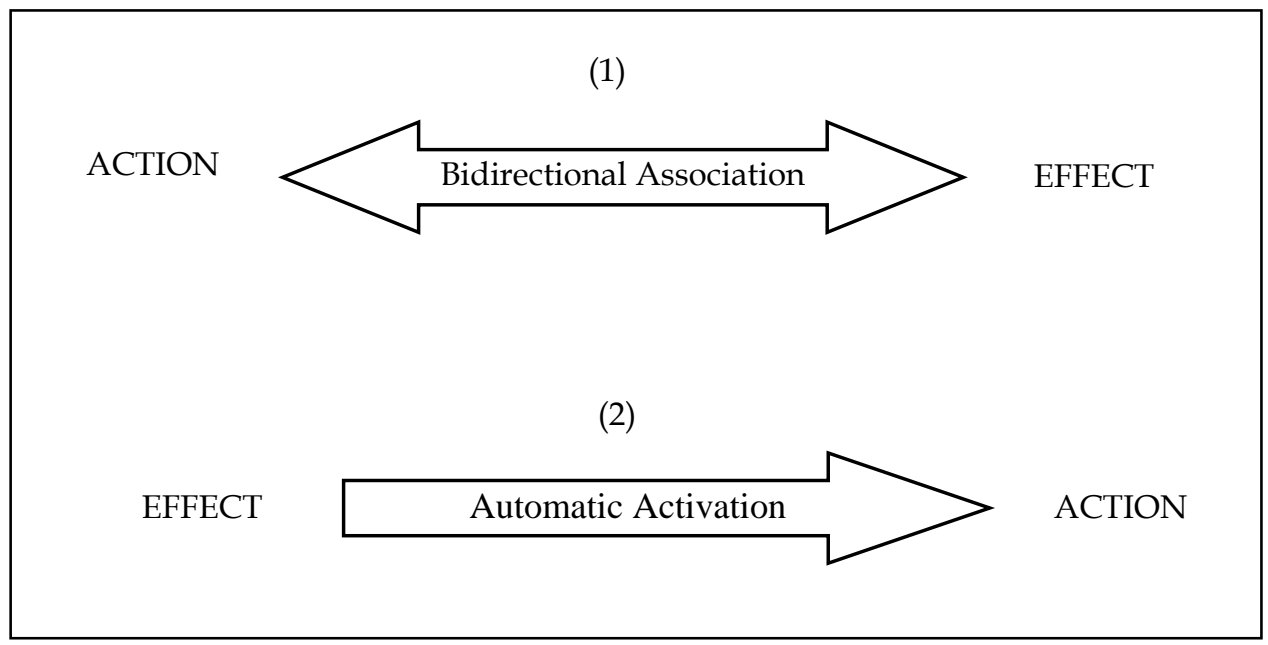

Figure 1. Action control according to the ideomotor principle. Two mechanisms are involved. (1) Initially, actions which are incidentally generated produce specific changes in the environment. The motor pattern of that action is then associated with that effect in a bidirectional way. Once action effect associations are obtained, action control occurs (2) on the basis that actions are automatically elicited by anticipating their effects.

The claim that the learning of skilled voluntary action occurs based on a two stage learning process paved the way for contemporary theories of voluntary action. A recent approach which was taken on this issue will be addressed in the following chapter.

\section{The acquisition of controlled action: a two-stage model}

In the spirit of the pioneering work of James, Lotze, and Harleß in the $19^{\text {th }}$ century, Elsner and Hommel $(2001,2004)$ proposed a model of action control which describes the mechanisms underlying the acquisition of action skills. Based on the idea that associations between actions and their effects are functional in action-control, their conception puts forth that these associations are acquired in a two-stage learning process. In the first stage, actions are generated at random. The sensory effects which follow from these actions are perceived, registered and stored in memory (see also Piaget, 1952). For example, a baby which - initially random - moves it legs. By chance it happens to kick toy-rattle above its bed. The baby might do this over and 
over again such that, after some time, when the movement-effect co-incidence has occurred repeatedly the baby will register this co-occurrence. At the next step, the baby will move its legs on purpose to achieve the - now anticipated or desired effect. That is, if a particular action, e.g., leg movement, and an effect, e.g., rattling, co-occur regularly the two events are, at the second stage, bi-directionally associated. Bi-directional associations of actions and their effects provide that representations action effects, e.g. mobile clacking, co-activate the motor pattern suitable to produce it, e.g., leg moving. It is suggested that this learning mechanism proceeds largely automatic. That means that no explicit intention, conscious effort or intentional assignment of attention is required to acquire bi-directional action-effect associations. Rather this learning process is supposed to happen incidentally by acting (Hommel, 1996).

To test their model empirically Elsner and Hommel (2001) conducted an experiment which consisted of two phases. In an initial learning phase participants were instructed to perform left and right key-presses. While doing this they observed cooccurrences between their key-presses and high- and low-pitched tones which followed the key-presses as effects. In order to establish incidental learning the action-outcome co-occurrences were irrelevant to the task and remained unmentioned in the instruction. In a subsequent test-phase the former effect-tones were used as imperative stimuli now indicating a mapped left- or right key-press response. The mapping of key and target was either consistent or inconsistent with the associations that had been learned in the previous acquisition phase. In accordance with the assumption that learned action-effect co-occurrences would on the second stage become functional to the control of action it was predicted that responses in the test-phase would be faster when the key-target mapping was consistent with key-effect mapping in the learning-phase compared to when it was inconsistent. This prediction was supported by the data. Depending on the learned action-effect associations participants responded faster and more accurate in the consistent than in the inconsistent mapping condition. This was considered as 
evidence that learning of action-outcome co-occurrences proceeds automatically and leads to bi-directional action-effect associations which. These acquired bidirectional action-effect associations become in turn functional to the control of action. Actions are controlled in terms of the effects which have been learned to produce them (Elsner \& Hommel, 2001, 2004; Prinz, 1997, 1998; Kunde, Hoffmann, \& Zellmann, 2002).

In a subsequent experiment which was part of the same study Elsner and Hommel (2001) tested whether anticipations of bi-directional action-effect associations would also influence the selection of actions which could be freely chosen by the participants. The paradigm was the same as in the first experiment, except for one major modification: the test phase now consisted of a free-choice task. As in the first experiment participants first observed action-outcome co-incidences. In the following free-choice test-phase the former effects were shown before an unspecific go-signal which indicated participants to freely choose whether to press a left or a right key. Results revealed that the learned associations had systematically modulated participants' responses also under free-choice conditions: they selected more key-presses that were consistent with the learned associations than keypresses which were inconsistent with the learned action-event mapping. Thus, even though participants had been "free" to select whether to perform a right or a left key-press, their choices were biased by the learned associations (see also Kunde, Koch, \& Hoffmann, 2004).

Taken together, these results support the idea that bi-directional action-effect associations which are acquired automatically in a bi-phasic learning process play an essential role in the initiation and selection of both pre-determined and freely chosen actions. How are these associations represented in the brain? 


\section{2. 2 Representational bases of controlled action}

Goal-directed interaction with the world involves both movement to realize an action and perception to register sensory events in the environment as possible action-effects. Perception, as an afferent process, starts with stimuli from the environment. These stimuli produce patterns of stimulation in sense organs and generate sensory codes in the brain. Movement, as an efferent process, originates in the motor codes of the brain. These motor codes represent certain patterns of activity and set in motion the relevant motor effectors to realize an action. Due to the fact that "...even the simplest behavior is assembled from both perception and action..." (Massaro, 1990, p. 135; see also Hommel, Müsseler, Aschersleben, \& Prinz, 2001), the achievement of a goal depends crucially on the efficient co-operation between perception and action (Prinz, 1997, 1998; Hommel, Müsseler, Aschersleben, \& Prinz, 2001; Eimer \& Schlaghecken, 2003). Two general ideas on how perception and action are represented in the brain in order to interact functionally have been proposed.

\section{Separate coding of perception and action}

The first idea goes back to Descartes (1664) who assumed separate pathways and different principles of processing for perception and action. In the spirit of his times, he pictured processing in the human sensory-motor system in terms of mechanics and hydraulics with the pineal gland on top of the hierarchy as an executive control instance to co-ordinate sensory input and motor output. Afferent conduction was described mechanically. The idea was that sensory input 'plucks at specific nerve fibers which terminate in the pineal gland. The pineal gland was supposed to 'translate' input from afferent mechanics by releasing a specific pattern of 'nerve fluid' into the efferent system. This 'translation' was assumed to cause hydraulic pressure onto the corresponding motor effectors. The hydraulic pressure was thought to finally elicit movement execution. Today we know that the pineal gland 
produces melantonine and is involved in controlling circadian and seasonal rhythmics, e.g., sleep, (Carlson, 2004).

Since Descartes, traditional models of pereptuo-motor interaction have adapted the view that perception and action are separate in terms of their representational status and their underlying control processes. The translation metaphor has therefore long remained the standard way to describe perceptuo-motor interaction in humans. For instance, Welford (1968) proposed a computational model according to which the human sensory-motor system operates on the basis of three separate divisions of central mechanisms: (1) perception, (2) translation of perception into action, and (3) control/execution of action. According to this view, motor action, e.g., in a choicereaction task, occur in three separate stages: in the first stage sensory data, e.g., received from the imperative stimulus, are processed in terms of action-relevant information that is stored in memory, e.g., a present goal or task instruction. After sufficient processing these data are passed on to the second stage, where the translation mechanism converts sensory information into 'response orders' that are sent to the motor system. At this third stage, the muscular movements are programmed to execute the action, e.g., a manual key-press (Welford, 1968; also Sanders, 1980; Sternberg, 1969; Massaro, 1990).

The view that perception and action control rely on distinct functional principles and constitute separate and strictly sequential stages of processing has been challenged by several empirical findings. For instance, response-time data obtained in choice-reaction tasks have attested that perceptual processing and response activation are temporarily overlapping rather than strictly serial: the impact of sensory information on response processes is evident before stimulus processing is completed (e.g., Smid, Mulder, \& Mulder, 1990). Even stimuli which are delivered subliminally and remain thus below the threshold of conscious awareness elicit response activation processes (e.g., Neumann \& Klotz, 1994; Klotz \& Neumann, 1999; Eimer \& Schlaghecken, 1998, 2003). The processing of unconsciously presented 
stimuli exceeds up to semantic levels of representation (e.g., Dehaene, Naccache, Le Clec'H, Koechlin, Mueller, Dehaene-Lambertz, van de Moortele, \& LeBihan, 1998; Dehaene, Naccache, Cohen, LeBihan, Mangin, Poline, \& Riviere, 2001; Kiefer \& Spitzer, 2000).

The stimulus-response compatibility effect discovered first by Simon, Hinrichs and Craft (1970) is also difficult to reconcile with a separate-coding approach. The stimulus-response compatibility effect describes the well-documented phenomenon observed in choice reaction tasks that responses are faster when perceived targets share certain features, e.g., spatial arrangement with the responses assigned to them compared to when no such feature correspondence exists. For instance, responses in forced choice reaction tasks a faster and more accurate when a stimulus that appears right of a central fixation-point requires a right key-press and a stimulus located on the left side requires a left key-press compared to when the task set requires an opposite mapping (cf. Prinz, 1997).

To account for such compatibility effects it has been suggested that compatibilitybased performance facilitation arises because shared features evoke corresponding overlaps of the cognitive representations of perceptual targets and the motor responses assigned to them (e.g., Kornblum, 1994; Kornblum, Hasbrouq, \& Osman, 1990). This idea has gained essential support by the finding that compatibility effects arise not only when feature sharing is physically obvious, as in the case of correspondence in spatial arrangement of target and assigned response, but also when perceptuo-motor correspondence is less evident (Lippa, 1996). Together with Müsseler's (1995) observation that the presentation of stimuli which share certain features with to be performed actions can also conflict with the execution of these actions these findings invoke a conception of the human sensory-motor system that stands in a marked contrast to the traditional Cartesian models of separate perceptuo- and motor processing: It implies a fundamental continuity in the 
functional mechanisms of perception and action and the way they are represented in the brain.

\section{Common coding of perception, action and intended action-effects}

Basically, the idea that perception and action are similar both in terms of their contents and their representational status roots, once more, in the works of nineteenth century scientists such as Lotze (1852), Münsterberg (1888), James (1890/1950), and, somewhat later, Ach (1905). More recently, Wolfgang Prinz and his colleagues (Prinz, 1997, 1998; Hommel, Müsseler, Aschersleben, \& Prinz, 2001; see also Kornblum, Hasbrouq, \& Osman, 1990) have proposed a model in the spirit of this approach. The core assumption of this conception is that perceptuo-motor interaction in humans relies on a common coding principle. Due to a principal similarity in the functional mechanisms which underlie perception and action perceptual events which share specific features with the actions that are assigned to them will be encoded in a common representational domain. This provides immediate continuity at the perception-action interface: a sensory event which activates a perceptual pattern in the brain automatically co-activates the related motor pattern, as both are encoded within the same representational medium. The co-activated motor code can in turn elicit the execution of the respective response. A translation or any other kind of mediation at the perception-action interface as it is required in separate coding models becomes obsolete under common coding conditions (Prinz, 1997; Hommel, Müsseler, Aschersleben, \& Prinz, 2001).

Importantly, common coding is not restricted to sensory events which are perceived in a current environment. Rather, as it has been revealed in a study by Hommel (1993), common coding includes also sensory events which are associated to certain actions as intended effects or goals of planned actions (Hommel, Müsseler, Aschersleben, \& Prinz, 2001; Prinz, 1997). In a modified version of the Simon-task (Simon, Hinrichs, \& Craft, 1970) participants were instructed to press either a left or 
a right key to indicate whether they had been delivered a high- or a low-pitched tone. The tones were presented via headphones either to the left- or to the right ear, but of relevance to participants' forced-choice response was only the dimension 'tone-pitch'. 'Tone-location' was irrelevant and thus to be ignored by participants. Subsequent to each key-press a light went on which was either located on the left or on the right side of the computer screen. This was the effect of participants' keypresses. Participants were assigned to two groups receiving different instructions. The control group received the standard Simon-task instruction, i.e., to press left or right key to indicate whether high- or low-pitched tone had been delivered and ignore the lights. The experimental group received a modified instruction and was asked to illuminate either the left- or right-sided light to indicate tone pitch. In contrast to the control group the response-keys remained unmentioned. Thus, the instruction (task set) established in the control group referred to the action (keypress), the task set established in the experimental group referred to the intended action-effect (light-location). The patterns of results that were obtained for the groups reflected exactly the difference between the two task sets. In the control group, participants' response pattern reflected a standard Simon-effect: performance varied depending on the correspondence between the locations of tone presentation and the location of the response-keys. Responses were faster for corresponding compared to opposite locations of tone-presentation and responsekeys. Yet, in the experimental group participants' performance varied depending on the correspondence between location of tones and location of the intended actioneffects: responses were faster when tone and light appeared on the same compared to when they appeared on opposite sides. The formerly critical relationship between the location of tones the response-keys was now of no differential impact to the responses. It was therefore concluded that common coding holds not only for actions and their perceptual antecedents, e.g., imperative target stimuli, as triggers of actions, but also for actions and their associated sensory consequences as anticipated/intended future effects. 
Such shared 'event-codes' for actions and the sensory consequences assigned to them establish a bi-directional and continuous relationship between action and effects and allow intentional action selection to be controlled in terms of the perceptual effects that they should generate (Prinz, 1997, 1998; Hommel, Müsseler, Aschersleben, \& Prinz, 2001; Jordan, 2003). Based on anticipated action goals the selection and initiation of voluntary actions is decoupled from immediate physical presence of external trigger-stimuli.

After having considered aspects concerning the basic cognitive and representational properties of voluntary action it will now be turned to the more phenomenal aspects of volition. The following chapter will focus on the role of consciousness in the control of voluntary action. Two issues will be addressed: (1) what is the role of unconscious processes in the selection and initiation of voluntary action? (2) What is the role of unconscious processes in the generation of the subjective experience of volition and control?

\section{3 Unconscious processes in intentional action}

Based on our common experience as intentional agents probably all of us will agree that voluntary action is closely tied to intuitive conceptions of 'self'. The most powerful intuition in this respect refers to the 'self' as a 'device' that controls and monitors our interaction with the environment. In mediating between stimulus input and behavioral output the 'self' is supposed to consciously trigger our intentional actions. In this view intentions are the conscious commands which the 'self' transmits to the executing motor systems, thereby causing action (Goschke \& Walter, 2005; see also Wegner, 2002; Jordan, 2003). In contrast to this intuition, however, results from experimental studies in psychology and the cognitive 
neurosciences have shown that the processes which underlie the control of voluntary actions operate largely unconscious. The electroencephalography (EEG) studies of Benjamin Libet and his colleagues (Libet, Gleason, Wright, \& Pearl, 1983; Libet, 1985, 1993, 1996) were amongst the first attempting to investigate whether our actions are in fact caused by conscious intentions and voluntary decisions or whether they rely on unconscious brain processes evading our conscious control. By tracking the time course of experienced intention and electrophysiological onset of motor activity these studies revealed an apparently intriguing finding: the conscious experience of intention follows rather than precedes the onset of movement preparation. This result was received with surprise as, being a candidate cause, the experience of intention should occur prior rather than subsequent to movement onset (Michotte, 1954/1963; Einhorn \& Hogarth, 1986; Wegner, 2002, 2003, 2005). Libet's results and his concluding rejection of intentional causality in voluntary action were subject to a most controversially debated target article in Behavioral and Brain Sciences published in 1985. Because, to date, the original study of Libet, Gleason, Wright, and Pearl (1983) is considered a 'classic' in this field it will be reported in the following section.

\section{3. 1 The Libet-study}

In the Libet-study, participant's basic task was to voluntarily lift the index finger of their dominant hand whenever they felt the "urge", i.e., the conscious intention to do so while they were focusing a clock hand rotating every 2.65 seconds (s) on a screened clock. A random time later, the clock hand stopped and participants were asked to report the position of the clock hand by the time they had first felt the urge to move. This so called "W-judgment" occurred on average 206 milliseconds (ms) before the visible execution of the movement. Yet, during this task, Libet and colleagues had also measured the preparatory brain activity which precedes 
voluntary action. This so-called readiness potential $(R P)$ - originally discovered by Kornhuber and Deecke in 1965 - is an electrophysiological index which indicates motor preparation. Its negative shift of the electroencephalogram begins at approximately $1 \mathrm{~s}$ prior to a voluntary movement, and then grows gradually to a maximum just before movement execution. In Libet's participants, the onset of the $\mathrm{RP}$ preceded the $\mathrm{W}$-judgment by several hundred milliseconds (see Figure 2). This chronometric order of measurable brain activity and the conscious awareness of "wanting" led the authors to conclude that the initiation of action involves an unconscious neural process, which generates both muscular activity and the conscious experience of intention. Libet and his associates (1983) concluded this to indicate that conscious intentions are an epiphenomenal result rather than the cause of the processes underlying a voluntary movement with both of them evading conscious access and control of actors (Libet, Gleason, Wright, \& Pearl, 1983; Libet, 1985; Libet, 1996).

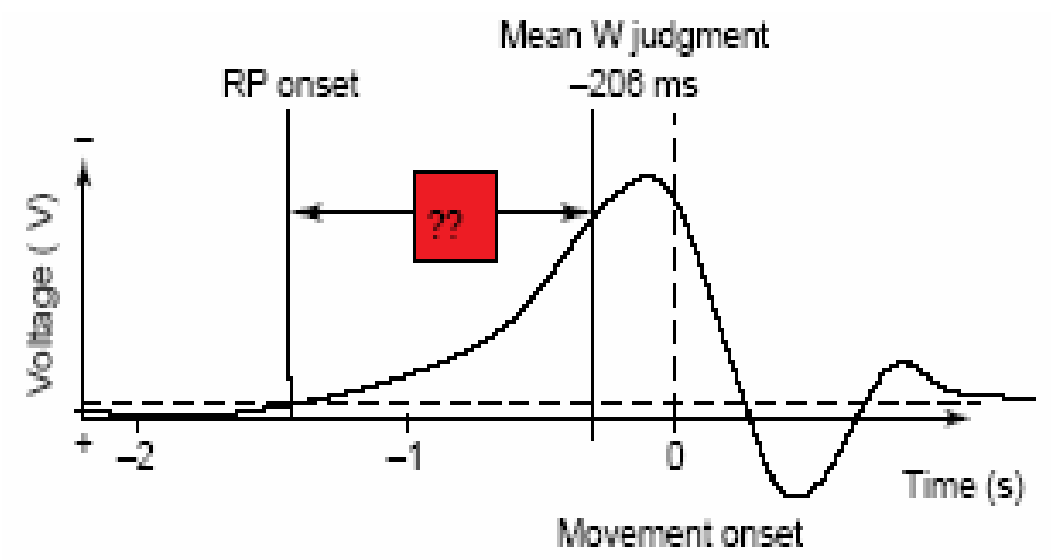

Figure 2. Schematic view of the results obtained by Libet and colleagues (1983), adapted from Haggard, (2005). The onset of neural preparation in the motor cortex precedes movement onset approximately $1 \mathrm{~s}$. The conscious intention to move follows the movement onset by about $206 \mathrm{~ms}$. Because causes precede effects conscious intention appears not to be the immediate cause of the neural processes leading to action.

Libet $(1999,2004)$ himself attempted to maintain the idea of a causal functionality of conscious will in the performance of a voluntary action. He referred to the opportunity to affect the final outcome the unconsciously initiated action 
immediately before its execution by consciously blocking or vetoing it (Libet, 1985, 1999). Libet (1999) argued that albeit consciousness of intention (W) follows the RPonset (Libet, Gleason, Wright, \& Pearl, 1983) it precedes the initial activation of a muscle to execute a movement at approximately $150 \mathrm{~ms}$. As Libet further pointed out this interval would be enough time for consciousness to intervene in the progress of the action process. To support their claim Libet et al. reported that participants were in fact capable to veto a movement planned for execution at a prefixed point in time within the critical interval of 100 to $200 \mathrm{~ms}$ (Libet, Wright, \& Gleason, 1983). Problematically, however, Libet proposed no answer as to whether the veto itself was elicited by unconscious neuronal processes.

The controversial debate which had been evoked by the Libet-study addressed not only the possible philosophical and ethical implications concerning conscious will but also several methodological problems (see the replies to Libet's target article in Behavior and Brain Sciences, 1985). A first major point pertained to the validity of the RP as being a valid correlate of intended movement. In fact, the RP is a rather unspecific electrophysiological marker which signifies a state of general alertness or readiness to move. However, it does not index the preparation of a specific planned voluntary movement. This became evident in a study by Keller and Heckhausen (1990). In an attempt to replicate Libet they found RPs also in the preparatory temporal interval preceding random incidental finger movements. Haggard and Eimer (1999) in turn conducted another replication of Libet's study. With respect to the problem uncovered by Keller and Heckhausen, Haggard and Eimer introduced an important modification. In contrast to Libet's original study their participants were asked to voluntarily lift the finger of either the left or the right hand whenever they felt the urge. This allowed the authors to measure the lateralized readiness potential (LRP) as a more specific marker of movement-preparation than the RP. As suggested by the name, the LRP indicates the body-side of the prepared movement. The LRP is based on event-related potentials which are recorded from the skullcap above the motor cortex fields that control movements of the left and right hand. It 
reflects the relative level of left-hand and right-hand response tendencies with deflections occurring contra-lateral to the moving hand (e.g., Eimer, 1998; Coles, 1989). Data analysis revealed that the time onset of the RP did not correlate with the time onset of the W-judgments. Yet, as consistent with the claim that conscious intention arises after the selection process as a consequence of the motor command for the chosen action the LRP-onsets were significantly ahead of participants' Wjudgments.

Apart from this, critics have argued that constant and variable errors are likely to be involved in the required mapping of the times of mental events (W-judgments) onto physical events (the spatial positions of the revolving clock). It has been questioned whether it is at all justified to plot them on the same scale (e.g., Dennett \& Kinsbourne, 1992; Gomes, 1998, 2002).

Another issue considered problematically refers to the validity of the $\mathrm{W}$-judgments as markers of 'conscious intentions' or acts of 'will'. It has been argued that not the 'urges' but the initial 'task set' instantiated at the beginning of the experiment constituted the critical antecedent and controlled participants' performance in the Libet task (Goschke \& Walter, 2005). Although this task set was not immediately conscious at the level of single trials it may have controlled behavior corresponding to the instructive task set throughout the experiment. Both the initiation of the single finger movements trial by trial and the experienced 'urges' would in this view rely on an intention that was conscious at the time it was initially formed, i.e., when participants received the experimental instruction (Prinz, 2000). In a related vein, Haggard (2005) considered problematic that the $\mathrm{W}$-judgment variable implied the assumption that intentions can be spotted to just one moment in time.

With respect to these methodological concerns Libet's results might have less substantial implication concerning the question of intentional causality in action. Nevertheless, the results have elucidated at least two essential points: firstly, the immediate causal triggers of our voluntary acts are not necessarily conscious and, secondly, conscious intentions play a less direct causal role in the control of action 
than introspective intuition would suggest. Apart from this, Libet's time tracking method - albeit not unproblematic - offered one of the rare tools applicable to study the relationship between phenomenal and neural events in action. In this, the Libetstudy inspired a wealth of research in this field over the recent decades (e.g., Haggard, Clark, \& Kalogeras, 2002; Sirigu, Daprati, Ciancia, Giraux, Nighoghossian, Posada, \& Haggard, 2004; Lau, Rogers, Haggard, \& Passingham, 2004; Haggard, Newman, \& Magno, 1999; Haggard \& Clark, 2003; Haggard \& Magno, 1999; McCloskey, Colebatch, Potter, \& Burke, 1983). The study has thus contributed to the long-due 'scientific revival' of volition as a topic of research.

\section{3. 2 Unconscious modulation of forced-choice actions}

Another line of research revealing that not all antecedents to our voluntary actions are available to awareness comes from studies on unconscious processing. These studies have demonstrated that both the initiation and the selection of intentional actions are systematically affected by stimuli presented below the threshold of conscious awareness. Some of these studies will thus be reported in the following section. Because the methodology of masked priming used in these studies is directly relevant to the experimental approach of the present work it will be described in detail.

The study of unconscious processing addresses the question whether stimuli which are not available to conscious perception have nevertheless a measurable and systematic impact on subsequent intentional actions (e.g., Vorberg, Mattler, Heinecke, Schmidt, \& Schwarzbach, 2003; Merikle, Smilek, \& Eastwood, 2001; Kihlstrom, 2003; Snodgrass, Shevrin, \& Kopka, 1993; Eriksen, 1960). A widely used paradigm in this domain is 'subliminal priming'. Conventional, i.e., conscious visual priming examines the impact of a formerly observed stimulus (prime) on the identification of a present stimulus (target). It is commonly measured by comparing 
speed and accuracy of responses to the target on compatible trials, where prime and target are mapped to the same response, with speed and accuracy of responses to the target on incompatible trials, where prime and target indicate opposite responses. Prior experience with a stimulus enhances the identification of the same stimulus (e.g., Bar \& Biederman, 1998; Leuthold \& Kopp, 1998), one that is physically alike (e.g., Fiser \& Biederman, 2001; Forster, Davis, Schoknecht, \& Carter, 1987), or semantically associated (e.g., Marcel, 1983; Cheesman \& Merikle, 1986). In subliminal priming, where primes are presented only very briefly (less than $50 \mathrm{~ms}$ ) and immediately masked ${ }^{3}$ such that they are not consciously perceived, the same priming-effects as under visible priming conditions are achieved (e.g., Cheesman \& Merikle, 1986; Merikle, Smilek, \& Eastwood, 2001; Merikle \& Reingold, 1998; Reingold \& Merikle, 1990; Naccache \& Dehaene, 2001; Kunde, Kiesel, \& Hoffmann, 2003; Marcel, 1983; Neumann \& Klotz, 1994; Eimer \& Schlaghecken, 1998, 2002, 2003).

\section{Unconscious activation of forced-choice responses}

One of these studies using unconscious priming was conducted by Neumann \& Klotz (1994). Participants' task was to press a left or a right key to indicate which of two targets appeared on the computer screen. Targets consisted of a diamond or a square, each with star like inner contours (see Figure 3, left panel). Each target was

\footnotetext{
3 'Visual masking' occurs when the perception of a briefly displayed stimulus (target) which is plainly visible, when shown alone, is reduced or prevented by the presentation of a second visual stimulus (mask). Critical in masking is the spatio-temporal proximity of target and mask. On the temporal dimension one distinguishes 'backward masking' (the mask is delivered after the prime) from 'forward masking' (the mask is presented before the prime) and 'common onset masking' (target and mask are delivered simultaneously) and the mask continues to be displayed after the target has been deleted (e.g., Enns \& Di Lollo, 2004; Di Lollo, Bischof, \& Dixon, 1993). Concerning the spatial relationship between target and mask most studies use 'pattern-' or 'metacontrast'-masks. In 'pattern masking' masks are composed of various lines (or letters, digits, etc.) which randomly cover the target-shape (e.g., Breitmeyer, 1984; Turvey, 1973; Bachmann \& Allik, 1976). In 'metacontrast masking, the mask tightly flankers the target-outlines without directly touching it (e.g., Fehrer \& Raab, 1962; Breitmeyer, 1984; Weisstein, Ozog, \& Szog, 1975; Neumann \& Klotz, 1994; Scharlau \& Neumann, 2003; Klotz \& Neumann, 1999; Vorberg, Mattler, Heinecke, Schmidt, \& Schwarzbach, 2003). Another, more recently studied mask type is 'four dots' where the mask consists of four separate dots which loosely surround the target-shape (Enns \& Di Lollo, 1997, 2004).
} 
preceded by a prime. The primes consisted also of a diamond and a square, each a smaller replica of the targets. Prime-size was designed such that the primes fitted exactly into the inner contours of the target. This type of stimuli was used to produce metacontrast-masking (Klotz \& Neumann, 1999; Scharlau \& Neumann, 2003). Trials consisted of prime-target pairs which were either congruent, e.g., diamond prime followed by diamond target, incongruent, e.g., diamond prime followed by square target, or neutral, i.e., neutral prime followed by either diamond or square. It was predicted that the primes - albeit unavailable to conscious perception - would activate the response assigned to them. This activation would facilitate responses to targets mapped to the same compared to targets mapped to the opposite response as the preceding prime. As Figure 3 (right panel) shows, this was exactly the pattern shown by the data. Even though participants were in fact unable to detect the masked primes, as confirmed by accuracy rates at chance level in a prime-identification task, their responses were systematically modulated depending on the masked primes. Responses were substantially faster and more accurate on trials with congruent compared to trials with neutral or incongruent prime-target pairs. Thus, although the primes were unavailable to conscious awareness they had activated the response assigned to them by the task.
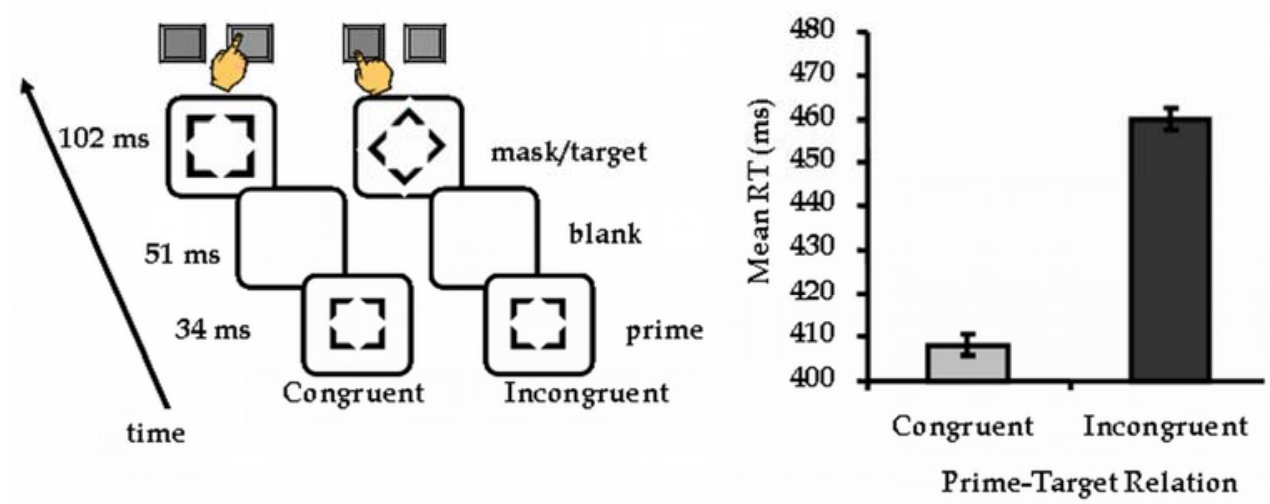

Figure 3. Unconscious activation of forced-choice action as found in the experiment by Neumann \& Klotz (1994). Left panel: Exemplary series of events on a trial. Right panel: Results show that responses were faster and more accurate after trials including congruent compared to incongruent prime target pairs. This indicates that even though the primes were not available to participants' consciousness they had activated the response assigned to them. 


\section{Unconscious inhibition of forced-choice responses}

As it turned out, masked priming of target-related responses can - somewhat surprisingly at first sight - produce as well a response pattern opposite to the one observed by Neumann and Klotz (1994) such that a performance deficit - rather than benefit - occurs for congruent compared to incongruent prime-target-pairs. The phenomenon when participants produce slower responses and more errors on congruent compared to neutral or incongruent trials was first reported by Eimer \& Schlaghecken (1998). It has been termed 'negative', 'incompatible' or 'reversed' priming effect and has since been studied extensively (e.g., Schlaghecken \& Eimer, 2000, 2001, 2002; Eimer \& Schlaghecken, 2001, 2002; Eimer, 1999; Praamstra \& Seiss, 2005; Aron, Schlaghecken, Fletcher, Bullmore, Eimer, Barker, Sahakian, \& Robbins, 2003). The results obtained by Eimer and Schlagheck in their original study (1998) are shown in Figure 4. They used a forced-choice task which was basically similar to that applied by Neumann and Klotz (1994). However, as critical to the reversal of the result pattern, Eimer and Schlaghecken (1998) had altered the timing of events on a trial. Specifically, the SOA (stimulus onset asynchrony) separating prime and target was prolonged such that the execution of the response to the target was delayed. Eimer and Schlaghecken (1998) suggested this delay to be responsible for the reversal of the response pattern. They argued that when response execution is delayed (because of the prolonged prime-target SOA) self-inhibitory control processes in intentional motor behavior intervene automatically and unconsciously and as such reverse the initial response-activation elicited by the prime (see also Eimer \& Schlaghecken, 2002). Evidence in support of the 'activation-followed-byinhibition hypothesis' (Schlaghecken \& Eimer, 2004) was not only behavioral but also electrophysiological. The concomitant measurement of the LRP revealed a characteristic waveform. It is pictured in Figure 4 (lower panel). This waveform indicated an initial activation of the prime-related, i.e., the correct response immediately after prime-onset. In the EEG, this activation is visualized by a negative deflection from baseline level of activation contra-lateral to the prime- 
mapped hand (see Figure 4, lower panel). Approximately 350 - $400 \mathrm{~ms}$ after prime onset, the initial motorical activation is followed by a polarity-shift. This polarity shift indicates an inhibition of the initially activated (primed) response. Thus, it indicates a relative activation benefit of the non-primed (incorrect) response tendency. In the EEG, this 'relative activation benefit' is reflected by a positive deflection from baseline contra-lateral to the prime-mapped hand (Eimer \& Schlaghecken, 1998; Praamstra \& Seiss, 2005).

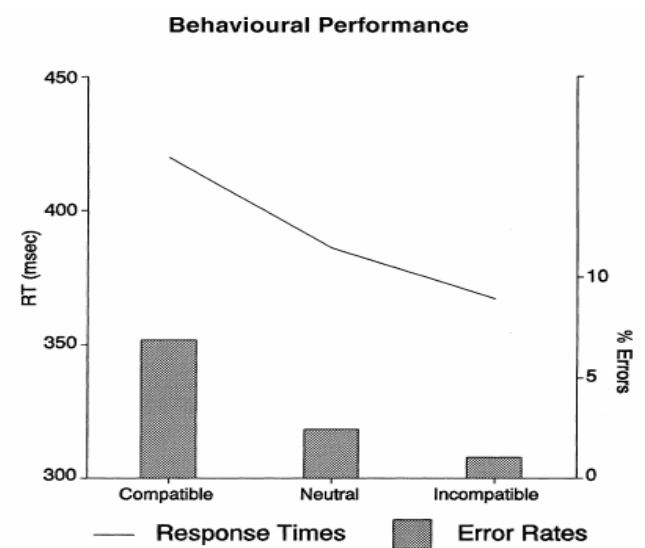

Lateralized readiness Potential

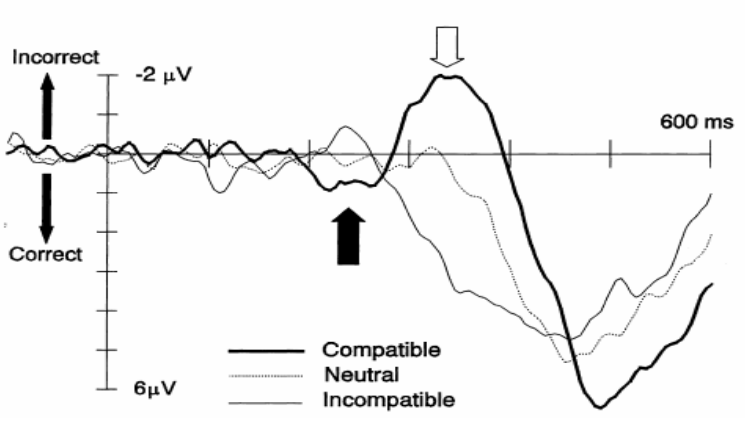

Figure 4. Unconscious inhibition of forced-choice action. Behavioral and electro-physiological evidence for the 'reversed' priming effect obtained by Eimer and Schlaghecken (1998), adapted from Eimer (1999).

Upper panel: Response times and error rates obtained in compatible, neutral, and incompatible trials. Responses were slower and less accurate on compatible compared to neutral or incompatible trials.

Lower panel: LRP waveforms obtained in compatible, neutral, and incompatible trials. Downward-going (positive) deflections indicate activation of the correct response (the response assigned to the target), whereas upward-going (negative) deflection indicate activation of the incorrect response. The black arrow indicates the time interval where the initial response activation was observed. The white arrow indicates the subsequent reversal of this effect.

By systematically varying mask-target SOA in a subsequent study this reversal was found to occur by rule with mask-target SOA exceeding a duration of approximately $90 \mathrm{~ms}$ (Schlaghecken \& Eimer, 2000; Praamstra \& Seiss, 2005), provided that the initial activation was sufficiently strong to have surpassed some 
'inhibition threshold' (Schlaghecken \& Eimer, 2002). It was therefore concluded that unconscious processes of voluntary action control include both activation, as an early process, and - against formerly held beliefs and findings (e.g., McCormick, 1997; Marcel, 1980; Merikle, Joordens, \& Stolz, 1995) - inhibition, as a later, yet also unconscious control process (Eimer \& Schlaghecken, 2002, 2003). Enns and colleagues (Enns \& Di Lollo, 1997; Llerras \& Enns, 2004) presented an alternative explanation for the reversed compatibility effect (see Enns \& Di Lollo, 2004 for a review). It will be discussed in the empirical part of the present work where it is relevant to the achieved results.

The results from the above reported studies illustrate that voluntary actions are systematically affected by stimuli which are not available to conscious awareness with influences emerging both in facilitatory and inhibitory directions. Does this invoke the conclusion that conscious intentions are basically irrelevant for the control of action? Clearly not, as conclusions to be drawn from these studies are limited in an essential point: in forced-choice tasks, the prime-dependent responseactivation relies on a clear-cut and initially conscious S-R-mapping established by the task (Neumann, 1992; Prinz, 1998, 2000; Goschke, 2004). Thus, although the immediate trigger to each response was in fact external, physical and unconscious, the critical modulation occurred only with respect to the intentional S-R associations or ' intentional task set' acquired by instruction.

To investigate whether unconscious stimuli would influence the selection of actions when there is no such instructive pre-specification researchers have applied subliminal priming in free-choice tasks. 


\section{3. 3 Unconscious modulation of free-choice actions}

Both in common understanding and in philosophical terminology 'voluntariness' is closely related to the notion of 'free choice' between alternative possible actions. Some kind of selection process is required for actions to be considered as 'willed'. Typically, such choices are suggested to result from explicit, i.e., conscious contemplating and deciding. However, the idea that the antecedents to the voluntary choice of actions are necessarily conscious has been challenged by the results obtained in recent studies using free-choice tasks.

One of the studies to reveal that action selections - albeit experienced as freely chosen by actors - were systematically influenced by preceding unconscious stimuli was conducted by Wendt-Kürschner (2006). Her experiment consisted of two phases (cf. Elsner \& Hommel, 2001). In the initial acquisition-phase, participants learned to associate a left and a right key-press with one of two visual effect-stimuli: diamond and square. In the subsequent test-phase, participants were requested to freely choose whether to press the left or the right key whenever they received an arbitrary go-signal. Unbeknownst to participants, the former action-effects (square and diamond) were now displayed subliminally as 'effect-primes' before the presentation of the go-signal. The go-signal actually functioned as a backwardmask for the subliminal effect-primes. The aim of the priming procedure was to activate an unconscious representation of the formerly learned action-effects such that this unconscious effect-anticipation would automatically co-activate the response which had been learned to produce this effect. The results were consistent with this prediction. Response-selections were systematically biased depending on the learned action-effect associations. Participants produced more selections which were consistent with the learned action-effect associations compared to selections which were inconsistent with the learned associations. Yet, they were unaware of this bias and experienced their responses as freely chosen. The author concluded that the masked effect-primes had in fact activated a representation of the learned 
effect. Even though this effect-anticipation was not experienced consciously it increased the tendency to select the action which had been learned to produce the represented effect. This shows distinctly that voluntary action selection is controlled in terms of anticipated effects even when these effect anticipations remain unconscious (see also Kiesel, Wagener, Kunde, Hoffmann, Fallgatter \& Stöcker, 2005).

An analogous but reversed selection bias for to-be-freely-chosen actions was observed under conditions of reversed priming. Using a task that was basically similar to the one used by Wendt-Kürschner (2006), Klapp and Hinkley (2002) found that under reversed priming conditions, participants more often selected the responses that were opposite rather than identical to previously learned actioneffect associations. Again, participants were unaware of this bias and had experienced their choices as 'free' (see also Schlaghecken \& Eimer, 2004; Klapp \& Haas, 2005). Does this invoke that non-perceived stimuli control actions to be selected contrary to current intentions? According to Eimer \& Schlaghecken (2004; also Klapp \& Hinkley, 2002; Klapp \& Haas, 2005; but see Enns \& Di Lollo, 2004; Llerras \& Enns, 2004) the 'incompatible' priming effect' results from automatic selfinhibitory mechanisms of motor control. Being purely motoric, the incompatible priming effect in free-choice would not indicate an unconscious 'polarity shift' of an intention, but indicate inhibited readiness to execute the prime-related response at the moment of target presentation resulting in a relative preference to select the opposite response.

In conclusion, the results obtained in free-choice tasks further substantiate that even actions which are experienced as 'freely' chosen are not immune to non-consciously triggered biases. Importantly, however, unconscious modulation of behavior does not occur at random but depends on the preceding learning of action-effect relations. If there would have been no such prior learning phase, the masked primes should, again, not have had any systematic influence on participants' selections (cf. 
Schlaghecken \& Eimer, 2004). In this respect, the results substantiate the idea that the voluntary selection of actions is controlled by learned representations of their associated effects (e.g. Hommel, Müsseler, Aschersleben \& Prinz, 2001; Elsner \& Hommel, 2001; also Hommel, 1996) even when these effect-anticipations are not available to awareness (Wendt-Kürschner, 2006; Kiesel, Wagener, Kunde, Hoffmann, Fallgatter \& Stöcker, 2005; Schlaghecken \& Eimer, 2004; Klapp \& Hinkley, 2002; Klapp \& Haas, 2005).

Taken together, the findings point towards a long-term indirect and often unconscious role of intention in the control of action. Recent conceptions of intentional action have therefore conceived of intentions as cognitive constraints which prepare the cognitive system of an actor, e.g., by augmenting the likelihood of selecting actions which are instrumental in realizing a current goal as soon as appropriate trigger stimuli are available (Goschke, 1996, 2002; Jordan, 2003; Hommel, 2000; Neumann \& Prinz, 1987). According to this view, intentions are no longer considered as immediate causal triggers of voluntary actions. Rather, intentions are assumed to be functional in the control of actions by configuring the cognitive system according to an actor's basic beliefs, long-term goals, and current desires.

Yet, if there is no 'conscious self' in our brain which triggers, causes, or controls our actions, why and how do we get to feel so convincingly as if there was one? Which mechanisms underlie the conscious feeling of voluntary control? The following chapter will consider recent approaches which argue that effect-anticipation is also essentially involved in generating the experience of agency. 


\section{4 The experience of voluntary control}

In line with Albert Michotte (1954/1963, p.10) who identified “...our ability to foresee the result before it actually takes place..." as the main source of the experience of agency, current approaches on voluntary action and experienced control are based on the hypothesis that effect-anticipation is central not only to planning and selecting voluntary actions (see previous chapter) but also to the experience of authorship and control (e.g., Wegner, 2002, 2003, 2004; Blakemore, Wolpert, \& Frith, 1998, 2000, 2002). More specifically, it is assumed that if a sensory action effect is accurately anticipated before the action individuals tend to experience the effect as self-caused. In contrast, in the case of mismatch between anticipated and actual effect the effect will be attributed to an external cause rather than to the self (Frith, 2005; see Haggard, 2005 for a review).

Why (or how) should predictions or anticipations of future action-effects produce a sense of agency and experienced control? One approach to answering this intriguing question has been proposed by Daniel Wegner (2002, 2003, 2004). His concept is based on the well-established idea that events, which are nearby in space and time are likely perceived as causally related (Hume, 1739/1888; Michotte, 1954/1963; Einhorn \& Hogarth, 1986).

\section{4. 1 Wegner's theory of apparent mental causation}

As early as in 1739, David Hume remarked that the conscious experience of control and agency might rely on a causal inference. He assumed that the 'constant union' and 'inference of the mind' that establish causality in physical events give rise to perceive causality in 'actions of the mind'. He recognized the experience of agency as "nothing but the internal impression we feel and are conscious of when we 
knowingly give rise to any new motion of our body, or new perception of our mind" (Hume, 1739/1888, p. 399).

Inspired by Hume's ideas, Daniel Wegner (2002) proposed that the experience of conscious will rests upon the perception of an alleged causal link between a previous thought about an action and the action (see Figure 5). Specifically, he assumed that the three conditions which facilitate the perception of authorship in action are priority, consistency, and exclusivity: an action is experienced as self-caused or "willed" when a thought occurs just prior to the action that is consistent with the action and when there are no salient alternative causes for the action ${ }^{4}$. Thus, for Wegner, the conscious experience of will is based on an inference that we caused an action because we accurately previewed it (Wegner, 2002, 2003, 2004; Wegner \& Wheatley, 1999). In this view, the experience of conscious will is supposed to be just as fallible as self-reports of mental processes in general (Nisbett \& Wilson, 1977).

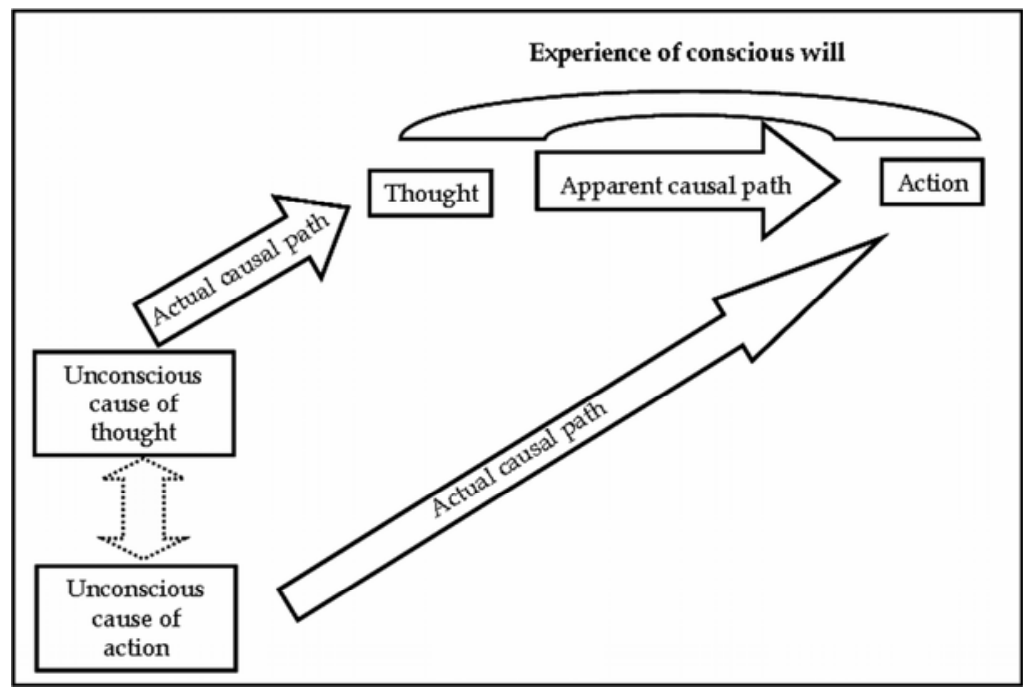

Figure 5. Daniel Wegner's model of apparent mental causation, adapted from Wegner (2003).

Experience of will occurs based on the perception of an apparent causal path from one's thought to action. The actual causal paths remain unavailable to consciousness. Thoughts and action are caused by unconscious mental processes. The experience of will arises of what is apparent.

\footnotetext{
4 It is well documented that the degree to which people perceive causal relationships in general (e.g., among physical events) varies proportional to the extent to which the conditions of priority, consistency and exclusivity in the relation between potential cause and effect are met (e.g., Hume, 1739, 1748; Michotte, 1954/1963; Kelley, 1972; Einhorn \& Hogarth, 1986).
} 
In support of this idea, Wegner and Wheatley (1999) demonstrated that individuals can be led to experience illusory control over actions which in reality are not selfcaused. Participants in their study were instructed to select one of several small objects, e.g., a giraffe, a flower, or a hat, pictured on the computer screen by stopping a cursor which they moved together with another person. Unbeknownst to participants, this person was a confederate of the experimenter who actually steered the cursor and produced the stops accordingly. On each trial, participants received an auditory prime word which either did or did not denominate the next selected item on screen. The priming was administered at 1 second before, or at 30 seconds before, or at 30 seconds after the corresponding stop. After each stop, participants were asked to rate whether they or their (alleged) co-player had caused the stop. The results showed that participants' ratings of control over the stops were higher for trials in which the prime word had activated a correct preview of the subsequent action effect immediately, i.e., at $1 \mathrm{~s}$ before the stop compared to when a temporally distant or no correct preview had been primed. Thus, inducing a thought about a potential action effect enhanced experienced authorship over the effect although the effect was in reality caused by someone else (see also Wegner, Sparrow, \& Winerman, 2004).

\section{Critical aspects of Wegner's approach}

Wegner's theory of apparent mental causation has been controversially discussed in several respects. The series of commentaries to Wegner's target article in Behavioral and Brain Sciences provide an elaborate insight to this discussion (Wegner, 2004). The present chapter gives only a selective idea of this debate.

A critical issue refers to the question of whether conscious will is an illusion (e.g., Nahmias, 2005; also commentaries in Wegner, 2004). As it will be discussed in detail in the general discussion of the empirical results of this work (chapter 4.4), the answer depends crucially on what is understood by the term illusion in this context 
(see also Goschke \& Walter, 2005; Linser \& Goschke, 2006). With respect to the findings of the present work as well as earlier related findings it will be argued against a naïve "Cartesian" view. Thus, in line with Wegner it will be argued that empirical evidence available to date (including the data of the present work) contradicts the intuitive idea that the experience of agency and voluntary control rests on a privileged and incorrigible introspective access to the causal antecedents of one's actions and their effects. Albeit one may indeed regard experienced agency and voluntary control as an "illusion" in the sense "that the experience of consciously willing an action is not a direct indication that the conscious thought has caused the action" (Wegner, 2002, p. 2) the fallibility of conscious will does not entail that the conscious experience of voluntary control is an illusion in the sense that it constantly deludes us about the causes of our actions and their effects (Goschke \& Walter, 2005; Linser \& Goschke, 2006). It does not follow from the occurrence of perceptual illusions that perception is always deluding us. In the same sense the observation that the experience of conscious will sometimes elicits the erroneous impression that we have controlled an effect which in reality was controlled externally does not imply that conscious will constantly deludes us about whether we are the originators of the events which follow our actions (cf. Goschke \& Walter, 2005; Linser \& Goschke, 2006; Nahmias, 2005).

Another controversial issue refers to the question of whether the processes involved in the generation of the experience of control are separate from or directly related to the processes involved in the control of action. Wegner's illustration of 'apparent mental causation' suggests separate processes. As can be seen in Figure 5, the illustration of his concept includes 'unconscious mental processes' which generate both 'action' and 'thoughts about the action'. There are no 'actual causal path arrows' leading from the 'thought box' to the 'action'-box. This suggests that Wegner assumes no link between the processes underlying action production and conscious will. More explicitly, Wegner argues that the 'authorship-processing system' is a distinct module from the action control system which "...stands outside 
the processes that cause the action itself, laboring in parallel with it ....", "...rumbles alongside the main machine", and "...is only loosely coupled to the action production system, a kind of observer of the system..." (Wegner, 2004, pp. 682, 683; italics in original). However, recent neurobiological findings strongly suggest that the processes involved in the production of action and those underlying the generation of experienced control interact closely (e.g., Blakemore, Wolpert, \& Frith, 2000; Haggard, 2005; Koch, 2004). In this respect, Wegner has been criticized to omit relevant neurobiological findings (e.g., Nahmias, 2005).

One theory of voluntary action that focuses more specifically on the neurobiological mechanisms involved in the generation of experienced agency and the control of action has been proposed by Chris Frith and his colleagues. It is closely tied to the internal model theory - an approach to explain motor control (e.g., Wolpert, 1997). Together with relevant neuropsychological findings, it will be addressed in the following chapter.

\section{4. 2 The Internal forward model theory and the sensory attenuation hypothesis}

Current research on motor control has shown that the execution of controlled action relies on predictions of movements and their perceptual consequences made by internal forward models - neural representations of own body movements in their relation to the external environment (e.g., Miall, Weir, Wolpert, \& Stein, 1993; Wolpert, Ghahramani, \& Jordan, 1995; Miall \& Wolpert, 1996). It is argued that such predictions also help to distinguish whether actions and their consequences are selfor externally produced (Blakemore, Wolpert, \& Frith, 1998, 2000; Frith, 2005). Two types of prediction are made (see Figure 6). First, a forward dynamic model predicts the spatio-temporal coordinates of a movement. By comparing the predicted with the intended movement trajectory it enables the system to rapidly adjust motor 
commands in order to perform an action as intended. The forward dynamic model is thus directly involved in action production and learning (Blakemore, 2003; see also Blakemore, Wolpert, \& Frith, 2000). The second type of prediction, forward output model, predicts the sensory consequences that will result from a movement based on the efference-copy of a respective movement. As soon as a movement is completed the predicted consequences are compared with the perceptual effects that actually follow the movement based on afference-copies. This comparison serves to distinguish self- from externally caused action. If the prediction was correct, i.e., predicted and actual action effects coincide, the sensory representation of the effect is attenuated which signals the effect is to be experienced as self-generated (Frith, 2005; Blakemore, Wolpert, \& Frith, 1998, 2000). In contrast, if no or an incorrect prediction is computed such that predicted and actual effect diverge which should occur in particular for externally produced movements, there will be no or a less pronounced attenuation of the sensory effect representation and an increased tendency to ascribe the effect to an external cause (Frith, 2005; Blakemore, Wolpert, \& Frith, 1998, 2000). The effect-prediction of the forward output model and its comparison with the actually observed sensory consequence of action is thus supposed to be directly involved in the generation of experienced control in voluntary action.

In support of the idea that the correspondence between an action and its perceptual effect modulates the degree of perceptual intensity Blakemore, Frith and Wolpert (1999) asked participants to rate the intensity (degree of 'ticklishness') of a tactile stimulation applied to their hand via a robotic interface. The robot was either externally controlled by the experimenter or self-controlled by participants via remote. Results revealed that, even though the actual intensity of the stimulation was identical in all conditions, intensity ratings were higher when the tickling was externally produced, i.e., not precisely predicted by forward model, compared to when the stimulation was self-generated. Moreover, in the self-caused condition, different degrees of spatiotemporal deviation between participants' initiation of the 
robot-movement, i.e., the resulting tactile stimulation, were introduced. Even though participants did not notice the deviation intensity ratings varied proportional to its degree. The higher the spatiotemporal discrepancy between the movement and the subsequent stimulation, the more intense the 'tickling' was experienced. This is consistent with the idea that perceived intensity of sensory action effects is attenuated when the effects are correctly compared to when they are incorrectly or unpredicted. Functional magnetic resonance imaging (fMRI) was found to reflect the behavioural data. Self-produced sensory stimuli produce less activation in somatosensory cortex and anterior cingulate cortex compared to the same stimuli when they were externally produced (Blakemore, Wolpert \& Frith, 1998).

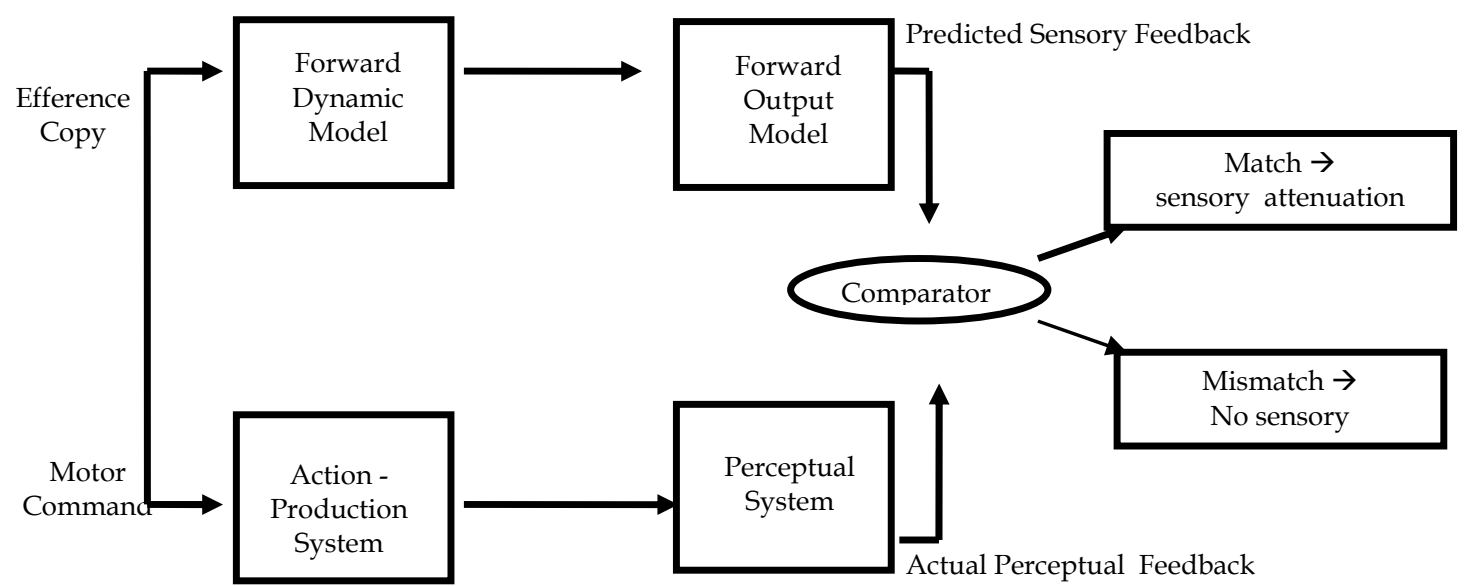

Figure 6. Action prediction and experienced control based on a forward model of motor control, adapted from Blakemore (2003). A forward dynamic model predicts consequences of motor commands. The forward output model predicts the perceptual effects of motor commands. This prediction is then compared with the actual consequences of movement. If this comparison leads to a detection of a match between the predicted perceptual consequences and the actual sensory representation which results from the perception of the effect following action the sensory representation will be attenuated and the effect will be experienced as self-caused. In case a mismatch is detected there will be no sensory attenuation and the effect will be experienced as externally controlled.

Further evidence that the experience of agency depends on the congruence between anticipated and actual sensory effects of an action was recently reported by Sato and 
Yasuda (2005). In their experiments, participants first learned that pressing a left or a right key was consistently followed after a constant delay either by a high or a low tone (the action effect). In a subsequent test phase the responses were either followed by the same tone as in the prior learning phase (congruent trials), or they were followed by the other, i.e., unexpected tone (incongruent trials). Participants were instructed that the tones could be the result of their own action or the experimenter's action. The results showed that the self-reported degree to which participants felt that the tone was a consequence of their own action diminished when the effect tones were inconsistent with the learned action-effect mapping. Moreover, the sense of agency was reduced when the tone was presented at an unexpected delay, although in fact it was self-produced. In line with the forward model theory, these findings support the idea that the execution of an action is accompanied by the generation of a prediction of the sensory consequences of the action, which is then compared with the actual consequences of the action (Blakemore, Wolpert, \& Frith, 1998, 2000; Frith, 2005). The higher the congruence between anticipated and actual action-effects, the stronger is the tendency to experience the effect as caused by one's own action.

The internal forward model theory also helps to understand certain psychiatric and neurological disorders which include dysfunctions in the awareness of action such as for instance schizophrenia. Schizophrenic patients often report passivity experiences. These so called 'delusions of alien control' are characterized by the feeling that one's action, speech and thoughts are controlled by another person or 'outer force' (e.g., Frith, 1987, 1992, 2005; Frith, Blakemore, \& Wolpert, 2000a,b). In terms of the internal forward model approach, such delusive control experiences are supposed to reflect a dysfunction in forward output model that normally predicts the perceptual effects of self-generated actions (Blakemore, Wolpert, \& Frith, 2002; Frith, 2005). It is suggested that, because of the dysfunction, the prediction of the behavioral outcome is inaccurate or missing even when actions are self-produced. As a consequence the sensory representation of the action-effects will not be 
attenuated such that -erroneously- behavior and its effects will be experienced as alien-controlled (Blakemore, 2003; Frith, 2005). Correspondingly, it was found that schizophrenic patients who reported delusions of alien control experienced both self- and externally caused stimulations as equally intense whilst healthy controls who correctly differentiated self- and externally produced action-effects judged the self-produced stimulations as less intense compared to the identical but externally administered stimulations (Blakemore, Smith, Steel, Johnstone, \& Frith, 2000; see also Daprati, Franck, Georgieff, Proust, Pacherie, Dalery, \& Jeannerod, 1997).

Thus, accurate predictions of action-effect and their match with the perceived outcome are central to adaptive control- and authorship experiences. Conversely, any dysfunction in the ability to form correct predictions of future action-effects leads to severely disturbing experiences concerning authorship and control of action such as they are reported for instance by schizophrenic patients suffering from delusions of alien control.

In summary, two recent theories of willed action were discussed which argue that anticipations of action-effects play a key-role in generating the experience of voluntary control. According to the theory of apparent mental causation proposed by Wegner conscious will relies on the perception of an alleged causal relationship between one's action and a subsequent perceptual event (action-effect) which is inferred when the action-effect has been consistently previewed (Wegner, 2002, 2003, 2004). In terms of the internal forward model concept by Frith and colleagues, body-movements and their sensory effects are experienced as self-caused when an internal forward output model has correctly predicted the effect such that the sensory representation of the effect is attenuated (Frith, 2005; Blakemore, 2003; Blakemore, Wolpert, \& Frith, 2000, 2002). Both conceptions and the empirical findings related to them converge in at least two central aspects. Firstly, they agree that accurate anticipations of sensory action effects are of crucial significance to experienced control. Secondly, they explain that experienced control does not 
necessarily reflect objective control conditions provided in a current situation in healthy participants (e.g., Wegner \& Wheateley, 1999) and in patients with schizophrenia (e.g., Frith, 1992; 2005; Frith, Blakemore, \& Wolpert, 2000a,b; Blakemore, Wolpert, \& Frith, 2000).

An important aspect that remains to be clarified concerns the question which processes involved in generating experienced control are themselves necessarily available to consciousness (Blakemore, Wolpert, \& Frith, 2002). The significance of this issue becomes obvious when we consider of voluntary action in everyday life, where we do not constantly anticipate our intended goals or monitor the chosen action-process to achieve them.

The question of whether effect-anticipations are necessarily conscious or whether they affect the generation of experienced agency even when they are themselves unavailable to awareness was the aim of the empirical studies conducted in the present work. Important inspiration for this aim was provided by the empirical findings discussed in the previous chapters which revealed that the control of voluntary action is systematically affected by unconscious anticipations of action effects (e.g., Neumann \& Klotz, 1994; Eimer \& Schlaghecken, 1998, 2001; Schlaghecken \& Eimer, 2004; Wendt-Kürschner, 2006).

\section{5 Aim of the current work}

The aim of this thesis was to examine whether unconscious effect-anticipations systematically affect the experience of voluntary control. Precisely it was hypothesized that (1) if a sensory action effect is accurately anticipated before the action individuals tend to experience the effect as self-caused, whereas in case of a mismatch between anticipated and actual effect the effect will be attributed to an 
external cause rather than to the self (Sato \& Yasuda, 2005; Frith, 2005; Blakemore, Wolpert \& Frith, 2002). (2) It was assumed that such effect-anticipations systematically affect the degree of experienced control even when they remain completely unavailable to an actor's conscious awareness (e.g., Neumann \& Klotz, 1994; Eimer \& Schlaghecken, 1998, 2003; Merikle, Smilek, \& Eastwood, 2001; Dehaene \& Naccache, 2001; Naccache \& Dehaene, 2001).

To investigate these assumptions four experiments were conducted. The purpose of the experimental design was twofold. (1) It was investigated whether the degree to which participants experienced to be in control over a perceptual event which followed their action as an alleged effect was systematically modulated by priming $a$ representation of this "effect", even when the was in reality not systematically related to the preceding action and thus not controllable by the participant. (2) It was examined whether this modulation of experienced control occurred even when the effect-anticipations were induced by masked "effect"-primes which remained unconscious. In other words it was hypothesized to induce an illusion of control by priming an unconscious "effect"-anticipation.

For that purpose a control-judgment task was designed in which on each trial participants performed one of two actions which were followed by one of two visual stimuli. By pressing keys participants either had limited control (Experiment 1) or no control at all (Exp. 2, 3, and 4) over which stimulus appeared on a given trial. Immediately before each action a masked prime-stimulus was presented which was either congruent or incongruent with the post-action stimulus. Each experiment included an additional methodological control experiment to assess that the primes remained fully unconscious according to a strict forced-choice recognition criterion. The following chapter will describe these experiments and report and discuss the obtained results. 


\section{Chapter 3}

\section{Experimental Part}

\section{1 Introduction}

In the present chapter, 4 Experiments will be reported. With respect to the questions discussed in the previous chapter the purpose of these experiments was twofold. First, it was attempted to investigate whether an illusion of conscious control over an objectively uncontrollable- event that follows one's action can be induced by priming a representation of this event prior to the action. Secondly, it was examined whether such a modulation of conscious control occurs even when the primed representation of the event remains completely unconscious according to an objective forced-choice criterion (e.g., Merikle, Smilek, \& Eastwood, 2001; Eimer Schlaghecken, 2003).

To this end a control-judgment task was designed in which on each trial participants performed one of two actions followed by one of two visual stimuli. By pressing keys participants either had limited (Experiment 1) or no control at all (Experiments 2-4) over which stimulus appeared on a given trial. Immediately before each action a masked prime was presented. This prime was either congruent or incongruent with the post-action effect-stimulus. The main prediction was that subliminally priming the representation of the post-action stimulus before each action would lead participants to overestimate the degree of control they had over the stimuli 
compared to when no or even an incongruent stimulus representation was primed. The critical idea underlying this prediction is that the mechanism that normally computes internal predictions of action effects may be "tricked" when an external prime activates an "effect"-representation immediately prior to a voluntary action, especially when in reality the actual effects are unpredictable. If this prediction turns out to be correct it would constitute strong evidence that the conscious experience of agency depends on the congruency between an (unconsciously activated) effect representation and the actual "effect" following the action. In Experiment 1 this prediction was tested in a forced-choice task. In Experiments $2-4$ participants were free to choose on each trial which action they performed.

\section{Apparatus}

In all experiments participants were seated $60 \mathrm{~cm}$ from a 17 inch monitor which had a refresh-rate of $75 \mathrm{~Hz}$. Stimulus presentation and response recording were controlled by a Personal Computer and synchronized with the vertical retrace signal of the monitor. All experiments were programmed and run by "Colapse"-Software which is a non-commercial stimulus-presentation program designed by Goschke (unpublished).

\section{Statistical analyses}

Repeated measures Analyses Of Variance (ANOVA) were conducted to assess whether the 3 levels of the within-subject factor of prime-effect-congruity (congruent, neutral, and incongruent) had a significant main effect on the mean degrees of participants' control-judgments. The procedure of ANOVA tests differences between group mean values (in the present case the difference between the mean control judgments in the three conditions of prime-effect-congruity as a within group factor) for significance by an F-test based on the Fischer-distribution. After 
ANOVA's F-test yielded a significant main effect of the factor of prime effect congruity on the degree of judged control, two tailed paired $t$-tests were used to compute planned single contrast comparisons between the control-judgment-means in the congruity conditions. The t-test tests for differences between group means based on the t-distribution. The same statistical procedures were used to analyze data of the methodological forced-choice response priming task. In the primeidentification task participants' identification performance (mean percentual amount of correctly identified primes) was tested against the chance level value of identification performance by a one sample $t$-test.

Statistical parameters of these procedures are reported by using the following abbreviations: $\boldsymbol{F}\left(\boldsymbol{d} f_{\text {factor levels, }} \boldsymbol{d} f_{\text {residual }}\right)$ for ANOVA's F-test parameter and its degrees of freedom $\left(d f_{\text {factor levels }}=\right.$ number of factor levels minus 1 ; $d f_{\text {residual }}=$ number of participants minus 1 by number of factor levels minus 1$) ; \boldsymbol{t}(\boldsymbol{n}-\mathbf{1})$ t-test parameter for n (number of data) - 1 degrees of freedom; $p$ for probability of null hypothesis, i.e., the significance level of the result; SD for Standard Deviation; MSE for Mean Squared Error. All statistical data analyses were performed using SPSS 11.5.

\subsection{Experiment 1 - Unconscious modulation of experienced control in forced-choice action}

Experiment 1 investigated whether masked priming of effect-stimuli which followed participants' actions as potential action-effects systematically affects the degree to which participants experienced to be in control over stimuli which followed their actions as potential effects. In reality participants had only a limited degree of control over these stimuli. To examine whether the presumed modulation of the conscious control experience by the effect-primes occurs on an unconscious 
level the effect-primes were presented very briefly and masked such that they were not consciously perceived.

\section{2. 1 Methods}

\section{Participants}

Thirty undergraduates (24 female, 27 right-handed) from the Dresden University of Technology, aged 19-34 years (mean 23.4 years) participated for $€ 4$ or course credit. All had normal or corrected to normal vision and were naïve to the purpose of the experiment within the limits of informed consent.

\section{Control-judgment task}

Stimuli and procedure. Each trial began with the presentation of a forward-mask which was followed by a prime and a backward-mask. The forward mask was presented for 150 milliseconds (ms), the prime for $30 \mathrm{~ms}$, and the backward mask for $17 \mathrm{~ms}$. After the backward-mask, one of two imperative target-stimuli appeared for $50 \mathrm{~ms}$ and was replaced by a blank screen remaining visible until a response was made. Primes consisted of left- or right-pointing arrows $(<<<<$ or $>>>>)$ which were $0.4 \mathrm{~cm}$ in height and $3 \mathrm{~cm}$ in width. The mask was composed of left- and right-pointing arrows superimposed on each other sized $0.8 \mathrm{~cm} \times 4.5 \mathrm{~cm}$. The same shape was also used as a neutral prime. Targets consisted of a diamond (\#) sized 0.5 $\mathrm{cm} \times 0.8 \mathrm{~cm}$ or a cross $(+)$ sized $0.5 \mathrm{~cm} \times 0.5 \mathrm{~cm}$. Participants were instructed to press with their index and middle fingers of their dominant hand one of two keys which were vertically arranged on the keyboard to indicate which of the two imperative target stimuli, i.e., "\#" or "+", had appeared on the screen. Stimulus-response mapping was counterbalanced across participants. Immediately after the response either left- or right-pointing arrows appeared for $500 \mathrm{~ms}$ as alleged effects of the 
key-press. Key to effect-stimulus assignment was counterbalanced across participants. After a delay of 1 second (s) the next trial started. All stimuli were presented in black on a grey background. Participants were asked to try to find out whether by pressing the one or other key they could control which of the two effectstimuli occurred. Figure 7 shows stimuli, series and durations of events of Experiment 1.

Design. The contingency between participants' key presses and the alleged effects was imperfect: in $75 \%$ of trials a particular effect-stimulus appeared when a particular imperative stimulus had been presented; in the remaining $25 \%$ of trials the other effect-stimulus appeared. Stimuli-assignment to probabilities was counterbalanced across participants. Thus if a participant always pressed the correct key there was a limited contingency between key-presses and effect-stimuli such that each of the two key-presses was followed by one particular effect-stimulus in $75 \%$ of trials and participants had limited control over whether left or right pointing arrows appeared. The critical independent variable was the relationship between the prime and the post-action effect-stimulus. As can be seen in Figure 7, this relation was either congruent, e.g., a left-pointing effect-arrow following a leftpointing arrow prime, incongruent, e.g., a left-pointing effect-arrow following a right-pointing arrow prime, or neutral, e.g., a left-pointing arrow effect following the neutral prime. The three prime-effect relations were realized in separate blocks each consisting of 40 trials. Each participant performed two blocks with only congruent, two with only incongruent and two with only neutral prime-effect pairs. Order of conditions was counterbalanced across participants. 


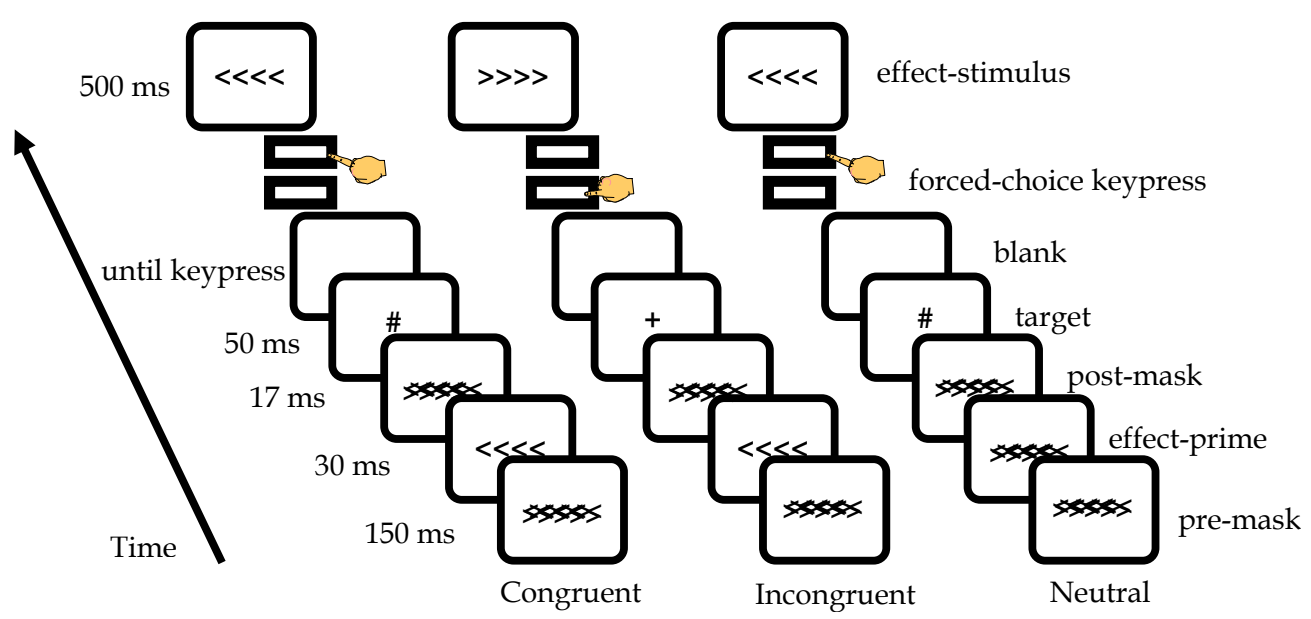

Figure 7. Experimental setup of the control-judgment task in Experiment 1. Exemplary sequence and duration of events on a trial for the three conditions of prime-effect-congruity (congruent, incongruent and neutral).

Dependent variable and predictions. After each block participants received a questionnaire to rate how much control they thought they had had over whether the arrows were pointing to the left or right on a rating scale ranging from $0 \%$ for "no control" to $100 \%$ for "complete control" (cf. Alloy \& Abramson, 1979). Control judgments were expected to be systematically modulated by prime-effect congruity: they were predicted to be higher on congruent than on neutral trials and higher on neutral than on incongruent trials. The control scale is shown in Figure 8. Participants originally received the questionnaire in German (see Appendix A1).

Please estimate the extent to which you think you could control (by pressing the blue or the red button) whether the arrows appearing on screen were pointing to the left or right!

By pressing keys I had .....

\begin{tabular}{|lcc|}
\hline & & \\
no control & $50 \%$ & $100 \%$ \\
& medium control & full control \\
& .......over whether the arrows were pointing to the left or right.
\end{tabular}

Figure 8. Control judgment scale used in Experiment 1. The original version in German can be seen in Appendix A1. 


\section{Prime-impact: forced-choice priming task}

To assess whether the masked primes had in fact activated the representation of their shapes a forced-choice priming task was accomplished.

Stimuli and procedure. As Figure 9 shows stimuli, series and durations of events were the same as in the control-judgment task except that now the stimuli that were used as imperative stimuli ("+", “\#”) in the control-judgment task were replaced by the former effect-stimuli (left- and right-pointing arrows). No further effect-stimuli appeared after the key-presses. On each trial the forward mask (150 ms) was followed by a prime (30 ms), the backward mask (17 ms) and a target (50 ms) which was replaced by a blank screen that remained visible until a response was made. Participants were instructed to press with the index- and middle-fingers of their dominant hand as fast and accurately as possible one of two vertically arranged keys to indicate whether the target-arrows were pointing to the left or right. Keytarget mapping was counterbalanced across participants. The intertrial interval (ITI) was $1 \mathrm{~s}$.

Design and prediction. Prime-target pairs were congruent, incongruent or neutral. After 18 practice trials 60 congruent, 60 incongruent, and 60 neutral trials were presented in random order. Responses were expected to be faster and more accurate after congruent compared to neutral or incongruent trials (cf. Neumann \& Klotz, 1994). 


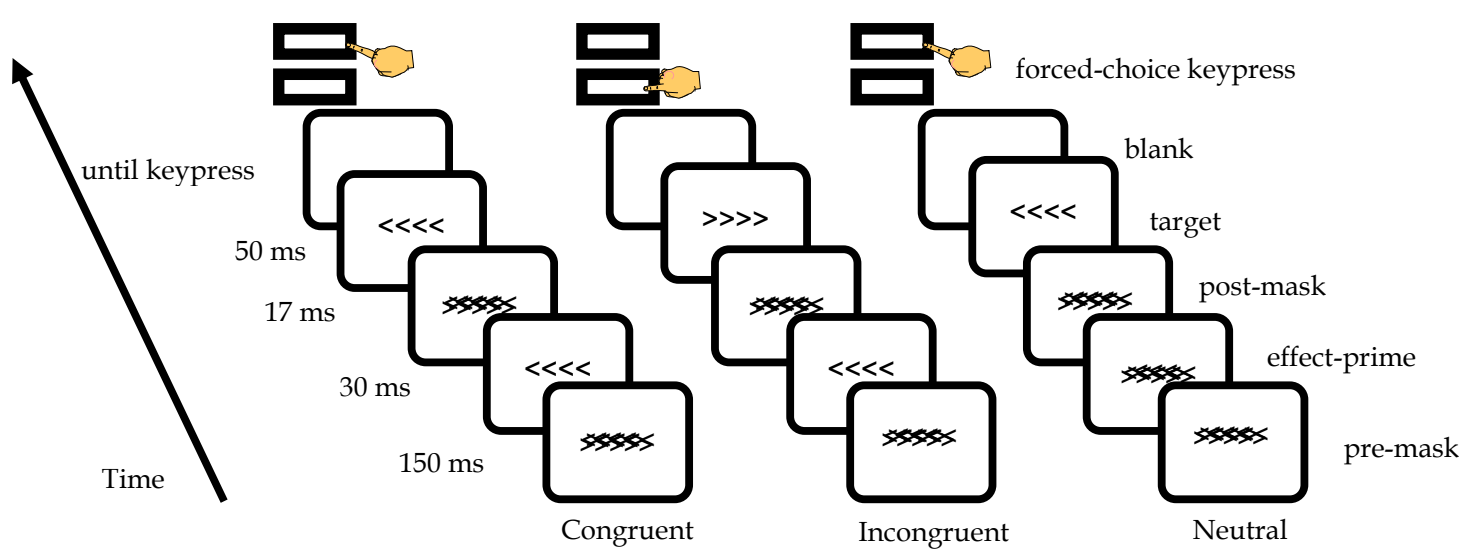

Figure 9. Experimental setup of the forced-choice priming task in Experiment 1. Exemplary sequence and duration of events on a trial for the three conditions of prime-effect-congruity (congruent, incongruent and neutral).

\section{Prime-perceptibility}

After the control-judgment task participants' awareness of the primes was determined both with respect to a subjective and an objective criterion (Merikle, Smilek, \& Eastwood, 2001).

Awareness questionnaire. Participants were asked on a questionnaire whether at any point they had seen anything on the monitor except for the mask and the effectstimuli and if so, what they had seen. This was the subjective criterion of prime awareness. The questionnaire can be seen in Appendix B 1.

Prime-identification task. After participants had completed the awareness questionnaire, they were informed about the presence of primes. Then they were instructed to perform a forced-choice prime-identification task to assess prime visibility also according to an objective awareness-criterion. As shown in Figure 10, materials were the same as in the response-priming task except that targets were now substituted by a question mark in black font sized $0.8 \mathrm{~cm} \times 0.4 \mathrm{~cm}$. Each trial commenced with the forward mask (150 ms) which was followed by a prime (30 $\mathrm{ms})$, the backward mask (17 ms) and the question mark $(50 \mathrm{~ms})$ which was replaced 
by a blank screen remaining visible until a response was made. On 80 trials, i.e., 40 trials each prime because the neutral prime was omitted, participants indicated whether the prime consisted of left- or right-pointing arrows by pressing one of two vertically arranged keys on the computer keyboard. Primes were presented in random order. The predicted rate of correctly identified primes was at the chance level of $50 \%$.

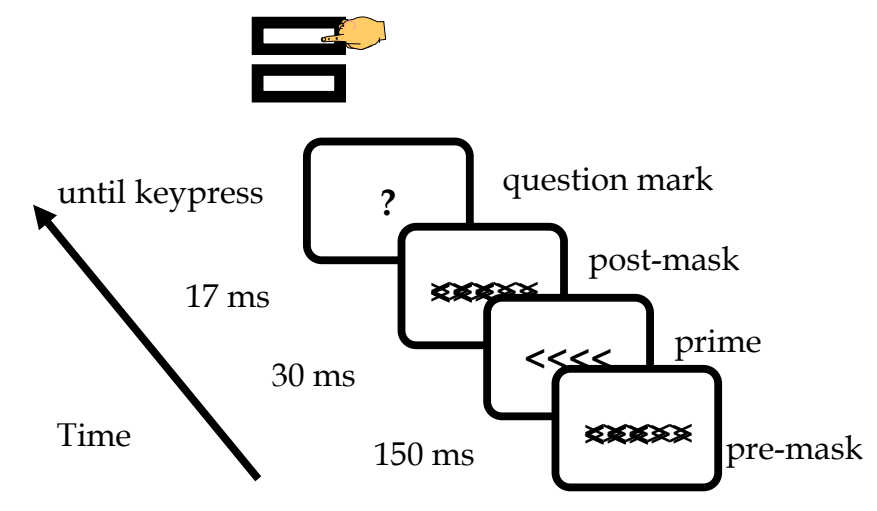

Figure 10. Experimental setup of the prime-identification task in Experiment 1. Exemplary sequence of events on a trial.

\section{2. 2 Data analyses and results}

Prime-identification. Two participants who declared identification of the masked primes were excluded from all further analyses. In the prime-identification task remaining participants' mean rate of correctly identified primes was $50.83 \%$. A $t$-test revealed that this was not significantly different from $50 \%$ chance, $p>.1$.

Control-judgments. Mean control-judgments were computed for each of the 6 blocks of the control-judgment task and then collapsed over the two blocks of each condition of prime-effect congruity. The degree of experienced control was clearly modulated by the masked primes: A repeated measures ANOVA revealed a highly significant effect of prime-effect congruity $[F(2,54)=7.76, p<.002]$. This reflects that control was judged higher after blocks with congruent compared to incongruent or 
neutral prime-effect pairs. A pair-tailed $t$-test for dependent samples showed that control-judgments were reliably higher on congruent than on incongruent trials, $[t(27)=2.74, p<.02, S D=10.97]$. This effect could not be attributed to differences in participants' responses in the different conditions because mean RT [ $M=668 \mathrm{~ms}$; SD $=148.47]$ and mean error rate $[M=4.5 \%, S D=5.06]$ did not significantly differ between congruity conditions. On a descriptive level control-ratings were lower on neutral compared to incongruent trials. However, this difference was not significant $[p>$.2]. The results of the control judgments are shown in Figure 11, left panel.

Forced-choice priming. Incorrect responses [overall mean error rate $=2.95 \%, S D=$ 2.61] and responses exceeding $1500 \mathrm{~ms}$ [overall mean $\mathrm{RT}=450 \mathrm{~ms}, S D=62.74$ ] were excluded. Mean RTs of the remaining responses were computed for each of the three conditions of prime-target congruity. As shown in Figure 11 (right panel), responses were faster on congruent than on neutral or incongruent trials. This indicates that the masked primes had in fact activated an unconscious representation of their shape. A repeated measures ANOVA yielded a significant main effect of congruity $[F(2,54)=34.80, p<.001, M S E=241.87]$. A pair-tailed t-test revealed that responses were significantly faster on congruent than neutral trials $[t(27)=-4.52, p<.001, S D=23.56]$ and faster on neutral than on incongruent trials $[t(27)=3.53, p<.002, S D=21.66]$. The analogous ANOVA on error rates designated a main effect of congruity $[F(2,54)=3.60, p<.04, M S E=6.63]$. A two-tailed paired $\mathrm{t}$-test comparison confirmed that participants committed significantly less errors on congruent than on incongruent trials $[t(27)=-2.44, p<.03, S D=3.99]$. 

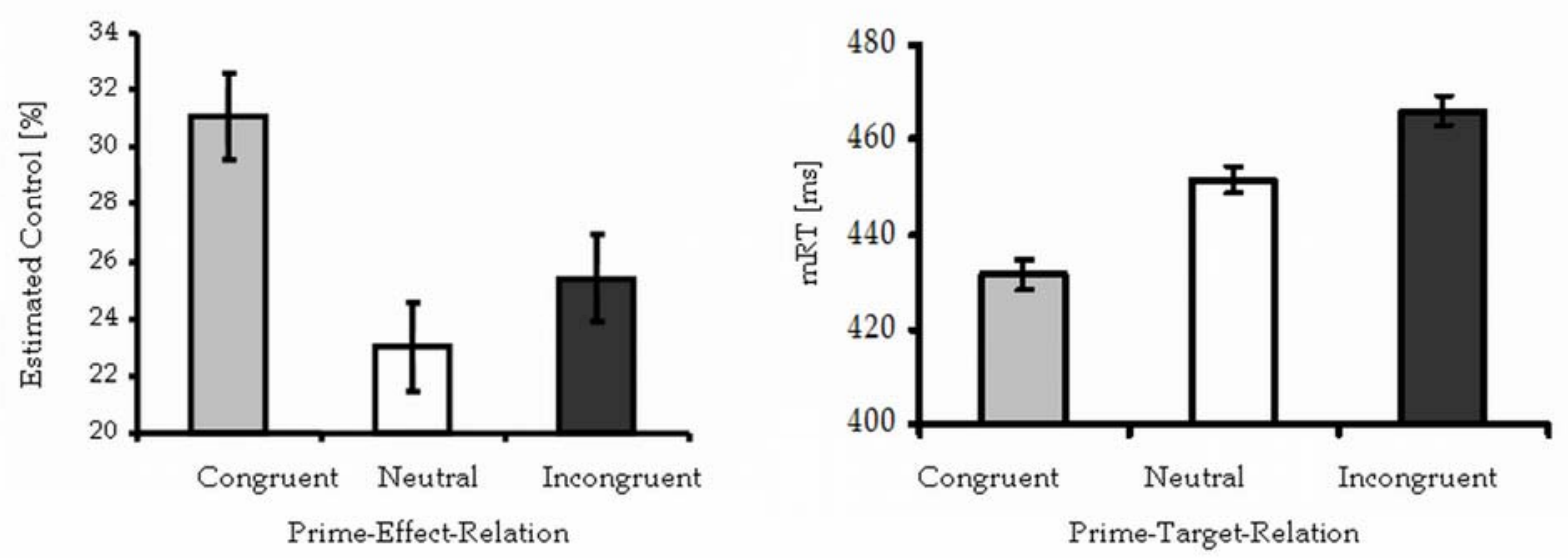

Figure 11. Results of Experiment 1. Left panel: Mean control-judgments in the control-judgment task as a function of prime-effect congruity. Right panel: Mean RTs in the forced-choice priming task as a function of prime-target congruity. Error bars show $95 \%$ withinparticipants confidence intervals (Loftus \& Masson, 1994).

\section{2. 3 Discussion}

In Experiment 1, subliminal priming of the representation of an alleged effect stimulus immediately prior to a voluntary action influenced the degree to which participants' experienced control over sensory events which appeared after their actions as potential action-effects. The extent of experienced control was significantly increased when the alleged effect-stimuli were congruently primed before each action compared to when an incongruent or a neutral effect-prime had been presented. These results are consistent with the hypothesis that the experience of conscious control emerges from an unconscious comparison between anticipated and actual sensory consequences of an action. If this comparison yields a match, control is more likely to be attributed to the self rather than to an external cause, whereas in the case of a mismatch between anticipated and actual action effect control is ascribed to an external cause rather than to the self. 


\subsection{Experiment 2 - Unconscious modulation of experienced control in free-choice action}

Experiment 2 attempted to substantiate and extend the findings of Experiment 1 in three ways. (1) It was examined whether masked priming of alleged effect-stimuli varies the degree of experienced control over these stimuli even when actions are freely chosen by the participants. Therefore, the control judgment task of Experiment 1 was modified such that participants now freely chose whether to press a left or a right key-press whenever they received an unspecific go-signal. (2) It was investigated whether the prime-induced modulation of conscious control occurs even when there is absolutely no systematic correlation between these actions and stimuli appearing subsequently as alleged action-effects. (3) It was addressed whether anticipatory priming of an unconscious effect-representation affects experienced control also on a more abstract conceptual level of processing. Hence, in Experiment 2 semantic stimuli (color words) were used to prime unconscious representations of post-action "effect"-stimuli (colored circles), (Dehaene, Naccache, LeClec'H, Koechlin, Mueller, Dehaene-Lambertz, van de Moortele, \& LeBihan, 1998, 2001; Fairhall, Hamm, \& Kirk, 2006; Kiefer \& Spitzer, 2000). As in Experiment 1, participants first performed six blocks of the -modified-control-judgment task and two subsequent methodological control experiments, i.e., the forced-choice priming task and the prime-identification task.

\section{3. 1 Methods}

\section{Participants}

Sixty-seven undergraduates (43 female, 67 right-handed) from the Technical University of Dresden participated for partial fulfillment of course credit or $€ 4$ after 
having given their written informed approval. They were on average 22 years old (range 19-35), had normal or corrected-to-normal vision and were naïve to the purpose of the experiment.

\section{Control judgment task}

Stimuli. Primes consisted of the words BLUE (German: BLAU), YELLOW (German: GELB), and the non-word AGLB (used as a neutral prime) all of which were $0.6 \mathrm{~cm}$ in height and $2 \mathrm{~cm}$ in width. The mask was a letter string "ORTFX" sized $0.8 \mathrm{~cm} \times 3$ $\mathrm{cm}$. The go-signal was a "click"-tone of $300 \mathrm{~Hz}$ presented over head-phones. The effect-stimuli consisted of a blue and a yellow circle which extended $2.5 \mathrm{~cm}$ in diameter. Except for the two color circles all visual stimuli were presented in black font. The background of the computer screen was white. Stimuli are seen in Figure 12.

Procedure. Each trial began with the presentation of a prime which was replaced by the mask appearing simultaneously with the auditory go-signal. The prime was shown for $50 \mathrm{~ms}^{5}$ and the mask remained visible for $100 \mathrm{~ms}$. The mask was followed by a blank screen that remained until a response was made. Participants were instructed to freely choose to press either the left or the right out of two indicated buttons on the computer-keyboard as soon as they had received the go-signal. They were asked to press both of the keys approximately equally often while avoiding systematic alternations or runs. Immediately after the response either a blue or a yellow circle appeared and remained on the screen for $2 \mathrm{~s}$ as the alleged "effect" of the key-presses. Participants were asked to try to find out by pressing the left or the right key whether they could control which of the two colored circles appeared.

\footnotetext{
${ }^{5}$ At first glance, the prime presentation duration of 50 ms may appear unusually long, in particular with respect to previous studies using much shorter durations for masked primes (e.g., Eimer \& Schlaghecken, 1998; Neumann \& Klotz, 1994). However, meticulous pilot studies which tested the present stimulus materials in forced choice priming tasks yielded no priming effect, i.e., no differences in response times, for shorter prime durations. $50 \mathrm{~ms}$ prime-duration was found to yield reliable priming effects and a satisfying extent of non-perceptibility.
} 
Design. Actually there was no correlation between participants' freely chosen keypresses and the colors of the circles. Instead one of the colors appeared with a probability of $75 \%$ while the other appeared with a probability of $25 \%$, irrespective of which key was pressed. Color-assignment to probabilities was counterbalanced across participants. Thus participants had no control over which colored circle appeared. The critical independent variable was the systematic relation between the color of the circle and the meaning of the prime word which was either congruent, e.g., a blue circle following the prime word "BLUE", incongruent, e.g., a blue circle following the prime word "YELLOW", or neutral, e.g., a blue circle following the nonword-prime "AGLB". The three conditions of prime-effect congruity were realized in separate blocks by 40 trials. Each participant performed two blocks with only congruent, two with only incongruent, and two with only neutral prime-effect pairs. Order of conditions was counterbalanced across participants.

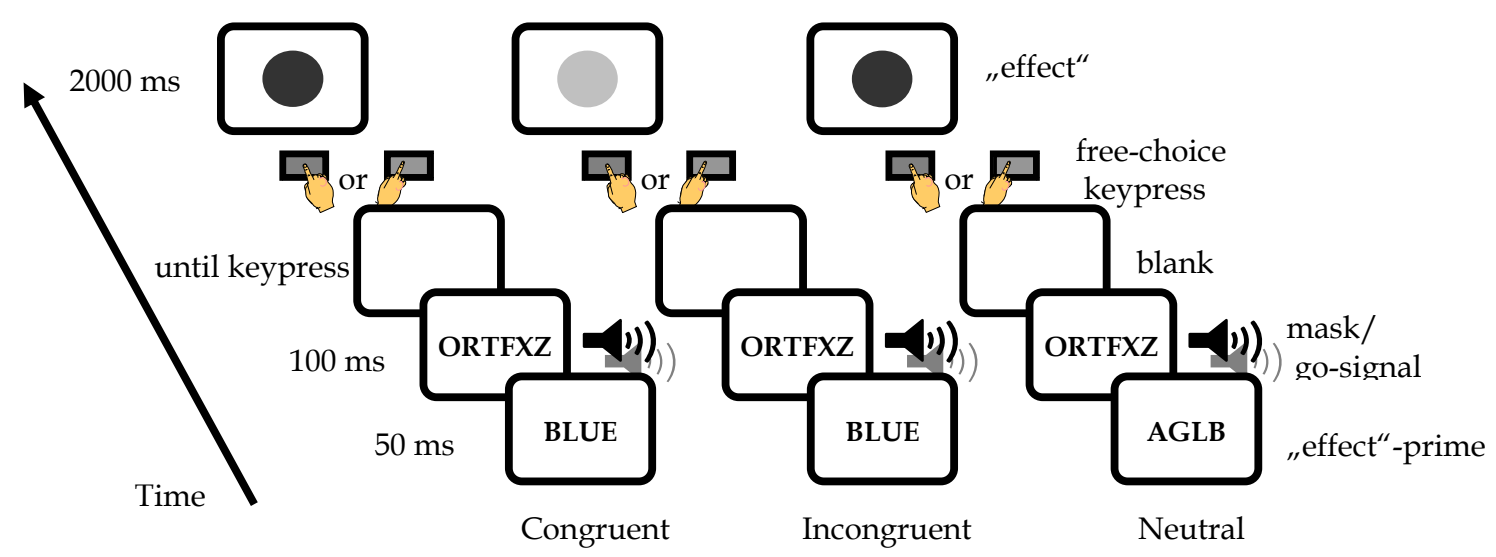

Figure 12. Experimental setup of the control judgment task in Experiment 2. Sequence and durations of events in a trial for the three conditions of prime-"effect"-congruity. Bluecolored circles are printed in black, yellow-colored circles in grey ink.

Dependent variable and prediction. After each block participants rated how much control they thought they had had over whether a blue or a yellow appeared after their key-presses (the control judgment questionnaire can be seen in Appendix A 2). 
As in Experiment 1 control-judgments were expected to be higher for congruent compared to incongruent or neutral prime-effect pairs even though there was no systematic correlation between participants' key-presses and the circle colors.

\section{Prime-impact: forced-choice priming task}

Stimuli and procedure. After the control-judgment task, it was assessed whether the masked primes did in fact activate the representation of their meaning in a forcedchoice priming task (e.g., Cheesman \& Merikle, 1984; Heil, Rolke, \& Pecchinenda, 2004; Marcel, 1983). Materials and durations of events were the same as in the control-judgment task except that the circles shown as "effects" in the control judgment task were now used as imperative target stimuli. Trials started with a prime (50 ms) which was followed by the mask $(100 \mathrm{~ms})$ and a target, i.e., one of the two color-circles, remaining visible until a response was given. No further stimuli appeared after the response. The ITI was $1 \mathrm{~s}$. Participants were instructed to press as fast and as accurate as possible a left or a right key to indicate whether the targetcircle was blue or yellow. Key-target mapping was counterbalanced across participants.

Design and prediction. Prime-target pairs were congruent, incongruent, or neutral. After 18 practice trials, 20 congruent, 20 incongruent, and 20 neutral trials were presented in random order. Participants were expected to respond faster and more accurately on congruent than on neutral trials and faster and more accurately on neutral than on incongruent trials.

\section{Prime-perceptibility}

Awareness questionnaire and prime-identification task. After having completed the priming task, participants received the questionnaire to indicate whether at any point they had seen any object on the screen apart from the mask, the targets and the effect-stimuli and if so, what they had seen (see Appendix B 2.). In the prime- 
identification task materials were the same as in the response-priming task except that target stimuli were now omitted. The prime-identification task comprised 33 trials such that each of the three prime-stimuli was delivered on 11 trials. Order of prime-presentation was randomized. Each trial began with the presentation of a prime $(50 \mathrm{~ms})$ which was followed by the mask $(100 \mathrm{~ms})$ and a blank screen remaining visible until participants had pressed the left-, the right-, or the spacekey to indicate the identity of the preceding prime-stimulus. Given that now three primes were at disposal the predicted rate of correctly identified primes was $33 \%$.

\section{3. 2 Data analyses and results}

Prime identification. In the awareness-questionnaire 17 participants declared identification of the prime-words. In the identification task participants identified on average $49 \%$ of the primes correctly. This was significantly above the $33 \%$ chance level $[t(66)=5.37, p<.001, S D=23.8]$. Therefore participants were classified as aware ("detectors") or unaware ("non-detectors") depending on whether their performance was above or below the median rate $(52 \%)$ of correctly identified primes. Detectors $(N=36)$ accurately recognized on average $63 \%$ of the masked primes which was significantly better than chance $[t(35)=8.9, p<.001, S D=19.8]$. Non-detectors $(N=30)$ identified on average $32 \%$ of the primes correctly which did not differ substantially from chance $[t(29)=-.7, p>.4, S D=14.8]$. Data from one participant who reported conscious identification of the primes but paradoxically performed far below chance level in the prime-identification task were discarded.

Control-judgments. For each participant mean control-judgments were computed for each of the 6 experimental blocks of the control-judgment task and then collapsed over the two blocks of each condition of prime-"effect" congruity. Both detectors and non-detectors gave higher control-judgments after blocks with congruent compared to neutral or incongruent prime-"effect" pairs. A mixed 3 by 2 ANOVA with the factors of "prime-effect congruity" and "prime-awareness" and 
"experienced control" as the dependent variable revealed a significant main effect of the factor "prime-effect congruity" $[F(2,128)=3.34, p<.04, M S E=105.8]$, but neither an effect of prime awareness $[p>.10]$ nor an interaction of the two variables $[p>$.80]. On a descriptive level control judgments were somewhat lower for the detectors compared to non-detectors. This possibly reflects the fact that conscious perception of the primes led detectors to speculate about the purpose of the primes and to proceed more strategically in the experiment. Importantly, the modulating impact of the primes on experienced control, i.e., the difference between controljudgments for congruent compared to incongruent trials, was of almost identical magnitude for detectors and non-detectors. This effect could not be attributed to differences in participants' responses in the different conditions. Mean RT for detectors $[M=314.8 \mathrm{~ms}, S D 131.48]$ and non-detectors $[M=305.8 \mathrm{~ms}, S D 159.69\}$ did not differ between the congruity conditions. Results of the control judgment task are shown in Figure 13, left panel.

Forced-choice priming. Incorrect responses [overall mean error rate $=2.77 \%, S D=$ 3.72] and responses exceeding a latency of $1500 \mathrm{~ms}$ [overall mean RT $=407.29 \mathrm{~ms}$, $S D=50.66]$ were excluded. Mean RTs of the remaining responses were computed for each awareness-group and condition. As can be seen in Figure 13 (right panel), mean RT was lower on congruent than on neutral trials, and lower on neutral than on incongruent trials. A mixed 3 (prime-target-congruity) $\times 2$ (prime-awareness) ANOVA yielded an effect of prime-target-congruity $[F(2,128)=11.43, p<.001$, $M S E=252.87]$, but neither an effect of prime awareness [ $p>$.5], nor an interaction of the two variables $[p>.4]$. An analogous ANOVA revealed that error rates did not differ significantly between congruity conditions $[p>.5]$. 

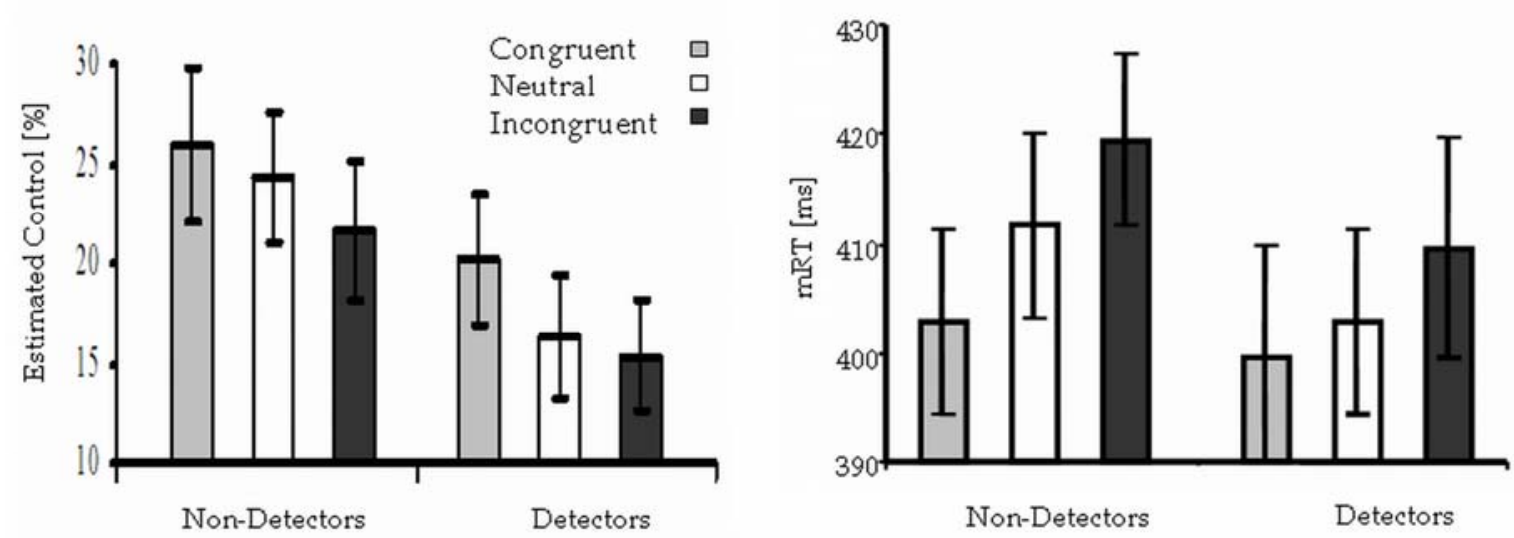

Figure 13. Data of Experiment 2 for participants classified as 'non-detectors' and 'detectors'. Left panel: Mean control-judgments in the control-judgment task as a function of prime"effect" congruity. Right panel: Mean RTs in the forced-choice priming task as a function of prime-target congruity. Error bars represent standard errors.

\section{3. 3 Discussion}

In conclusion, the pattern of results of Experiment 1 was almost perfectly replicated in Experiment 2 although participants now freely chose which action to perform and although there was no contingency between their actions and the alleged effectstimuli. The degree of experienced control was again substantially modulated by the masked primes. This effect was independent from whether participants were aware or unaware of the primes according to an objective forced-choice criterion.

In summary, even though participants now performed freely chosen actions and had no control at all over the alleged "effect" stimuli they judged their control significantly higher after blocks with congruent compared to neutral or incongruent prime-"effect" pairs. That this effect occurred with semantic "effect"-primes (color words) reveals that the impact of masked effect-primes extends to a conceptual level of processing. 


\subsection{Experiment 3 - 'Reversed' unconscious modulation of experienced control}

In Experiment 3 it was attempted in to reverse the impact of masked "effect"-primes on experienced control. To this end Experiment 3 exploited the fact that subliminal forced-choice priming tasks produce under certain conditions a response pattern opposite to the one reported in Experiments 1 and 2, i.e., a performance deficit rather than a benefit occurs for congruent compared to incongruent prime-target-pairs. The phenomenon when participants produce slower responses and more errors on congruent compared to neutral or incongruent trials is termed 'reversed priming' and was first reported by Eimer and Schlaghecken (1998; see also Eimer \& Schlaghecken, 2001, 2002; Eimer, 1999; Schlaghecken \& Eimer, 2000, 2001, 2002; Praamstra \& Seiss, 2005; Aron, Schlaghecken, Fletcher, Bullmore, Eimer, Barker, Sahakian, \& Robbins, 2003; see section 2.3.2 of the present work). In the literature two different approaches to account for this phenomenon are discussed (see Enns \& Di Lollo, 2004 for a review). Following the original explanation given by Eimer \& Schlaghecken (2003) reversed priming is a motor effect and reflects automatic selfinhibitory processes of motor control which follow the initial automatic activation elicited by the masked prime. According to Eimer \& Schlaghecken, this happens when the SOA separating prime and target is prolonged such that the execution of the response to the target is delayed. As a consequence of that SOA-due response delay, automatic, i.e., unconscious self-inhibitory processes of motor control intervene and reverse the initial response-activation elicited by the prime (Eimer \& Schlaghecken, 2002). Consistent with that idea LRP-recording revealed an initial activation of the prime-related, i.e., correct response immediately after prime-onset. Thus, the LRP curve indicates a negative deflection from a baseline level of activation contralateral to the prime-mapped hand followed by a polarity-shift 300$400 \mathrm{~ms}$ after prime onset. This polarity shift is seen as a positive deflection from baseline contralateral to the prime-mapped hand which was interpreted to indicate an inhibition of the primed and thus a relative activation benefit of the non-primed, 
i.e., incorrect response tendency (Eimer \& Schlaghecken, 1998; Praamstra \& Seiss, 2005). By systematically varying mask-target SOA in a subsequent study, this reversal was found to occur by rule when mask-target SOA exceeded about $90 \mathrm{~ms}$ (Schlaghecken \& Eimer, 2000; also Praamstra \& Seiss, 2005) provided that the initial activation was sufficiently strong to have surpassed some 'inhibition threshold' (Schlaghecken \& Eimer, 2002). According to the alternative explanation, reversed priming is principally a perceptual effect that reflects automatic updating of the visual system whenever one tracks a dynamic visual scene (Enns \& DiLollo, 1997; Lleras \& Enns, 2004; see Enns \& DiLollo, 2004 for a review). The starting point for this alternative account was the finding that incompatible priming was obtained only with masks that consisted of the visual features that made up the stimuli used as primes. This was the case in the original 'reversed priming study' by Eimer and Schlaghecken (1998) where primes and targets consisted of left- and right pointing arrows and the mask was made up of mixed arrows superimposed on one another. Masks of that kind, however, were found to contain information relevant to the target-related responses (Lleras \& Enns, 2004). In contrast, studies using a neutral (response-unrelated) mask, e.g., a mask consisting of four dots (Enns \& DiLollo, 1997), ordinary compatible priming was obtained also when prime-mask-target interval was prolonged. Prolonged prime-mask-target interval -not mask-shapewas considered critical to produce incompatible priming effects according to Eimer and Schlaghecken's activation-followed-by-inhibition-hypothesis (e.g., Eimer \& Schlaghecken, 1998, 2001, 2002; Klapp \& Hinkley 2002). It can thus not account for the observation made by Enns and DiLollo (1997). Accordingly, they proposed an alternative explanation according to which reversed priming relies on automatic perceptual updating mechanisms of the visual system when confronted with a dynamic visual scene. The masked priming paradigm is a dynamic visual scene. Typically, stimulus succession is extraordinarily rapid such that the mask follows even before processing of the prime has been completed. Therefore, processing of the two stimuli interacts. When the mask is a composite of the primes each mapped 
to a specific response, as in the Eimer-Schlaghecken study, the visual system extracts that part of perceptual information added by the mask that is (1) of relevance to the present task and that (2) goes beyond the information that has been provided by the preceding prime. For instance, when a left-pointing arrow is followed by a mixed-pointing arrow mask (as in Eimer \& Schlaghecken, 1998) taskrelevant perceptual updating will pertain to the right-pointing arrow included in the mask-pattern. Provided the target follows the mask at a sufficiently short delay the visual system is caught in a time window when the 'different-from-prime' component added by the mask is dominant. In this situation, the succeeding target will be processed and responded to in a facilitated way when it is congruent with these most recent features of the mask. Yet importantly, these mask-features are at the same time the features of the prime-incongruent target. Thus, the 'differentfrom-prime-and-also-response-relevant' features that are added by the mask act as a congruent prime for the response related to the prime-incongruent target. In conclusion, according to the alternative explanation by Llerras and Enns (2004) the processes which underlie the phenomenon of reversed priming are supposedly activational and primarily perceptual rather than inhibitory and purely motor as suggested by Eimer and Schlaghecken $(1998,2003)$.

Of particular interest with respect to the present work is the finding that reversed priming effects arise not only for instructed responses which are mapped to an imperative target stimulus but also for actions that are freely chosen by participants (Klapp \& Hinkley, 2002, Experiment 5; Schlaghecken \& Eimer, 2004; see section 2.3.2 of the current work). In Experiment 3 it was attempted to go one step further. In detail, it was hypothesized that under reversed priming conditions the influence of masked "effect"-primes on experienced control would reverse accordingly. This was assumed because under reversed priming conditions the supposed comparison process should yield a discrepancy after congruent "effect"-priming and respectively detect a match after incongruent prime-effect pairs. Thus, it was predicted that compatible priming of an effect representation prior to action would 
decrease experienced control over stimuli following participants freely chosen actions as alleged "effects" such that higher control-judgments should be given for incompatible compared to neutral or compatible prime-"effect" pairs.

To establish conditions adequate to produce an incompatible priming effect Experiment 3 commenced with a pilot study which included only a forced-choice priming task and measures of prime-perceptibility. The control-judgment task was conducted in the subsequent main study using a different and again naïve sample of participants.

\subsection{Pilot study:Forced-choice priming task}

\section{4. 1. 1 Methods and procedure}

\section{Participants}

Twelve volunteers (7 female, all right-handed, naïve and of normal or corrected to normal vision), 19-34 years of age (mean 23.9 years) from Dresden University of Technology participated after having given their written informed approval.

\section{Stimuli}

Primes consisted of a diamond sized $1.8 \mathrm{~cm} \times 1.8 \mathrm{~cm}$ and a square sized $1.2 \mathrm{~cm} \times 1.2$ $\mathrm{cm}$. The neutral prime was a star-shaped composite of diamond and square superimposed on one another. Targets were larger replica of the primes: a diamond sized $2.5 \mathrm{~cm} \times 2.5 \mathrm{~cm}$ and a square sized $1.8 \mathrm{~cm} \times 1.8 \mathrm{~cm}$. The mask was the $2.5 \mathrm{~cm} \times 2.5$ cm sized star-shaped composite of diamond and square. Importantly, the mask thus included the perceptual features of both primes respectively targets. All stimuli were presented in black on a white background. Stimuli are seen in Figure 14. 


\section{Forced-choice priming}

Trials began with the $50 \mathrm{~ms}$ long presentation of a prime which was followed by the mask shown for $100 \mathrm{~ms}$ and a target remaining on screen until a response was made. The next trial started after a delay of 1s. All stimuli were presented at fixation. Participants were instructed to press as fast and as accurate as possible a left or a right key to indicate whether the target was a diamond or a square. Keytarget mapping was counterbalanced across participants. Prime-target pairs were either congruent, e.g., a diamond-target following a diamond-prime, incongruent, e.g., diamond-target following square-prime, or neutral, i.e., diamond or square following the neutral prime. After 15 practice trials, 50 congruent, 50 incongruent and 50 neutral trials were delivered in random order. With the mask being composed of the visual features of both primes respectively targets presented for $100 \mathrm{~ms}$ on each trial a reversed priming effect was expected. Thus, responses were predicted to be faster and more accurate on incongruent compared to neutral or congruent trials. Figure 14 shows series and durations of events on a trial in the pilot study of Experiment 3 for the three conditions of prime-target-congruity.

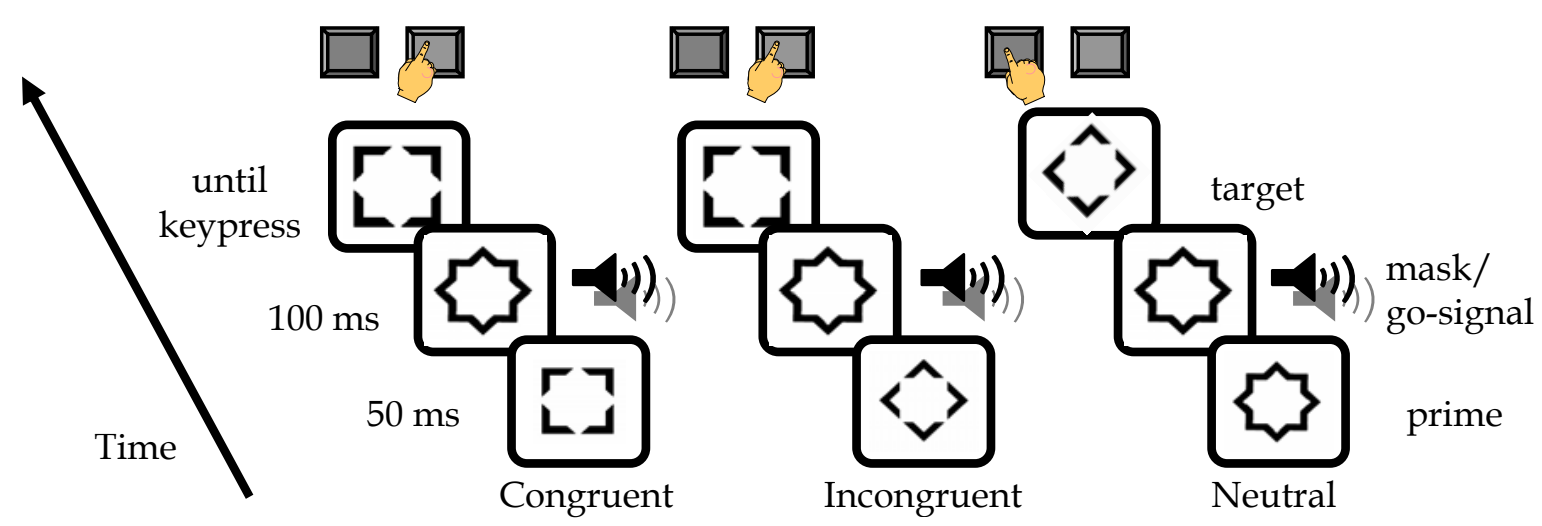

Figure 14. Experimental setup of the 'reversed'-priming task in Experiment 3 (pilot-study). Sequence and durations of events on a trial for the three conditions of prime-target-congruity. 


\section{Prime identification}

After the priming-task participants received a questionnaire to indicate whether they had seen anything on the monitor except for the mask and the target stimuli and if so, what they had seen (see Appendix B 3). Then they were informed about the presence of primes and accomplished a forced-choice identification task which consisted of the same materials as in the priming-task except that the target stimuli were omitted. On 100 trials, i.e., 50 trials each prime, they pressed a left- or a right key to indicate whether a diamond or a square was presented. The neutral prime was omitted. Primes were displayed in random order. The expected mean rate of correctly identified primes was expected at the chance level of guessing which was at $50 \%$.

\section{4. 1. 2 Results and conclusion}

\section{Prime-perceptibility}

None of the participants claimed to have seen the primes. In the forced-choice prime-identification task participants on average identified $50.08 \%$ of primes correctly which did not differ from chance level $(p>.90)$.

\section{Response priming}

Incorrect responses [overall mean error rate $=4.04 \%, S D=3.46$ ] and responses exceeding a latency of $1500 \mathrm{~ms}$ [overall mean RT $=529 \mathrm{~ms}, S D=48.09$ ] were discarded. As seen in Figure 16 (right panel), a reversed priming effect was obtained. A repeated measures ANOVA revealed that mean RTs were significantly faster after incongruent compared to neutral or congruent trials $[F(2,22)=6.35, p<$ $.008, M S E=473.69]$. A two tailed paired $t$-test confirmed that responses were significantly faster on incongruent compared to congruent trials $[t(11)=3.07, p<$ 
$.012, S D=34.54]$. These results indicate that even though the primes were not consciously perceived they modulated participants' responses in the priming task as indicated by the reversed priming effect.

\subsection{Main study: Free-choice control-judgment task}

As intended, a reversed priming effect was obtained in the pilot study. Primeperceptibility was at chance level. Thus, it was now attempted to investigate whether under these 'reversed priming conditions' the pattern of control-judgments obtained in Experiments 1 and 2 would reverse accordingly. To this end the freechoice control-judgment task introduced in Experiment 2 was conducted using the stimuli, masking- and priming-conditions that yielded reversed priming in the pilot experiment. In the control judgment task, the masked primes were expected to activate the "opposite-to-effect-prime representation" producing a reverse modulation of experienced control. Control judgments were predicted to be lower after blocks containing congruent compared to blocks including neutral or incongruent prime-"effect" pairs.

\section{4. 2. 1 Methods and procedure}

\section{Participants}

Twenty-four undergraduates from Dresden University of Technology (17 female, all right-handed and of normal or corrected to normal eye-vision) aged 18-47 years (mean age: 21.7 years) gave their written consent to participate for course credit or $€$ 4.

\section{Control-judgment task}

Stimuli and procedure. Stimuli were the same as in the pilot priming-study except that the stimuli that were used as targets in the priming study were now used as 
"effect"-stimuli. Thus, as Figure 15 shows, trials commenced with the presentation of a prime (50 ms) which was replaced by the mask appearing simultaneously with the auditory click-tone go-signal (cf. Experiments 1 and 2). The mask was presented for $100 \mathrm{~ms}$ and then replaced by a blank screen which remained until a response was made. Participants were instructed to choose freely whether to press the left or right out of two indicated buttons on the computer keyboard as soon as they received the go-signal. They were asked to press both keys approximately equally often while avoiding systematic alternations or runs. Immediately after the keypress, either a diamond or a square appeared for $2 \mathrm{~s}$ as the alleged "effect" of the key-press. After a delay of $1 \mathrm{~s}$ the next trial started. Participants were instructed to try to find out whether by pressing the left or the right key they could control whether a diamond or a square appeared on the screen.

Design and prediction. There was no systematic correlation between participants' freely chosen key-presses and the identity of the alleged "effect"-stimuli. Instead, one of the two stimuli appeared with a probability of $75 \%$, while the other appeared with a probability of $25 \%$ irrespective of which key was pressed. Stimulus assignment to probabilities was counterbalanced across participants. Thus participants had no control over which figure appeared. The critical independent variable was the relation between the shape of the prime and the shape of the stimulus that appeared as the alleged effect. This relation was either congruent, e.g., a diamond-effect following a diamond-prime, incongruent; e.g., a diamond-effect following a square-prime, or neutral, i.e., diamond- or square-effect following the neutral prime. In Figure 15 sequence and durations of events in the control judgment task of experiment 3 are illustrated. Participants performed 6 blocks by 40 trials, two of which included only congruent, two only incongruent, and two only neutral prime-effect pairs. Order of congruity conditions was counter-balanced across participants. 
After each block, participants rated how much control they thought they had over diamond and square on a scale ranging from $0 \%$ for "no control" to $100 \%$ for "complete control" (see Appendix A3). Control-judgments were expected to be lower after blocks with congruent compared to neutral or incongruent prime-"effect" pairs.

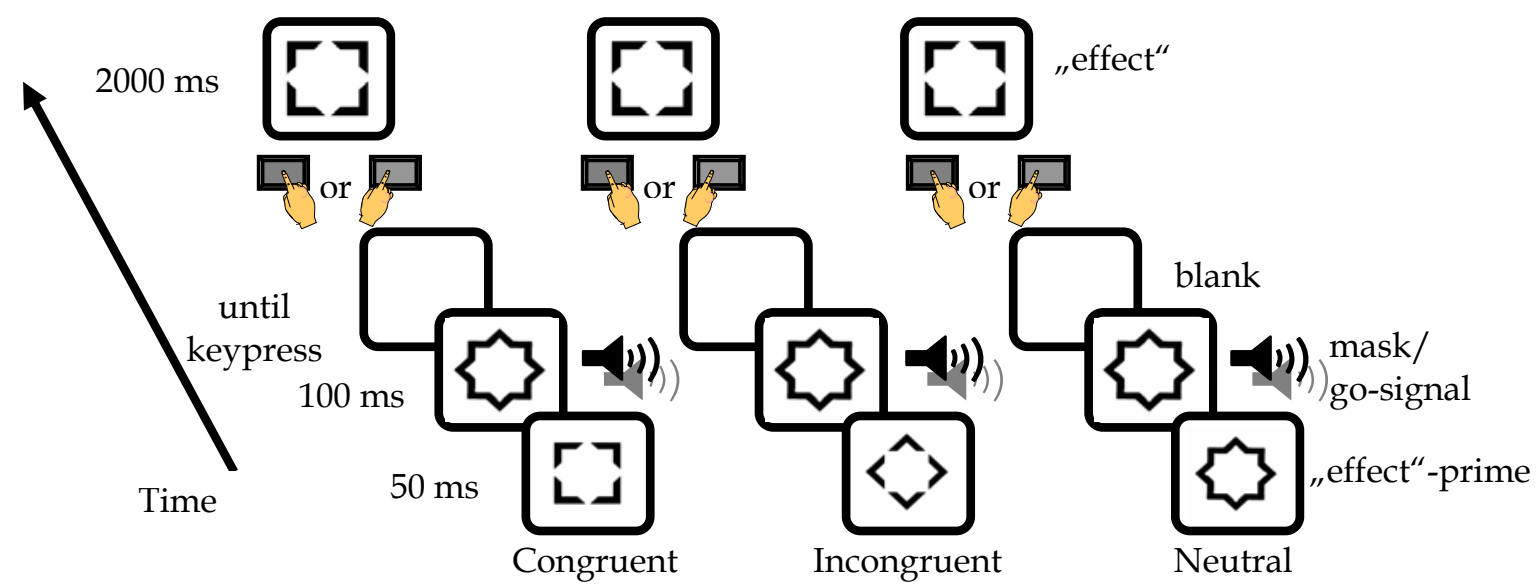

Figure 15. Experimental setup of the control-judgment task in Experiment 3 (main study). Sequence and duration of events on a trial for the three conditions of prime-"effect"-congruity.

\section{Prime-identification task}

After the control-judgment task participants were asked on a questionnaire whether they had seen anything on the monitor except for the mask and the effect-stimuli, and if so, what they had seen (see Appendix B3). Then they performed the primeidentification task. Materials and procedure were the same as in the pilot study except that, this time, all three primes (including also the neutral prime) were at proposal. Participants who were now informed about the presence of primes performed 33 trials in which they were asked to indicate prime-identity by pressing left-, right-, or space-key. 


\section{4. 2. 2 Results}

\section{Prime-perceptibility}

Only one participant declared identification of the primes and was thus excluded from the analyses. In the prime-identification task the remaining participants' mean rate of correctly identified primes was 35\% which was not significantly better than $33 \%$ chance as revealed by a $t$-test, $[p>.40]$.

\section{Control-judgments}

Mean control-judgments were computed by block and collapsed over the two blocks of each condition of prime-"effect" congruity. As predicted, mean controljudgments were lower after congruent than after neutral blocks, and lower after neutral blocks compared to incongruent blocks. In a repeated measures ANOVA, the main effect of congruity nearly reached significance $[F(2,44)=3.14, p=.053$, $M S E=136.07]$. A two-tailed paired $t$-test revealed that control-judgments were reliably smaller on congruent than on incongruent trials $[t(22)=-2.6, p<.02, S D=$ 14.38]. Over all mean RT of the free-choice key-presses was $426.93 \mathrm{~ms}$ [SD 163.03]. There were no significant RT-differences between conditions $[p>.9]$.
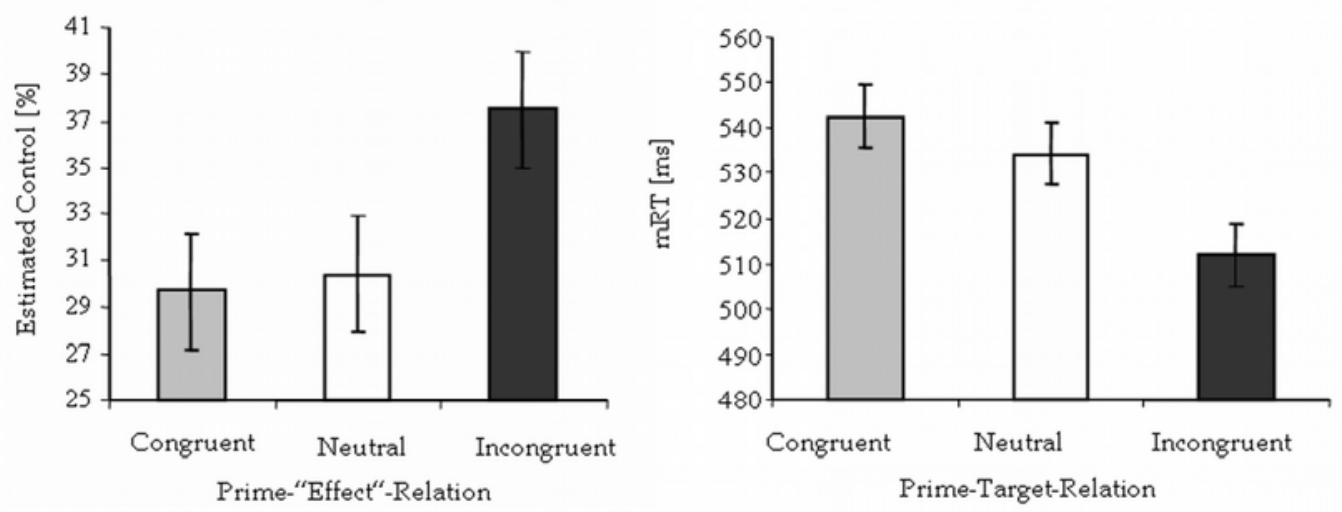

Figure 16. Results of Experiment 3. Left panel: Reversed modulation of experienced control observed in the control judgment task (main study). Mean control-judgments were lower for congruent compared to neutral or incongruent trials. Right panel: Corresponding to the reversed modulation of experienced control, mean RTs in the pilot priming study were lower for congruent compared neutral of incongruent trials. Error bars show 95\% withinsubject confidence intervals (Loftus \& Masson, 1994). 


\section{4. 2. 3 Discussion}

In a priming paradigm that yielded a reversed priming effect as indicated by slower responses in a forced-choice priming task on trials with congruent compared to trials with incongruent prime-target pairs the pattern of control-judgments reversed accordingly. In a free-choice control judgment task participants experienced less control over alleged action-"effects" after blocks with congruent compared to blocks with neutral or incongruent prime-"effect" pairs. The modulatory impact of the effect-primes on experienced control was again independent from conscious awareness, as indicated by the fact that performance in the prime-identification task was at chance level.

Which process may underlie this result? The 'pure' motor explanation (automatic response inhibition followed by initial activation) (e.g., Klapp \& Hinkley, 2002; Eimer and Schlaghecken, 1998; Schlaghecken \& Eimer, 2002) can account many findings made in forced-choice reaction paradigms. Yet, it cannot fully explain the findings made in the present experiment - why? In the control judgment task participants did not perform a forced-choice response mapped to an imperative stimulus. Rather they performed a freely chosen action whenever the received an 'unspecific' go-signal. This suggests that if an inhibitory process was at work it would in the present experiment be primarily a perceptual rather than a motor effect. Thus, if inhibition was at work it would concern the perceptual pattern of the anticipatory "effect"-representation elicited by the masked prime. Following this train of thought it would be conceivable that when inhibited, the primed "effect"pattern would be no longer available to the post-action comparison process tuned to match anticipated and observed action-"effect". With the primed effect representation being inhibited below some -hypothetical- baseline level of activation there should be a relative supremacy in activation of the non-primed, i.e., incongruent "effect"-representation. This 'relatively more active' effectrepresentation would in turn be available to the comparison process suggested to 
compare anticipated and actually perceived consequences of action. The comparison would, as a result, yield higher control judgments for incongruent than for congruent prime-"effect" pairs. This explanation, however, holds only for situations with not more than two potential action effects at proposal.

Assuming that reversed priming effects would rely on automatic perceptual updating mechanisms of the visual system (e.g., Llerras \& Enns, 2004) the reversed pattern of the control judgments in the present experiment would not be inhibitory but activational. The 'different-from-prime-and-also-task-relevant' feature added by the mask would activate a representation of the incongruent, i.e., non-primed "effect"-stimulus. Supposed this most recently updated "effect"-representation became available to the comparison module, control should more likely be attributed to the self if the subsequent "effect"-stimulus was the prime-incongruent one, because it would be congruent with the new mask features. Conversely, when the effect is congruent with the prime - but incongruent with the new mask features - control would rather be ascribed to an external cause.

Would this explanation - with the conscious mask as an additional "effect"prime challenge the assumption that the matching-process underlying authorship ascription is unconscious and due to the prime? I suppose that it would not. Even though the perceptual component relevant to the internal comparison module is part of the -visibly presented- mask, the systematic manipulation of experienced control would still root in the prior -nonperceptible- prime. With the prime being omitted the mask should not function any longer as a relevant prime. Rather without the preceding prime the mask-shape should be processed 'as a whole' and thus a neutral stimulus without specific relevance concerning the control decision. Thus supposedly, only because of their novelty in relation to the preceding unconscious prime the 'different-from-prime-and-also-task-relevant' features of the mask functioned as an update relevant to the control decision. Certainly the present data do not provide a clear answer whether in the present case the effect- 
anticipation was unconscious or conscious because of the visible mask. However, that the unconscious anticipatory effect-prime did have a systematic and controlrelevant impact is clearly indicated by the fact that control judgments differed systematically dependent on the three conditions of prime-"effect" congruity.

\subsection{Experiment 4 - 'Reversed' modulation of experienced "effect"-predictability in free-choice action}

To obtain a more solid base for the observation that the direction to which experienced control is modulated by priming a representation of an event following participant's action as an alleged effect reverses under conditions of incompatible priming Experiment 4 was conducted. Therefore, the procedure and stimuli established in Experiment 3 were retained. As the only modification the assessment of experienced control was changed. The literature reveals that experienced control has been operationalized in many different ways (e.g., Skinner, 1985, 1996; Haidt \& Rodin, 1999; Presson \& Benassi, 1996). As an alternative frequently used measure of experienced control participants in Experiment 4 were asked for judgments of experienced "effect"-predictability (e.g., Benassi, Sweeney \& Drevno, 1979).

\section{5. 1 Methods}

\section{Participants}

Twenty-four undergraduates from Dresden University of Technology (16 female, 2 left-handed), aged 18-30 years (mean: 22 years) participated for course credit or $€ 4$ after having given written informed approval. All had normal or corrected to normal eye-vision and were naïve to the purpose of the experiment. 


\section{Prediction- judgment task}

Stimuli and procedure were exactly the same as in Experiment 3 and are thus shown in Figure 15. Different from Experiment 3 participants were at this time asked to try to predict in a silent manner to themselves immediately before they pressed a selfchosen left-or right key whether a diamond or a square would appear subsequently. As in the previous experiments there was no systematic correlation between the freely chosen key-presses and the identity of the alleged "effect"-stimuli. Participants had thus no control over whether a square or diamond appeared on the screen. Both, diamond and square appeared with a probability of $50 \%$ irrespective of which key was pressed. Which "effect" appeared depended on the masked prime delivered before subject's key-press. Primes and "effects" on a trial were congruent, incongruent, or neutral. Congruity conditions were again realized block-wise. Each block included 40 trials, 2 with only congruent, 2 with only incongruent and 2 blocks with only neutral prime-"effect" pairs. After each of the six blocks participants rated the percentual amount of how many "effect"-stimuli they had correctly predicted on a scale ranging from $0 \%$ for "always wrong" to $100 \%$ "always correct". The judgment scale experienced "effect"-predictability is shown in Figure 17 and in the original German version in Appendix A 4.

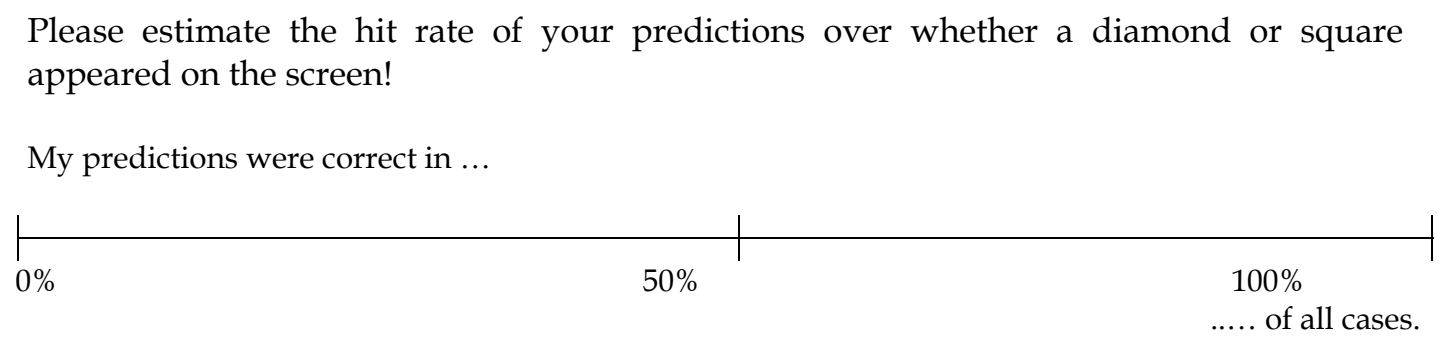

Figure 17. Judgment-scale of experienced "effect"-predictability in Experiment 4. The original version in German can be seen in Appendix A 4. 


\section{Forced-choice priming task and prime-identification assessment}

To measure whether a reverse priming effect was obtained, a forced-choice priming task was conducted. Prime-perceptibility was assessed via awareness-questionnaire and forced-choice prime identification task. Materials and procedure used in these tasks were identical with the pilot priming study of Experiment 3 and are seen in Figure 14.

\subsection{Data analyses and results}

\section{Prime perceptibility}

None of the participants declared identification of the primes. In the primeidentification task, the mean rate of correctly identified primes was 35.7\%. As confirmed by a $t$-test this performance did not significantly differ from $33.3 \%$ chance level $[p>.3]$.

\section{Forced-choice priming}

Incorrect responses [overall mean error rate $=2.69 \%, S D=2.12$ ] and responses exceeding a latency of $1500 \mathrm{~ms}$ [overall mean $\mathrm{RT}=544.69, \mathrm{SD}=53.9$ \} were discarded. As seen in Figure 18, right panel, a reversed priming effect was obtained. Thus as predicted, mean RTs were faster after incongruent compared to neutral trials, and faster after neutral compared to congruent trials. A repeated measures ANOVA substantiated this pattern yielding a significant main effect of primetarget-congruity $[F(2,46)=14.51, p<.001, M S E=307.148]$. A two tailed paire $t$-test confirmed that responses were significantly faster on incongruent compared to congruent trials $[t(23)=4.24, p<.001, S D=30.56]$. An ANOVA for mean error rates also yielded a reliable main effect of prime-target-congruity $[F(2,46)=4.19, p<.03$, MSE $=7.46]$. Participants committed most errors on congruent trials compared to incongruent or neutral trials. Two tailed paired $t$-test comparisons indicated a 
significant difference in error rates between congruent and neutral trials $[t(23)=$ $2.44, p<.03, S D=4.58]$, but not between congruent and incongruent trials $[p>.09$.

\section{Experienced "effect"-predictability}

For each participant mean prediction-judgments were computed by block and then collapsed over the two blocks of each prime-effect congruity condition. As Figure 18, left panel, shows participants judged "effect"-predictability as less after blocks with congruent compared to neutral prime-"effect" pairs and as less after blocks with neutral compared to incongruent prime-"effect" pairs. A repeated measures ANOVA substantiated this pattern yielding a significant main effect of prime"effect"-congruity $[F(2,46)=5.82, p<.007, M S E=52.18]$. A two-tailed paired $t$-test revealed that "effect"-predictability was judged reliably lower after blocks with congruent compared to blocks with neutral prime-"effect"-pairs $[t(23)=-3.08, p<$ $.006, S D=8.64]$, and lower after neutral compared to incongruent prime-"effect" pairs $[t(23)=-3.16, p<.005, S D=10.38]$. Importantly though, planned comparisons revealed that in all three conditions of prime-"effect" congruity left and right keys were followed virtually equally often by diamond as they were followed by square such that there was no actual systematic contingency of participants' keypresses and the alleged effects. Left keypresses were followed virtually equally often by diamond as they were followed by square in the congruent $[p>.8]$, the neutral $[p .3]$ and the incongruent condition $[p>1$. Similarly, right presses were followed equally often by diamond as they were followed by square in the congruent $[p>.3]$, the neutral $[p>.3]$, and the incongruent condition $[p>.1]$. Over all mean RT of the free-choice key-presses was $534.28 \mathrm{~ms}$ [ $S D=204.67]$ with no significant differences between conditions [ $p>.5]$. 

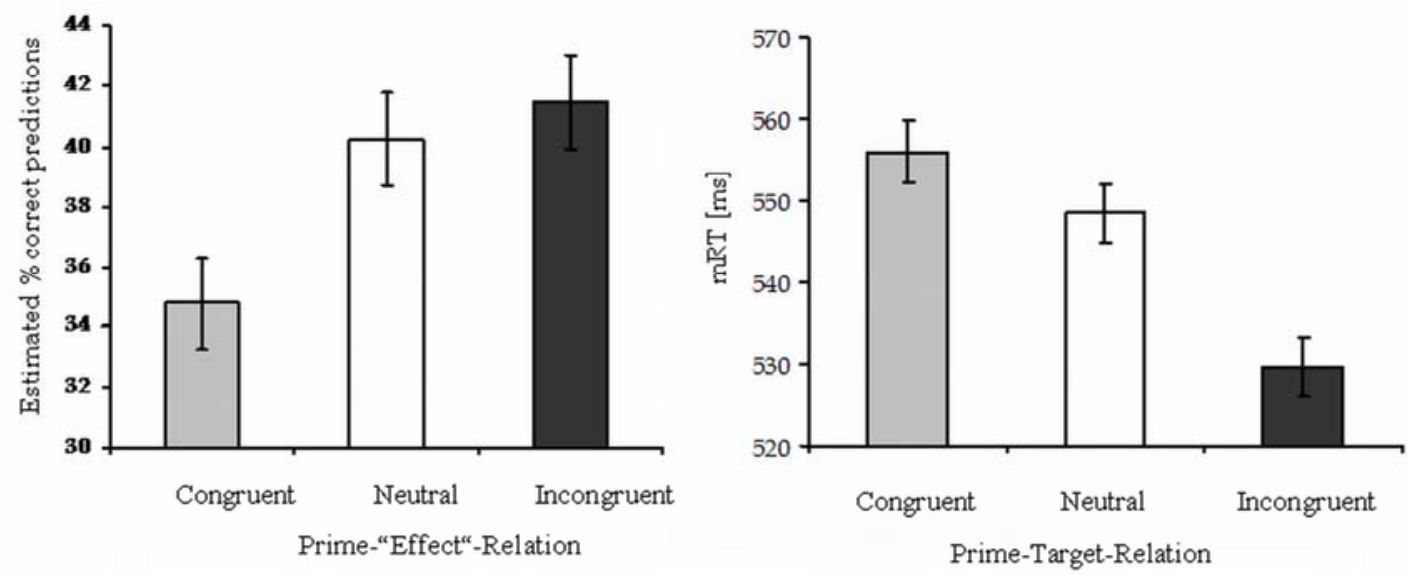

Figure 18. Results of Experiment 4. Left panel: Mean estimates of "effect"-predictability in the prediction-judgment task show a reversed priming effect. Predictability was estimated to be less after congruent compared to neutral or incongruent prime-“effect”-pairs. Right panel: Corresponding mean RTs in the forced-choice priming task reflect also a reversed priming effect. Responses were slower after congruent compared to neutral or incongruent prime-target pairs. Error bars show 95\% within-participant confidence intervals (Loftus \& Masson, 1994).

\section{5. 3 Discussion}

Experiment 4 replicated the data of Experiment 3 by using judgments of experienced "effect"-predictability as an alternative measure of experienced control (e.g., Presson \& Benassi, 1996). Under conditions which in a forced-choice priming task produced a reversed priming effect, i.e., response costs on compatible relative to neutral or incompatible trials, the pattern of experienced "effect"-predictability for stimuli which followed participants' actions "effects" reversed accordingly. "Effect"-predictability was judged substantially lower after blocks including congruent compared to blocks including neutral or incongruent prime-"effect" pairs. Again this prime-dependent modulation of experienced "effect"predictability occurred even though the masked effect-primes remained strictly unconscious and irrespective of the fact, that there was in reality no systematic correlation between participants' actions and the subsequent post-action-"effects". 
This was indicated by the finding that there was no systematic correlation between participants' key-presses and the alleged "effects".

In conclusion, the results obtained Experiment 4 uphold the suggestion that under reverse priming-conditions a primed "effect"-anticipation is updated by those new features of the subsequent mask that are of relevance to the conscious control decision and go beyond the information given by the preceding "effect" prime. As in the present case, these mask-features are those of the prime-incongruent "effect"stimulus. Thus, the suggested post-action comparison process which matches anticipated and perceived action effect to yield a conscious control decision will detect a match after blocks including incongruent prime-"effect" pairs. Conversely, a mismatch will be detected after blocks including congruent prime-"effect" pairs. As consistent with this idea participants experienced "effect"-predictability as higher, i.e., they experienced a higher degree of control after blocks containing incongruent compared to blocks containing neutral or congruent prime-effect pairs. 


\section{Chapter 4}

\section{General discussion}

\section{1 Summary of results}

The central aim of this thesis was to investigate the role of unconscious effectanticipation in the generation of the experience of voluntary control. More precisely, it was hypothesized (1) that effect-anticipations systematically modulate the degree to which people experience to be in control over perceptual events which follow their actions as alleged effects even when these "effects" are in reality not systematically related to those actions and thus not under the control of the participants; (2) that this modulation of experienced control occurs even when effect-anticipations are induced by subliminal effect-primes which remain below the threshold of conscious awareness. In other words it was attempted to induce an illusion of control in participants by priming unconscious "effect"-anticipations.

To realize this aim, four experiments each including a control judgment task and two supplementary reaction time tasks were designed and yielded support for the prediction. In the control judgment task participants performed on each trial free or forced choice actions which were followed by one of two visual "effect"-stimuli. Unbeknownst to participants each action was preceded by a masked effect-prime that was presented so briefly that it remained invisible (e.g., Merikle, Smilek, \& Eastwood, 2001; Merikle \& Reingold, 1998; Neumann \& Klotz, 1994; Naccache \& 
Dehaene, 2001; Kunde, Kiesel \& Hoffmann, 2003; Marcel, 1983). This effect-prime was either congruent or incongruent with the post-action "effect"-stimulus. Importantly there was only a limited (Experiment 1 ) or no systematic correlation (Experiments 2-4) between the actions and the post-action "effect"-stimuli such that participants had only limited or no control over the effects. Based on a theoretical model of the generation of the experience of conscious control, it was predicted that activating a congruent representation of the post-action stimulus before each action would induce a tendency in the participants to overestimate the amount of control they had over the "effect"-stimuli compared to when an unrelated or an incongruent "effect"-representation was primed. This effect was expected to occur even when the primed "effect"-representation remained unconscious.

In support of this prediction, Experiment 1 revealed that unconscious effect primes which activated a perceptual representation of the shape of an action-effect systematically modulated the degree to which participants experienced to be in control over perceptual events which followed their actions as potential effects even though in fact participants had only a limited degree of control over the post action effect stimuli. In the control judgment task participants experienced a higher degree of control over the post-action effect stimulus after blocks with congruent primeeffect pairs than after blocks with incongruent or neutral prime-effect pairs. This modulation of experienced control occurred even though participants were unaware of the primed effect-anticipations as confirmed by a forced-choice primeidentification task in which participants' performance did not differ significantly from chance level. That the primes nevertheless activated a representation of their particular shape was confirmed by the results of a forced-choice masked priming task in which participants made faster and more accurate responses on trials with congruent compared to trials with neutral or incongruent prime-target pairs.

Experiment 2 substantiated and extended the findings of Experiment 1. Masked priming of alleged effect-stimuli systematically modulated the degree of 
experienced control even when actions in the control judgment task were freely chosen by participants and when there was absolutely no systematic correlation between these actions and the post-action "effect"-stimuli. Moreover, Experiment 2 further extended the findings obtained in Experiment 1 by using masked semantic effect-primes (color words). This revealed that unconscious effect-anticipations affect conscious control experience up to a conceptual - rather than a merely physical - level of representation (Dehaene et al., 1998, 2001; Fairhall, Hamm, \& Kirk, 2006; Kiefer \& Spitzer, 2000).

Experiments 3 and 4 revealed that the impact of unconscious "effect"-primes on experienced control found in Experiments 1 and 2 can be reversed when the masked effect-primes generate a reversed priming effect as it was first discovered in forcedchoice response priming studies by Eimer and Schlaghecken (1998). "Reversed priming" in this context denotes the phenomenon that under certain conditions response costs - rather than benefits - arise on trials with congruent compared to trials with neutral or incongruent prime-target pairs (see also Eimer \& Schlaghecken, 2001, 2003; Schlaghecken \& Eimer, 2004, 2002; Klapp \& Hinkley, 2002; Klapp \& Haas, 2005; Llerras \& Enns, 2004). To establish a reversed priming effect Experiment 3 commenced with a pilot study which consisted of a forced choice priming task. After the pilot experiment had yielded a reversed priming effect the main experiment including the free-choice control judgment task was conducted. As predicted the pattern of participants' control-judgments now reversed accordingly, i.e., participants experienced less control after blocks including congruent compared to blocks including neutral or incongruent prime-"effect" pairs. This reversed modulation of conscious control occurred again albeit the primes remained completely unconscious. This result was discussed in the context of the perceptual updating hypothesis (e.g., Llerras \& Enns, 2004; Enns \& Di Lollo, 2004).

With respect to the perceptual updating hypothesis, it is critical that in the present case the mask consisted of a superimposition of the shapes of both primes (diamond 
and square) and was presented sufficiently long to enable the visual system to extract that part of the visual information included in the mask that differed from the information included in the preceding prime. Importantly, this information included precisely the visual features of the opposite (i.e. incongruent) effectstimulus. Thus, it was supposed that under these circumstances the effectanticipation elicited by the prime was updated or replaced by the new visual information added by the mask, which was in the current case the shape of the opposite, i.e., prime-incongruent "effect". Because this updating process supposedly also "reversed" the effect-anticipations, the comparison between anticipated and observed action "effect" detected a match on incongruent prime-effect pairs and a mismatch on congruent prime-effect pairs. Consequently, experienced control was lower on congruent compared to incongruent trials, i.e., the pattern of control judgments reversed.

Experiment 4 conceptually replicated the reversed pattern of experienced control obtained in Experiment 3 using judgments of "prediction accuracy" as an alternative measure of experienced control. ${ }^{6}$ Using the stimulus material and priming conditions that had produced a reversed priming effect in Experiment 3, participants judged their predictions to be more accurate after incongruent compared to neutral or congruent prime-"effect" blocks. Again this reversed modulation of conscious control occurred even though participants were unable to consciously recognize the masked effect-primes in the forced choice prime identification task.

In summary, the results obtained in this thesis provide strong evidence that an illusion of conscious control over objectively uncontrollable events which follow

\footnotetext{
6 Previous research on experienced control, particularly on "illusory control" (e.g., Langer, 1975; Langer \& Rodin, 1976) has shown that judgments of how well one can predict the outcome of an event (e.g. the outcome of one's performance in a gambling task) correlates highly with the degree of experienced control (cf. Presson \& Benassi, 1996). At the same time judgment of prediction accuracy is a less obvious way to measure experienced control than to ask directly for a judgment of experienced control. This ensures participants' naivety to the experimental purpose. Therefore judgments of "prediction accuracy" established as a popular way to operationalize experienced control.
} 
one's actions can be induced by priming a representation of these events prior to the actions. Moreover, the results show convincingly that such a modulation of conscious control occurs even when the primed "effect" representations remain completely unconscious.

\section{2 The present data in relation to earlier work}

On a fundamental level the findings obtained in the present thesis are in line with the well established idea that the ability to anticipate the future effects of one's actions plays a central role not only in the control of action but also in the generation of the experience of control (Haggard, 2005; Wegner, 2002, 2003, 2004; see also James, 1890; Lotze, 1852; Michotte, 1954/1963;). In this respect the current results are also consistent with earlier work that has documented that unconscious effectanticipations, which are activated by subliminal effect-primes, influence the selection and initiation of voluntary actions (e.g., Eimer \& Schlaghecken, 1998; Schlaghecken \& Eimer, 2004; Wendt-Kuerschner, 2006; Klapp \& Hinkley, 2002; Neumann \& Klotz, 1994). Importantly, the present data extend these insights by revealing that unconscious effect-anticipations also influence the experience of voluntary control.

In a narrower context, the current results indicate that the experience of control over sensory events emerges from a comparison process that continuously matches actual and anticipated effects of one's actions. If anticipated and actual action-effects coincide, there is an increased tendency to experience the effects as self-caused, whereas a discrepancy between anticipated and actual effect increases the tendency to attribute the effects to an external cause (Sato \& Yasuda, 2005; Blakemore, Wolpert, \& Frith, 1998, 2000, 2002). That the modulation of conscious control 
occurred independently from whether the effect-primes were available to awareness supports the idea that this process does not depend on consciousness, but supports the idea that the process by which anticipated and actual action effects are compared does not depend on consciousness, but often occurs unconsciously (Linser \& Goschke, 2006).

\section{2. 1 The present data and Wegner's theory of apparent mental causation - The role of unconscious processes in the generation of experienced control}

The present findings are consistent with the idea that events which are close in space and time are more likely to be perceived as causally linked than spatiotemporally distant events (Hume, 1748; Michotte, 1963; Haggard, Clark, \& Kalogeras, 2002) and are in this respect consistent with Wegner's theory of apparent mental causation (Wegner, 2002, 2003, 2004). According to the key proposal of his theory the experience of conscious will rests on a perceived link between anticipatory thoughts about an action and the subsequent action itself: voluntary control experience occurs when an action effect has been anticipated consistently and immediately prior to the action and the anticipatory thought about the action appears to be the exclusive plausible cause of the action (Wegner, 2002, 2003, 2004). The present data go beyond the assumption of this concept demonstrating that the conscious experience of control is influenced even by unconscious information about action effects. Evidently in this case, the control experience can not rely on a consciously perceived link between anticipated and actual effects.

Initial evidence that unconscious information related to an actor modulates experienced control was obtained by Dijksterhuis, Wegner, and Aarts (2001). They could show that perceived agency can be modulated unconsciously by subliminal 
prime words which directed the attention to the "self" of the actor. Participants' task in this study was to categorize letter-strings as words or non-words as rapidly as possible in an alleged competition with the computer. The screen displaying the letters either went blank when the participant pushed the correct response key or it was turned blank automatically shortly after the presentation of the letters. Thus for the participants it was uncertain whether they or the computer had turned off the display. Prior to each letter string the masked word "I", "me" or some neutral word was displayed. Although participants denied to have seen the primes, they influenced their judgments of authorship: They judged to have beaten the computer more often when a self-relevant pronoun had been primed compared to when a neutral word had been shown. It was concluded that being confronted with selfrelated information systematically increases perceived control even when this information remained unconscious.

In another recent study Aarts, Custers and Wegner (2005) furthermore observed that the feeling of control over in fact externally caused response-effects is enhanced through subliminally delivered information about the location of action effects. In this task participants moved a target shifting along a rectangular path consisting of several separate fields on the computer display. Concurrently a second target which was controlled by the computer moved along the same track, but in opposite direction. In response to a tone-signal participants had to stop the movement by pressing a stop-key. When stopped the two targets were replaced by just one "stoptarget" located on one of the fields. Participants had to decide whether the location of that "stop-target" indicated the stopping position of either their or the computer's target. The critical manipulation was that immediately prior to each stop the location of the final "stop-target" either was or was not subliminally primed by a brief flash at the respective stop-target location. As hypothesized these effectpreviews systematically biased participant's responses. The degree to which participants experienced to have caused the stops by themselves was higher after 
primed compared to non-primed stop-locations although on about $45 \%$ of the trials the location-primes were not consciously perceived.

The present results extend these previous findings in at least three important respects. Firstly, they provide clear evidence for a modulating impact of effectprimes on experienced control even if the primes remained unconscious according to a much stricter forced-choice recognition criterion - rather than a retrospective self-report criterion as used in the experiments of Wegner and his colleagues. Secondly, the present results show that an illusion of control can be induced by priming a representation of an alleged action-effect before a freely chosen action rather than an externally triggered fixed response. Thirdly, the current data reveal that the influence of unconscious effect-representations on experienced control are not restricted to the priming of the location of an action effect as shown by Wegner and colleagues, but rather holds also for primes which activate a representation of the shape or meaning of effect-stimuli. This shows that unconscious effect anticipations elicited by masked effect-primes are processed up to a conceptual level (cf. Linser \& Goschke, 2006).

The above discussed findings all refer to cases in which the experience of control could not rely on a consciously perceived link between anticipated and actual action effects, because the critical effect-representation remained unconscious. They go thus beyond the explanatory scope of the theory of apparent mental causation (Wegner, 2002) and thus raise the question of which mechanisms mediated the influence of unconscious effect-primes on conscious control? In the next section, possible answers to this question will be discussed in relation to the internal forward model theory (e.g., Frith, 2005; Haggard, 2005). 


\section{2. 2 Which mechanisms mediate the influence of unconscious effect-primes on conscious control? The present data in relation to the internal forward model theory}

On a theoretical level the present findings raise the question of how the match between anticipated and alleged actual effects could have influenced experienced control although the anticipatory representation of the effect remained unconscious (cf. Linser \& Goschke, 2006). One possible mechanism that may underlie the unconscious modulation of conscious control is suggested by recent evidence indicating that the representation of a correctly predicted sensory effect of an action is attenuated and experienced as less intense (Frith, 2005; Frith, Blakemore, \& Wolpert, 2000; Blakemore, 2003; Blakemore, Wolpert, \& Frith, 2000). For instance, self-produced tactile stimulations are experienced as less intense compared to when the same stimulation is externally produced (Weiskrantz, Elliott, \& Darlington, 1971; Shergill, Bays, Frith, \& Wolpert, 2003). Moreover, the perceived intensity of selfproduced tactile stimulations increases if a temporal delay is inserted between participants' actions and the tactile effects produced by these actions, presumably because the timing of the effects is less precisely predicted (Blakemore, Frith, \& Wolpert, 1999). Furthermore, functional neuroimaging studies have revealed that self- compared to externally administered touches produce less activation in somatosensory and parietal cortex (Blakemore, Wolpert, \& Frith, 1998; Weiller, Juptner, Fellows, Rijntjes, Leonhardt, Kiebel, Muller, Diener, \& Thilmann, 1996). Importantly, sensory attenuation is not restricted to tactile experiences, but appears to hold more generally for perceptual experiences following a movement (see Frith, 2005, for a review).

Sensory attenuation of self-generated sensory stimulation may reflect the fact that correct predictions of the sensory effects of voluntary movements are generated on the basis of the motor system's execution commands. This is consistent with current 
theories of intentional action control (e.g., Blakemore, Wolpert, \& Frith, 2002; Haggard, 2005) which are based on the assumption that during goal-directed action an "inverse model" maps a goal representation to motor commands that are suited to produce a desired effect and which are then sent to the effectors (cf. Linser \& Goschke, 2006). Simultaneously, an efference copy of the motor command is passed on to an "internal predictive model" which computes predictions of the sensory effects of the movement even before feedback from the actual execution of the movement is received, thereby allowing for rapid adjustments of the movement. If the predicted consequences and the actual sensory feedback coincide the representation of the sensory effect is attenuated and the effect is experienced as self-generated (Blakemore, Wolpert, \& Frith, 1998, 2000; Sato \& Yasuda, 2005). In contrast, if a sensory effect is externally generated the forward model generates a less precise prediction which leads to a reduced or no attenuation of the sensory effect-representation and thus an increased tendency to ascribe the effect to an external cause. Consistent with this assumption it has been observed that the attenuation of self-caused sensory experiences was absent in schizophrenic patients experiencing delusions of alien control (Blakemore, Smith, Steel, Johnstone, \& Frith, 2000). Moreover, schizophrenic patients reporting delusions of control also showed abnormally high activity in parietal cortex during self-produced voluntary movements (Spence, Brooks, Hirsch, Liddle, Meehan, \& Grasby, 1997) which might reflect reduced attenuation of sensory feedback. This may explain why for these patients voluntary movements sometimes feel like passive movements which are controlled by alien forces (cf. Frith, 2005).

Applied to the experiments of the present work these considerations suggest that subliminal effect-primes presumably produced an analogous attenuation of the sensory representation of the effect-stimuli that followed participants' actions (cf. Linser \& Goschke, 2006). In experiments 1 and 2 this prime-induced sensory attenuation of the effect-stimuli may have increased participants' tendency to experience the stimuli as effects of their own actions even if the primes remained 
below the threshold of conscious awareness on congruent trials respectively on incongruent trials in experiments 3 and 4. Conversely, when an incorrect action effect was primed, as it was the case on incongruent trials in experiments 1 and 2 and on congruent trials in experiments 3 and 4, there should have been no sensory attenuation and thus a more pronounced sensory representation of the actual effectstimuli. That subliminal primes can indeed cause a sensory attenuation of subsequent stimuli is supported by neuroimaging findings showing that stimuli preceded by congruent masked primes were associated with a reduced level of activation compared to incongruently primed stimuli (Dehaene, Naccache, Cohen, Le Bihan, Mangin, Poline, \& Riviére, 2001). In conclusion, sensory attenuation appears to be a plausible explanation for the prime-induced modulation of the experience of control observed in the experiments of the present work. However, it is clearly up to further investigation to obtain more direct evidence for this interpretation. One idea would be to try to identify a physiological correlate for sensory attenuation. This could for example be attempted by concomitantly measuring the event related potentials in the EEG in a task like the present control judgment paradigm. Following the sensory attenuation hypothesis one should expect reduced event related potential components after effect-primes which activate a correct representation of a subsequent effect. Another idea would be to directly manipulate the degree of sensory intensity (e.g. the color density of a colored visual effect stimulus, like for instance the color circles used in Experiment 2) and see whether the degree of sensory intensity correlates with the degree of experienced control. Following the sensory attenuation hypothesis one should expect a reversed correlation between these variables. That is, the lower the degree of sensory intensity the higher should be the degree of experienced control. Apart from this it will be an important issue for future research to investigate in more detail to what extent experienced control results from unconscious effectrepresentations and under which conditions conscious anticipations of action effects 
contribute to or may even be required for the experience of voluntary control (cf. Linser \& Goschke, 2006).

\section{3 "Voluntary action" investigated in the lab}

Can conclusions derived from experimental settings as controlled and artificial as in the present investigations be generalized to voluntary action in real life (cf. Goschke \& Walter, 2005)? In other words, are key-presses appropriate reflections of what we consider a voluntary action? In discussions concerning not only the present research, but experimental psychological research on voluntary action and experienced control in general, critics - especially from other disciplines - often put forth that actions as simple as the key-presses used in the present tasks are too simple and the visual stimuli used as alleged "effects" too "trivial", especifally as these actions and effects have no meaning with respect to the participants' intentions or goals. As noted by Goschke and Walter (2005) one should not dismiss such qualms too easily - even as a confessing experimental psychologist. By definition, experimental settings are highly controlled and thus necessarily artificial. Therefore they can hardly, if ever, mimic real life situations perfectly. Key-presses are admittedly simple even if they are "freely chosen" as in the present study. They are far less complex than voluntary actions in "real-life" with respect to their consequences and the goals related to them. However, on the other hand, freechoice key-presses can be considered as truly voluntary actions in the sense that they are neither performed automatically nor mapped to external triggers in a fixed way, as was the case in most previous studies of voluntary control (e.g., Aarts, Custers, \& Wegner, 2005). Given that the key-presses in the control judgment tasks of Experiments 2 - 4 were self-chosen by the participants after they had consciously agreed to participate in the experiment, the key-presses, despite their simplicity, 
fulfill the critical requirements to be considered as voluntary actions (Goschke \& Walter, 2005).

Besides, recent experiments in social cognitive psychology show that unconscious goals can systematically affect behavior even in more complex and naturalistic experimental settings. For instance, in a study by Bargh and his colleagues participants performed in a gambling task in which the goal either to perform well or to cooperate was activated without the awareness of participants through an incidental priming manipulation. Participants were at first instructed to solve a "cover-task" in which they were presented with prime words that were either related to the behavioral concept of "cooperation" or "achievement" or with neutral prime words. The purpose of the primes was to activate either a cooperational, a competitive or a neutral behavioural goal for the following gambling task. Importantly participants were not informed about the relevance of the primes for the following task and remained thus unaware of the relationship and the fact that they had undergone a goal priming procedure. However, data analyses revealed that the goal-primes had nevertheless systematically biased participants' gambling behavior. Participants receiving the undercover "achievement"-priming achieved higher in a competitive intellectual task compared to participants who received neutral primes. Respectively participants receiving "cooperation"-primes compared to players who had received neutral primes were superior following a strategy in which they shared their individual gain with a co-player, thereby increasing the final gain for both. As revealed by post-experimental exploration the primes had not systematically modulated participants' experienced intentionality to cooperate or to achieve. This suggests that participants were unaware of the activation of the goal and of its operation during the gambling performance (Bargh, Gollwitzer, Lee-Chai, Barndollar, \& Trotschel, 2001). 


\section{4 Is conscious will an illusion?}

The experiments of this dissertation and several related findings in the literature demonstrate that the conscious experience of voluntary control can be at variance with whether in reality the perceptual event was caused by one's action or whether it derives from an external source. Although the experience of voluntary control is often experienced as immediate and we seem to have a privileged introspective access to the causes of our actions, this experience can be misled as can be observed in psychiatric patients, particularly schizophrenics, who sometimes experience "delusions of control" as part of their pathology (e.g. Frith, 1998, 2005), as well as in healthy individuals under hypnosis (e.g. Lynn, Rhue, Weekes, 1990; Kirsch \& Lynn, 1998; Spanos, 1986; Haggard, Daffydd, \& Oakley, 2004) or under experimental treatment (e.g. Wegner \& Wheateley, 1999). In line with these observations, the results obtained in the present work show that the experience of control can be modulated systematically by subliminal effect-primes. Participants experienced an illusion of control over in fact uncontrollable events that followed their action to the degree that the primed effect anticipation activated a consistent anticipation of that post-action event. These findings show that the conscious experience of control does not indicate privileged introspective access to the causal antecedents of our action but relies rather on a fallible causal attribution (cf. Linser \& Goschke, 2006).

Does this conclusion imply that conscious will is an illusion - as has been argued eloquently by Wegner (2002)? As Goschke and Walter (2005) argue "the answer to this question depends crucially on what is understood by the term illusion in this context. Clearly, the present as well as preceding related findings discussed above provide convincing evidence against a naïve "Cartesian" view according to which the experience of agency and voluntary control rests on a privileged and incorrigible introspective access to the causal antecedents of one's actions and their effects. Goschke and Walter (2005) further refer to David Hume (1739) who remarked that 
one can not directly perceive cause-effect relations but rather infer them from the observation of systematic relations between events. The authors point our that likewise, the experience that one's conscious intentions cause one's actions and that one's actions cause certain effects emerges from a fallible causal attribution (Goschke \& Walter, 2005; see also Goschke, 2006; Linser \& Goschke, 2006). In this respect the results of the present work indicate that this attribution does not only involve inferences based on conscious expectations about the likely causes of actions but is also modulated by unconsciously computed predictions of action effects. ${ }^{7}$ The fact that the processes that compute predictions of immediate action effects can operate unconsciously may explain why, from the phenomenological first person perspective, the experience of agency and voluntary control often seems so immediate and intuitively evident. It may elucidate why we become aware of the fact that our cognitive system continuously computes predictions of the sensory consequences of our actions primarily when these predictions fail and we are confronted with an unexpected action effect. Nevertheless, despite its apparent intuitive immediacy, like all causal attributions the processes underlying the feeling of agency are clearly fallible and may under certain circumstances elicit the erroneous impression that one is the originator of an effect which in reality was controlled externally. In line with Goschke (2006; Goschke \& Walter, 2005; Goschke \& Linser, 2006) it can be concluded that in this sense one may indeed regard experienced agency and voluntary control as an "illusion". As Wegner (2002, p. 2) notes: "conscious will is an illusion... in the sense that the experience of consciously willing an action is not a direct indication that the conscious thought has caused the action".

As Goschke and Walter (2005) further conclude, this does not entail that the conscious experience of voluntary control is an illusion in the sense that it constantly deludes us about the causes of our actions and their effects. Leastwise this follows to no greater or lesser extent than it follows from the occurrence of perceptual illusions

\footnotetext{
${ }^{7}$ The following conclusions are partly derived from a similar argument made by Goschke \& Walter (2005; see also Goschke, 2006; Linser \& Goschke, 2006; Walter \& Goschke, 2006).
} 
that perception always deludes us (Goschke \& Walter, 2005; Goschke, 2006; Linser \& Goschke, 2006). Rather the cognitive processes underlying the experience of voluntary control - and in particular the prediction of action effects and the comparison of predicted and actual sensory effects of one's actions - constitute highly adaptive mechanisms that generally provide us with valid information about whether an event was caused by one's own action or by some external force. It appears unlikely that such a mechanism would have evolved if it constantly deceived organisms about the causes and effects of their actions (Goschke \& Walter, 2005; Goschke, 2006). Rather, by continuously comparing predicted with actual action-effects a mechanism like this enables us to learn to anticipate increasingly better which effects are caused by which actions under which conditions (Hoffmann, 1993) and thereby to infer correctly, whether an event was caused by us or some external force.Thus, under natural (i.e., non-experimental) conditions, the fact that we tend to experience ourselves as originators of events following our actions, if the events were correctly anticipated before the action, represents an adaptive mechanism that in most cases generates valid inferences as to whether an event is generated by one's own action (Goschke \& Walter, 2005; Frith et al., 2000; Jeannerod \& Pacherie, 2004).

In conclusion, the findings of the present work are in line with evidence against a Cartesian view according to which the experience of voluntary control rests on a privileged and incorrigible introspective access to the causes of our actions and their effects. Rather, the experience of control appears to emerge from an - in principle fallible - causal attribution which is based on largely unconscious brain processes. It is up to future research to investigate under which conditions effect-anticipations must be conscious in order to contribute to the experience of control, and when experienced control is modulated unconsciously. 


\section{Chapter 5}

\section{References}

Aarts, H., Custers, R., \& Wegner, D.M. (2005). On the inference of personal authorship: Enhancing experienced agency by priming effect information. Consciousness $\mathcal{E}$ Cognition, 14, 439-458.

Ach, N. (1905). Über die Willenstätigkeit und das Denken. Göttingen: Vandenhoeck \& Ruprecht.

Alloy, L.B., \& Abramson, L.Y. (1979). Judgment of contingency in depressed and nondepressed students: Sadder but wiser? Journal of Experimental Psychology: General, 108/4, 441-485.

Aron, A., Schlaghecken, F., Fletcher, P., Bullmore, E., Eimer, M., Barker, R., Sahakian, B.J., \& Robbins, T.W. (2003). Inhibition of subliminally primed responses is mediated by the caudate and thalamus: Evidence from fMRI and Huntington's disease. Brain, 126, 713-723.

Bachmann, T., \& Allik, J. (1976). Integration and interruption in masking of form by form. Perception, 5, 79-97.

Bar, M., \& Biederman, I. (1998). Subliminal visual priming. Psychological Science, 9, 464-469.

Bargh, J., Gollwitzer, P., Lee-Chai, A., Barndollar, K., \& Trotschel, R. (2001). The automated will: Nonconscious activation and the pursuit of behavioral goals. Journal of Personality and Social Psychology, 81, 1014-1027.

Beckermann, A. (2004). Schließt biologische Determiertheit Freiheit aus? In F. Hermanni \& P. Koslowski, Der freie und der unfreie Wille - Philosophische und theologische Perspektiven. Paderborn. 
Benassi, V.A., Sweeney, P.D., \& Drevno, G.E. (1979). Mind over matter: Perceived success at psychokinesis. Journal of Personality and Social Psychology, 37, 13771386.

Bieri, P. (2001). Das Handwerk der Freiheit - Über die Freiheit und die Unfreiheit des Willens. München: Carl Hanser.

Blakemore, S.-J. (2003). Deluding the motor system. Consciousness $\mathcal{E}$ Cognition, 12/4, 647-655.

Blakemore, S.-J., Frith, C.D., \& Wolpert, D.M. (1999). Spatio-temporal prediction modulates the perception of self-produced stimuli. Journal of Cognitive Neuroscience, 11/5, 551-9.

Blakemore S.-J., Smith, J., Steel, R., Johnstone, C.E., Frith, C.D. (2000). The perception of self-produced sensory stimuli in patients with auditory hallucinations and passivity experiences: evidence for a breakdown in selfmonitoring. Psychological Medicine, 30, 1131-1139.

Blakemore, S.-J., Wolpert, D.M., \& Frith, C.D. (1998). Central cancellation of selfproduced tickle sensation. Nature Neuroscience, 1, 635-640.

Blakemore, S.-J., Wolpert, D.M., \& Frith, C.D. (2000). Why can't you tickle yourself? NeuroReport, 11/11, R11-R16.

Blakemore, S.-J., Wolpert, D.M., \& Frith, C.D. (2002). Abnormalities in the awareness of action. Trends in Cognitive Science, 6/6, 237-242.

Bonnie, R.J., Coughlin, A.M., Jeffries, J.C., \& Low, P.W. (1997). Criminal law. Westbury, NY: Foundation Press.

Breitmeyer, B.G. (1984). Visual Masking: An integrative approach. Oxford, England: University Press.

Carlson, N.R. (2004). Physiologische Psychologie. München: Pearson.

Carpenter, W.B. (1888). Principles of mental physiology, with their applications to the training and discipline of the mind and the study of its morbid conditions. New York: Appleton.

Cheesman, J., \& Merikle, P.M. (1984). Perception with and without awareness. Perception \& Psychophysics, 36/4, 387-95.

Cheesman, J., \& Merikle, P.M. (1986). Distinguishing conscious from unconscious perceptual processes, Canadian Journal of Psychology, 40, 343-367.

Coles, M.G.H. (1989). Modern mind-brain reading: psychophysiology, physiology and cognition. Psychophysiology, 26/3, 251-269. 
Daprati, E., Franck, N., Georgieff, N., Proust, J., Pacherie, E., Dalery, J., \& Jeannerod, M., (1997). Looking for the agent: an investigation into consciousness of action and self-consciousness in schizophrenic patients. Cognition, 65/1, 71-86.

Dehaene, S., Naccache, L., LeClec'H, G., Koechlin, E., Mueller, M., DehaeneLambertz, G., van de Moortele, P.F., \& LeBihan, D. (1998). Imaging unconscious priming. Nature, 395, 597-600.

Dehaene, S., \& Nacchache, L. (2001). Towards a cognitive neuroscience of consciousness: basic evidence and a workspace framework. Cognition, 79, 1-37.

Dehaene, S., Naccache, L., Cohen, L., LeBihan, D.L., Mangin, J.F., Poline, J.B., \& Riviere, D. (2001). Cerebral mechanisms of word masking and unconscious repetition priming. Nature Neuroscience, 4/7, 752-758.

Dennett, D.C. (1984). Elbow room: The varieties of free will worth wanting. Cambridge, Mass.: MIT Press.

Dennett, D.C. (2003). Freedom evolves. New York: Viking Press.

Dennett, D.C., \& Kinsbourne, M. (1992). Time and the observer: The where and when of consciousness in the brain. Behavioral and Brain Sciences, 15, 183-247.

Descartes, R. (1664). Traité de l'home. Paris : Girard.

Dijksterhuis, A., Aarts, H., \& Smith, P. K. (2005). The power of the subliminal: On subliminal persuasions and other potential applications. In R. Hassin, J.S. Uhlemann, \& J.A. Bargh (eds.), The new unconscious, 77-106. New York: Oxford University Press.

Dijksterhuis, A., Wegner, D.M., \& Aarts, H., (2001). Unconscious priming of conscious will, unpublished manuscript, (cited in Wegner, 2002).

Di Lollo, V., Bischof, W.F., \& Dixon, P. (1993). Stimulus-onset asynchrony is not necessary for motion perception of metacontrast masking. Psychological Science, 4, 260-263.

Dörner, D. (1999). Bauplan für eine Seele. Reinbek: Rowohlt.

Eimer, M. (1998). The lateralized readiness-potential as an online measure of central response activation processes. Behavioural Research Methods, Instruments, and Computers, 30, 146-156.

Eimer, M. (1999). Facilitatory and inhibitory effects of masked prime stimuli on motor activation and behavioural performance. Acta Psychologica, 101, 293-313.

Eimer, M., \& Schlaghecken, F. (1998). Effects of masked stimuli: Behavioural and electrophysiological evidence. Journal of Experimental Psychology: Human Perception and Performance, 24/6, 1737-1747. 
Eimer, M., \& Schlaghecken, F. (2001). Response facilitation and inhibition in manual, vocal, and oculomotor performance: evidence for a modality-unspecific mechanism. Journal of Motor Behavior, 33/1, 16-26.

Eimer, M., \& Schlaghecken, F. (2002). Links between conscious awareness and response inhibition: Evidence from masked priming. Psychonomic Bulletin $\mathcal{E}$ Review, 9/3, 514-520.

Eimer, M., \& Schlaghecken, F. (2003). Response facilitation and inhibition in subliminal priming. Biological Psychology, 64/1-2, 7-26.

Einhorn, H. J., \& Hogarth, R. M. (1986). Judging probable cause. Psychological Bulletin, 99/1, 3-19.

Elsner, B., \& Hommel, B. (2001). Effect anticipation and action control. Journal of Experimental Psychology: Human Perception and Performance, 27/1, 229-240.

Elsner, B., \& Hommel, B. (2004). Contiguity and contingency in action-effect learning. Psychological Research, 69/2-3, 138-154.

Enns, J.T., \& Di Lollo, V. (1997). Object substitution: A new form of masking in unattended visual locations. Psychological Science, 8, 135-139.

Enns, J.T., \& Di Lollo, V. (2004). What's new in visual masking? Trends in Cognitive Science, 4, 345-352.

Eriksen, C.W. (1960). Discrimination and learning without awareness: A methodological survey and evaluation. Psychological Review, 67, 279-300.

Fairhall, S.L., Hamm, J.P., \& Kirk, I.J. (2007). Temporal dynamics of masked word reading. Consciousness \& Cognition, 16/1, 112-123.

Fehrer, E., \& Raab, E. (1962). Reaction time to stimuli masked by metacontrast. Journal of Experimental Psychology, 63, 143-147.

Fiser, J., \& Biederman, I. (2001). Invariance of long-term visual priming to scale, reflection, translation, and hemisphere. Vision Research, 41, 221-234.

Forster, K.I, Davis, C., Schoknecht, C., \& Carter, R. (1987). Masked priming with graphemically related forms: Repetition or partial activation? The Quarterly Journal of Experimental Psychology, 39A, 211-251.

Frith, C.D. (1987). The positive and negative symptoms of schizophrenia reflect impairments in the perception and initiation of action. Psychological Medicine, 3, 631-48.

Frith, C.D. (1992). The cognitive neuropsychology of schizophrenia. United Kingdom: Psychology Press.

Frith, C.D. (2005). The neural basis of hallucinations and delusions. C.R. Biologies, $328,169-175$. 
Frith, C.D., Blakemore, S.-J., \& Wolpert, D.M. (2000). Explaining the symptoms of schizophrenia: Abnormalities in the awareness of action. Brain Research Review, 31, 357-363.

Frith, C.D., Blakemore, S.-J., \& Wolpert, D.M. (2000). Abnormalities in the awareness and control of action. Philosophical Transactions of the Royal Society London, B. Biological Sciences, 355, 1771-1788.

Gergely, G., \& Watson, J.S. (1999). Early socio-emotional development: Contingency perception and the social-biofeedback model. In P. Rochat (ed.), Early social cognition: Understanding others in the first months of life, 101-136. Mahwah, NJ: Lawrence Erlbaum Associates, Inc.

Gollwitzer, P.M. (1990). Action phases and mind-sets. In E. T. Higgins, \& R. M. Sorrentino (eds.), Handbook of motivation and cognition: Foundations of social behavior, Vol. II, 53-92. New York, London: Guilford Press.

Gomes, G. (1998). The timing of conscious experience: A critical review and reinterpretation of Libet's research. Consciousness $\mathcal{E}$ Cognition, 7/4, 559-595.

Gomes, G. (2002). The interpretation of Libet's results on the timing of conscious events: A commentary. Consciousness $\mathcal{E}$ Cognition, 11/2, 221-230.

Goschke, T. (1996). Wille und Kognition. Zur funktionalen Architektur der intentionalen Handlungssteuerung. In J. Kuhl, \& H. Heckhausen (eds.), Enzyklopädie der Psychologie, Serie IV, Vol. 4: Motivation, Volition und Handeln, 583-663. Göttingen: Hogrefe.

Goschke, T. (2000). Involuntary persistence and intentional reconfiguration in taskset switching. In S. Monsell, \& J. Driver (eds.), Attention and Performance XVIII: Control of Cognitive Processes, 331-356. Cambrigde, MA: MIT Press.

Goschke, T. (2002). Volition und kognitive Kontrolle. In J. Müsseler, \& W. Prinz (eds.), Allgemeine Psychologie, 271-335. Heidelberg: Spektrum Akademischer Verlag.

Goschke, T. (2003). Voluntary action and cognitive control from a cognitive neuroscience perspective. In W. Prinz, S. Maasen, \& G. Roth (eds.), Voluntary action: an issue at the Interface of nature and culture, 49-85. Oxford, England: University Press.

Goschke, T. (2004). Vom freien Willen zur Selbstdetermination. Kognitive und volitionale Mechanismen der intentionalen Handlungssteuerung. Psychologische Rundschau, 55/4, 186-197.

Goschke, T. (2006). Der bedingte Wille: Willensfreiheit aus der Sicht der kognitiven Neurowissenschaft. In: G. Roth \& K.-J. Grün (eds.), Das Gehirn und seine 
Freiheit. Beiträge zur neurowissenschaftlichen Grundlegung der Philosophie. Göttingen: Vandenhoeck \& Ruprecht.

Goschke, T., \& Walter, H. (2005). Bewusstsein und Willensfreiheit: Philosophische und empirische Annäherungen. In C. Herrmann, M. Pauen, J. Rieger, \& S. Schicktanz (eds.), Bewusstsein, Philosophie, Neurowissenschaften, Ethik (S. 81119). München: Wilhelm Fink/UTB.

Hacker, W. (1998). Allgemeine Arbeitspsychologie. Psychische Struktur und Regulation von Arbeitstätigkeiten. Bern/Stuttgart/Toronto: Huber.

Haggard, P. (2005). Conscious intention and motor cognition. Trends in Cognitive Science, 9, 290-295.

Haggard, P. Cartledge, P., Dafydd, M., \& Oakley, D.A. (2004). Anomalous control: when 'free-will' is not conscious, Consciousness \& Cognition, 13, 646-54.

Haggard, P., \& Clark, S. (2003). Intentional action: Conscious experience and neural prediction. Consciousness \& Cognition 12, 695-707.

Haggard, P., Clark, S., \& Kalogeras, J. (2002). Voluntary action and conscious awareness. Nature Neuroscience, 5/4, 382-385.

Haggard, P. \& Eimer, M. (1999). On the relation between brain potentials and the awarness of voluntary movements, Experimental Brain Research, 126, 128-133.

Haggard, P., \& Magno, E. (1999). Localising awareness of action with transcranial magnetic stimulation. Experimental Brain Research, 127, 102-107.

Haggard, P., Newman, C., \& Magno, E. (1999). On the perceived time of voluntary actions. British Journal of Psychology, 90, 291-303.

Haidt, J., \& Rodin, J. (1999). Control and efficacy as interdisciplinary bridges. Review of General Psychology, 3, 317-337.

Harleß, E. (1861). Der Apparat des Willens. Zeitschrift für Philosophie und philosophische Kritik, 38, 50-73.

Hart, H.L.A. (1968). Punishment and responsibility: Essays in the philosophy of law. Oxford: Clarendon Press.

Heil, M., Rolke, B., \& Pecchinenda, A. (2004). Automatic semantic activation is no myth. Psychological Science, 15, 852-857.

Hoffmann, J. (1993). Vorhersage und Erkenntnis. Göttingen: Hogrefe.

Hommel, B. (1993). Inverting the Simon effect by intention: Determinants of direction and extent of effects of irrelevant spatial information. Psychological Research, 55, 270-279. 
Hommel, B. (1996). The cognitive representation of action: Automatic integration of perceived action effects. Psychological Research, 59, 176-186.

Hommel, B. (1998). Perceiving one's own action--and what it leads to. In J. S. Jordan (ed.), Systems theory and apriori aspects of perception, 143-179. Amsterdam: North-Holland.

Hommel, B. (2000). The prepared reflex: Automaticity and control in stimulusresponse translation. In S. Monsell, \& J. Driver (eds.). Control of Cognitive Processes: Attention and Performance XVII, 247-273. Cambridge, MA: MIT Press.

Hommel, B. (2002). Handlungsplanung und -ausführung. In J. Müsseler, \& W. Prinz (eds.). Allgemeine Psychologie, 795-863. Heidelberg, Berlin: Spektrum.

Hommel, B. (2003). Planning and representing intentional action. Science World Journal, 3, 593-608.

Hommel, B., Müsseler, J., Aschersleben, G., \& Prinz, W. (2001). The theory of event coding (TEC): A framework for perception and action planning. Behavioral and Brain Sciences, 24, 849-878.

Hume, D. (1739). A treatise of human nature. L. A. Selby-Bigge (ed.). Oxford, England: University Press (1888).

Hume, D. (1748). An inquiry concerning human understanding. New York: The Liberal Arts Press (1955).

Jahanshahi, M., \& Frith, C.D. (1998). Willed action and its impairments. Cognitive Neuropsychology, 15/6-8, 483-533.

James, W. (1890). The principles of psychology, Vols. I \& II. New York: Dover Publications, 1950.

James, W. (1910). Pragmatism and other essays. New York: Washington Square Press, 1963.

Janet, P. (1889). L'automatisme psychologique. Paris: F. Alcan.

Jeannerod, M. (1994). The representing brain - neural correlates of motor intention and imagery. Behavioral and Brain Sciences, 17, 187-202.

Jeannerod, M. \& Pacherie, E. (2004). Agency, simulation and self-identification. Mind and Language, 19, 113-146.

Jordan, J.S. (2003). Emergence of self and other in perception and action: an eventcontrol approach. Consciousness \& Cognition, 12/4, 633-46.

Kant, I. (1788). Kritik der praktischen Vernunft: Grundlegung zur Metaphysik der Sitten. W. Weischedel (ed.). Frankfurt/M.: Suhrkamp, 1995. 
Keller, I. \& Heckhausen, H. (1990). Readiness potentials preceding spontaneous motoracts: Voluntary vs. involuntary control. Electroencephalography and Clinical Neurophysiology, 82/1, 85-86.

Kelley, H.H. (1972). Causal schemata and the attribution process. Morristown, NJ: General Learning Press.

Kiefer, M. \& Spitzer, M. (2000). Time course of conscious and unconscious semantic brain activation. NeuroReport, 11/11, 2401-2407.

Kiesel, A., Wagener, A., Kunde, W., Hoffmann, J., Fallgatter, A., \& Stöcker, C. (2005). Unconscious manipulation of free choice in humans. Consciousness $\mathcal{E}$ Cognition 15/2, 397-408.

Kihlstrom, J.F. (2003). The Fox, the Hedgehog, and Hypnosis. International Journal of Clinical and Experimental Hypnosis 51/22, 2166-189.

Kirsch, I., \& Lynn, S.J. (1998). The altered state of hypnosis: Changes in the theoretical landscape. American Psychologist 50/10, 846-858.

Klapp, S.T., \& Hinkley, L.B. (2002). The negative compatibility effect: Unconscious inhibition influences reaction time and response selection. Journal of Experimental Psychology: General, 131, 255-269.

Klapp, S.T. \& Haas, B.W. (2005). Nonconscious influence of masked stimuli on response selection is limited to concrete stimulus-response associations. Journal of Experimental Psychology: Human Perception and Performance, 31, 193209.

Klotz, W., \& Neumann, O. (1999). Motor activation without conscious discrimination in metacontrast masking. Journal of Experimental Psychology: Human Perception and Performance, 25, 976-992.

Koch, C. (2004). The Quest for Consciousness: A Neurobiological Approach. Roberts \& Co.

Kornblum, S. (1994). The way irrelevant dimensions are processed depends on what they overlap with: The case of Stroop- and Simon-like stimuli. Psychological Research, 56, 130-135.

Kornblum, S., Hasbroucq, T., \& Osman, A. (1990). Dimensional overlap: Cognitive basis for stimulus response compatibility: A model and taxonomy. Psychological Review, 97, 253-270.

Kornhuber, H.H., \& Deecke, L. (1965). Hirnpotentialänderungen bei Willkürbewegungen und passiven Bewegungen des Menschen: Bereitschaftspotential und reafferente Potentiale. Pflugers Archiv für Gesamte Physiologie, 248, 1-17. 
Kunde, W. Hoffmann, J., \& Zellmann, P. (2002). The impact of anticipated action effects on action planning. Acta Psychologica, 109/2, 137-155.

Kunde, W., Kiesel, A., \& Hoffmann, J. (2003). Conscious control over the content of unconscious cognition. Cognition, 88, 223-242.

Kunde, W., Koch, I., \& Hoffmann, J. (2004). Anticipated action effects affect the selection, initiation, and execution of actions. The Quarterly Journal of Experimental Psychology. Section A: Human Experimental Psychology, 57, 87-106.

Langer, E.J. (1975). The illusion of control. Journal of Personality and Social Psychology, 32, 311-328.

Langer, E.J., \& Rodin, J. (1976). The effects of choice and enhanced personal responsibility for the aged: A field experiment in an institutional setting. Journal of Personality and Social Psychology, 34, 191-198

Lau, H.C., Rogers, R.D., Haggard, P., \& Passingham, R.E. (2004). Attention to Intention. Science, 303, 1208-1210.

Lautenbacher, S., \& Gauggel, S. (2004). Einführung. In S. Lautenbacher \& S. Gauggel (eds.), Neuropsychologie psychischer Störungen. Berlin: Springer.

Leuthold, H., \& Kopp, B. (1998). Mechanisms of priming by masked stimuli: Inferences from event-related brain potentials. Psychological Science, 9, 263-269.

Lewin, K. (1926). Vorsatz, Wille und Bedürfnis. Psychologische Forschung, 7, 330-385.

Libet, B. (1985). Unconscious cerebral initiative and the role of conscious will in voluntary action, Behavioral and Brain Sciences, 8, 529-66.

Libet, B. (1993). The neural time factor in conscious and unconscious events, in Ciba Foundation Symposion \#174, Experimental and Theoretical Studies of Consciousness. Chichester: Wiley.

Libet, B. (1996). The neural time factor in conscious and unconscious events. Philosophy, Psychiatry, Psychology, 3, 95-106.

Libet, B. (1999). Do we have free will? Journal of Consciousness Studies, 6/8-9, 47-57.

Libet, B. (2004) Mind time. The temporal factor in consciousness. Harvard University Press. Cambridge, MA.

Libet, B., Gleason, C.A., Wright, E.W., \& Pearl, D.K. (1983). Time of conscious intention to act in relation to onset of cerebral activity (readiness-potential). The unconscious initiation of a freely voluntary act. Brain, 102, 193-224.

Libet, B., Wright, E.W., \& Gleason, C.A. (1983). Preparation - or intention-to-act, in relation to pre-event potentials recorded at the vertex. Electroencephalographie E Clinical Neurophysiology, 56, 367-372. 
Linser, K., \& Goschke, T. (2006). Unconscious modulation of the conscious experience of voluntary control. Cognition, in press.

Lippa, Y. (1996). A referential-coding explanation for compatibility effects of physically orthogonal stimulus and response dimensions. Quarterly Journal of Experimental Psychology, 49A, 950-971.

Lleras, A., \& Enns, J.T. (2004). Negative compatibility or object updating? A cautionary tale of mask-dependent priming. Journal of Experimental Psychology: General, 133, 475-493.

Loftus, G.R., \& Masson, M.J. (1994). Using confidence intervals in within-subject designs. Psychonomic Bulletin \& Review, 4, 476-490.

Lotze, R.H. (1852). Medicinische Psychologie oder die Physiologie der Seele. Leipzig, Germany: Weidmann.

Lynn, S.J., Rhue, J.W., \& Weekes, J.R., (1990). Hypnotic involuntariness: A social cognitive analysis. Psychological Review, 97, 169-184.

Marcel, T. (1980). Conscious and preconscious recognition of polysemous words: locating the selective effects of prior verbal context. In R.S. Nickersen (ed.), Attention and Performance VIII, 435-457. Hillsdale, NJ: Erlbaum.

Marcel, A. (1983). Conscious and unconscious perception: an approach to the relations between phenomenal experience and perceptual processes. Cognitive Psychology, 15, 238-300.

Markowitsch, H.J. (2004). Warum wir keinen freien Willen haben. Der sogenannte freie Wille aus Sicht der Hirnforschung. Psychologische Rundschau, 4, 163-168.

Massaro, D.W. (1990). An information-processing analysis of perception and action. In O. Neumann \& W. Prinz (eds.), Relationships between perception and action: Current approaches, 133-166. Berlin: Springer.

McCloskey, D.I., Colebatch, J.G., Potter, E.K., \& Burke, D. (1983) Judgements about onset of rapid voluntary movements in man. Journal of Neurophysiology, 49, 851-863.

McCormick, P.A. (1997). Orienting attention without awareness. Journal of Experimental Psychology: Human Perception and Performance, 23, 168-180.

Merikle, P.M., Joordens, S., \& Stolz, J. (1995). Measuring the relative magnitude of unconscious influences. Consciousness $\mathcal{E}$ Cognition, 4, 422-439.

Merikle, P.M., \& Reingold, E.M. (1998). On demonstrating unconscious perception. Journal of Experimental Psychology: General, 127, 304-310. 
Merikle, P.M., Smilek, D., \& Eastwood, J.D. (2001). Perception without awareness: Perspectives from cognitive psychology. Cognition, 79, 115-134.

Miall, R.C., Weir, D.J., Wolpert, D.M., \& Stein, J.M. (1993). Is the cerebellum a smithpredictor? Journal of Motor Behavior, 25/3, 203-216.

Miall, R.C., \& Wolpert, D.M. (1996). Forward models for physiological motor control. Neural Networks, 9/8, 1265-1279.

Michotte, A. (1954). The perception of causality. trans. T.R. Miles \& E. Miles. New York. Basic Books, 1963.

Münsterberg, H. (1888). Die Willenshandlung: Ein Beitrag zur physiologischen Psychologie. Freiburg: Mohr.

Müsseler, J. (1995). Wahrnehmung und Handlungssteuerung. Effekte kompatibler und inkompatibler Reize bei der Initiierung und Ausführung von Reaktionssequenzen. Aachen: Shaker.

Naccache, L., \& Dehaene, S. (2001). Unconscious semantic priming extends to novel unseen stimuli. Cognition, 80, 215-229.

Nahmias, E. (2005). Agency, authorship, and illusion. Consciousness $\mathcal{E}$ Cognition, 14, 771-785.

Neumann, O. (1992). Theorien der Aufmerksamkeit: von Metaphern zu Mechanismen. Psychologische Rundschau, 43, 83-101.

Neumann, O., \& Klotz, W. (1994). Motor response to nonreportable, masked stimuli: Where is the limit of direct parameter specification? In M. Moscovitch, \& C. Umiltá (eds.), Attention \& Performance XV: Conscious and unconscious information processing, 123-150. Cambridge, MA: MIT Press.

Neumann, O., \& Prinz, W. (1987). Kognitive Antezedenzien von Willkürhandlungen. In P.M. Gollwitzer, H. Heckhausen, \& F.E. Weinert (eds.), Jenseits des Rubikon: Der Wille in den Humanwissenschaften, 195-215. Berlin: Springer.

Nisbett, R.E., \& Wilson, T.D. (1977). Telling more than we can know: Verbal reports on mental processes. Psychological Review, 84, 231-259.

Pauen, M. (2004), Illusion Freiheit? Frankfurt/Main: Fischer.

Piaget, J. (1952). The origins of intelligence in children. New York: International Universities Press.

Praamstra, P., \& Seiss, E. (2005). The neurophysiology of response competition: Motor cortex activation and inhibition following subliminal response priming. Journal of Cognitive Neuroscience, 17, 483-493. 
Presson, P.K., \& Benassi, V.A. (1996). Illusion of control: A meta- analytic review. Journal of Social Behavior and Personality, 11, 493- 510.

Prinz, W. (1997). Perception and action planning. European Journal of Cognitive Psychology, 9/2, 129-154.

Prinz, W. (1998). Die Reaktion als Willenshandlung. Psychologische Rundschau, 49/1, 10-20.

Prinz, W. (2000). Kognitionspsychologische Handlungsforschung. Zeitschrift für Psychologie, 208, 32-54.

Prinz, W. (2004). Kritik des freien Willens: Bemerkungen über eine soziale Institution. Psychologische Rundschau, 50/4, 198-206.

Reingold, E.M., \& Merikle, P.M. (1990). On the inter-relatedness of theory and measurement in the study of unconscious processes. Mind and Language, 5, 928.

Rubinstein, S.L. (1984). Grundlagen der allgemeinen Psychologie (10. Auflage). Berlin: Volk und Wissen.

Sanders, A.F. (1980). Stage analysis of reaction processes. In G. E. Stelmach, \& J. Requin (eds.), Tutorials in Motor Behavior, 331-354. Amsterdam: NorthHolland.

Sato, A., \& Yasuda, A. (2005). Illusion of sense of self-agency: Discrepancy between the predicted and actual sensory consequences of actions modulates the sense of self-agency, but not the sense of self-ownership. Cognition, 94, 241-255.

Schall, J.D. (2001). Neural basis of deciding, choosing and acting. Nature Reviews Neuroscience 2, 33-42.

Scharlau, I., \& Neumann, O. (2003). Perceptual latency priming by masked and unmasked stimuli: Evidence for an attentional interpretation. Psychological Research, 67/3, 184-196.

Shergill, S.S., Bays, P.M., Frith, C.D., \& Wolpert, D.M. (2003). Two Eyes for an Eye: The Neuroscience of Force Escalation, Science, 301, 187.

Schlaghecken, F., \& Eimer, M. (2000). A central/peripheral asymmetry in subliminal priming. Perception and Psychophysics, 62, 1367-1382.

Schlaghecken, F., \& Eimer, M. (2001). Partial response activation to masked primes is not dependent on response readiness. Perceptual and Motor Skills, 92, 208222.

Schlaghecken, F., \& Eimer, M. (2002). Motor activation with and without inhibition: Evidence for a threshold mechanism in motor control. Perception and Psychophysics, 64, 148-162. 
Schlaghecken, F., \& Eimer, M. (2004). Masked prime stimuli can bias "free" choices between response alternatives. Psychonomic Bulletin and Review, 11/3, 463-468.

Simon, J.R., Hinrichs, J.V., \& Craft, J.L. (1970). Auditory S-R compatibility: Reaction-time as a function of ear-hand correspondence and ear-responselocation correspondence. Journal of Experimental Psychology, 86, 97-102.

Singer, W. (2004). Verschaltungen legen uns fest: Wir sollten aufhören, von Freiheit zu sprechen. In C. Geyer (ed.), Hirnforschung und Willensfreiheit. Zur Deutung der neuesten Experimente. Frankfurt am Main: Suhrkamp.

Sirigu, A., Daprati, E., Ciancia, S., Giraux, P., Nighoghossian, N., Posada, A., \& Haggard, P. (2004). Altered awareness of voluntary action after damage to the parietal cortex. Nature Neuroscience, 7/1, 80-84.

Skinner, E.A, (1985). Action, control judgments, and the structure of control experience. Psychological Review, 92, 39-58.

Skinner, E.A. (1996). A guide to constructs of control. Journal of Personality and Social Psychology, 71, 549-570.

Smid, H.G.O.M., Mulder, G., \& Mulder, L.J.M. (1990). Selective response activation can begin before stimulus recognition is complete: a psychophysiological and error analysis of continuous flow. Acta Psychologica, 74, 169-201.

Snodgrass, M., Shevrin, H., \& Kopka, M. (1993).The mediation of intentional judgments by unconscious perceptions: The influence of task strategy, task preference, word meaning, and motivation. Consciousness $\mathcal{E}$ Cognition, 2, 16993.

Solomons, L.M., \& Stein, G. (1896). Normal motor automatism. Psychological Review, 3, 492-512.

Spanos, N.P. (1986). Hypnotic behavior: A social-psychological interpretation of amnesia, analgesia, and "trance logic". Behavioral and Brain Sciences, 9, 449-502.

Spence, S.A. (2001). Disorders of willed action. In P. W. Halligan, C. Bass, \& J. C. Marshall (eds.), Contemporary approaches to the study of hysteria: clinical and theoretical perspectives, 235-250. Oxford, England: University Press.

Spence, S.A., Brooks, D.J., Hirsch, S.R., Liddle, P.F., Meehan, J., \& Grasby P.M. (1997). A PET study of voluntary movement in schizophrenic patients experiencing passivity phenomena (delusions of alien control). Brain, 120, 1997-2011.

Sternberg, S. (1969). The discovery of processing stages: Extensions of Donders' method. Acta Psychologica, 30, 276-315.

Turvey, M.T. (1973). On peripheral and central processes in vision. Psychological Review, 80, 1-52. 
Van Inwagen, P. (1983). An essay on free will. Oxford: Clarendon Press.

Volpert, W. (1974). Handlungsstrukturanalyse als Beitrag zur Qualifikationsforschung. Köln: Pahl-Rugenstein.

Vorberg, D., Mattler, U., Heinecke, A., Schmidt, T., \& Schwarzbach, J. (2003). Invariant time-course of priming with and without awareness. In C. Kaernbach, E. Schröger, \& H. Müller (eds.), Psychophysics beyond sensation: Laws and invariants of human cognition. Hillsdale, NJ: Erlbaum.

Walter, H. (1998). Neurophilosophie der Willensfreiheit. Paderborn, München: Schöningh.

Walter, H. (2004). Willensfreiheit und Verantwortlichkeit. Psychologische Rundschau, $55 / 4,169-177$.

Walter, H., \& Goschke, T. (2006). Autonomie und Selbstkontrolle: Bausteine für eine naturalistische Konzeption von Willensfreiheit. In D. Stederoth \& K. Köchy (eds.), Willensfreiheit als interdisziplinäres Problem. Freiburg i. Br.: Alber.

Wegner, D.M. (2002). The illusion of conscious will. Cambridge, MA: MIT Press.

Wegner, D.M. (2003). The mind's best trick: How we experience conscious will. Trends in Cognitive Science, 7, 65-69.

Wegner, D.M. (2004). Precis of The Illusion of Conscious Will. Behavioral and Brain Sciences, 27, 649-692.

Wegner, D.M., Sparrow, B., \& Winerman, L. (2004). Vicarious agency: Experiencing control over the movements of others. Journal of Personality and Social Psychology, 86/6, 838-848.

Wegner, D.M., \& Wheatley, T.P. (1999). Why it feels as if we are doing things: Sources of the experience of will, American Psychologist, 54, 480-492.

Weiller, C., Jüptner, M., Fellows, S., Rijntjes, M. Leonhardt, G. Kiebel, S., Muller, S. Diener, H.C., \& Thilmann, A.F. (1996). Brain representation of active and passive movements. Neuroimage, 4, 105-110.

Weiskrantz, L., Elliot, J., \& Darlington, C. (1971). Preliminary observations on tickling oneself. Nature, 230, 598-599.

Weisstein, N., Ozog, G., \& Szog, R. (1975). A comparison and elaboration of two models of metacontrast. Psychological Review, 82, 325-343.

Welford, A.T. (1968). Fundamentals of skill. London: Methuen.

Wendt-Kürschner, J. (2006). Unconscious priming of "freely" chosen voluntary actions: behavioural and electrophysiological evidence. Dissertation Manuscript. 
Wolpert, D.M. (1997). Computational approaches to motor control. Trends in Cognitive Science, 1/6, 209-216.

Wolpert, D.M., Ghahramani, Z., \& Jordan, M.I. (1995). Are arm trajectories planned in kinematic or dynamic coordinates? An adaptation study. Experimental Brain Research, 103/3, 460-470. 


\section{Chapter 6}

\section{Zusammenfassung}

Willentliches Handeln ist ein fundamentales Verhalten unseres täglichen Lebens. Fast ununterbrochen sind wir damit beschäftigt, $\mathrm{zu}$ entscheiden, was wir als nächstes tun werden. Willentliches Handeln meint hier zielgerichtetes Handeln, d.h., Handeln, das dazu dient, einen bestimmten Effekt in unserer Umwelt herbeizuführen (vgl. Prinz, 1997). So betätigen wir beispielsweise gezielt einen Lichtschalter, um den Raum zu erhellen. Willentliches Handeln hängt daher entscheidend von der Fähigkeit ab, zukünftige Effekte unserer Handlungen mental zu repräsentieren (Lotze, 1852; James, 1890/1950; Michotte, 1954/1963) und mit den zielführenden Handlungen funktional zu assoziieren (Elsner \& Hommel, 2001; Prinz, 1998, 2000; Goschke, 2003, 2004). Mit willentlichem Handeln einher geht eine spezifische, uns zutiefst vertraute und für unser menschliches Selbstkonzept zentrale bewusste Erfahrung, die Willenserfahrung. Diese vermittelt uns als handelnde Personen die Überzeugung, dass wir es sind, die als Autoren das eigene Handeln und die daraus resultierenden Effekte willentlich kontrollieren. Welche 
Prozesse generieren diese Erfahrung? Mit dieser Frage beschäftigte sich die vorliegende Arbeit.

Einer Vielzahl von Forschungsergebnissen zufolge spielt Effektantizipation nicht nur beim willentlichen Handeln selbst, sondern auch im Rahmen der Generation der Erfahrung willentlicher Kontrolle eine zentrale Rolle (z.B., Michotte, 1954/1963; Wegner, 2002, 2003, 2004; Blakemore, Wolpert, \& Frith, 1998, 2000, 2002). Ausgehend von dieser Idee wurde in der vorliegenden Arbeit die Annahme untersucht, dass ein sensorischer Handlungseffekt insbesondere dann als selbst verursacht und durch eigenes Handeln kontrolliert erlebt wird, wenn der Effekt vor Ausführung der Handlung korrekt antizipiert wird. Besteht hingegen eine wahrgenommene Divergenz zwischen antizipiertem und tatsächlichem Effekt, wird dieser als fremd verursacht erlebt und die Kontrolle einem externen Agenten zugeschrieben. Varianten dieser Idee finden sich in verschiedenen neueren Konzepten zum willentlichen Handeln (z.B., Frith, 2005; vgl. Haggard, 2005, für einen Überblick). So postulieren Blakemore, Wolpert und Frith (2002), dass während der Ausführung einer willentlichen Bewegung ein Vorhersage-Modell (forward model) die sensorischen Konsequenzen von Bewegungen vorausberechnet. Wenn die prognostizierten Konsequenzen mit dem tatsächlichen sensorischen Feedback übereinstimmen, erfolgt auf neuronaler Ebene eine Abschwächung der sensorischen Repräsentation (sensory attenuation), woraufhin der Effekt als selbst-verursacht erlebt wird (Blakemore, Wolpert, \& Frith, 1998, 2000). Experimentelle Befunde anderer Forscher stützen diese Annahme (z.B., Sato and Yasuda, 2005). Auch Wegners Theorie der "scheinbaren mentalen Verursachung" schreibt Vorhersagen von Handlungen und deren Effekten für die Generierung der Willenserfahrung eine Schlüsselrolle zu (Wegner, 2002, 2004). Sein Konzept besagt, dass die Willenserfahrung das Ergebnis einer kausalen Schlussfolgerung ist, in der eine Handlung genau dann als kausale Folge bewusster Intentionen erlebt wird, wenn (1) ein Gedanke (typischerweise eine Intention) unmittelbar vor der Handlung auftritt, wenn (2) der Gedanke inhaltlich konsistent mit der Handlung ist, und wenn 
(3) keine plausiblen alternativen Ursachen für die Handlung ersichtlich sind. Basierend auf Antizipationen unserer Handlungen und deren Effekten reflektiert die Willenserfahrung demnach die Wahrnehmung eines scheinbaren kausalen Pfades zwischen Gedanken und Handlung und ist - wie jede kausale Schlussfolgerung - prinzipiell fehlbar (z.B., Wegner \& Wheatley, 1999; Aarts, Custers \& Wegner, 2005).

Eine der vielen noch weitgehend offenen Fragen betrifft die Frage, ob und inwieweit auch unbewusste Effektantizipationen das Ausmaß erlebter Kontrolle systematisch beeinflussen können (Blakemore, Wolpert \& Frith, 2000; Aarts, Custers \& Wegner, 2005). Zwei Fragen standen daher im Fokus der vorliegenden Arbeit. Erstens wurde untersucht, ob eine Illusion von willentlicher Kontrolle über eine objektiv unkontrollierbare - Handlungsfolge mittels Priming einer Repräsentation dieses Ereignisses vor der Handlung gezielt induziert werden kann. Zweitens wurde untersucht, ob eine solche Modulation bewusster Kontrolle auch dann erfolgt, wenn die mittels Priming aktivierte sensorische Repräsentation auf unbewusster Ebene erfolgt (vgl. Merikle, Smilek \& Eastwood, 2001; Merikle \& Reingold, 1998; Naccache \& Dehaene, 2001; Dehaene \& Naccache, 2001; Eimer \& Schlaghecken, 1998, 2003). Mit dem Ziel der empirischen Untersuchung dieser Fragen, wurde ein Kontroll-Urteil-Paradigma entworfen. Darin hatten Probanden die Aufgabe, jeweils eine von zwei Handlungen auszuführen (linker oder rechter Tastendruck), die von jeweils einem von zwei visuellen Reizen gefolgt war. Mittels Tastendrücken hatten die Probanden entweder ein gewisses limitiertes Maß an Kontrolle (Exp. 1) oder überhaupt keine Kontrolle (Exp. 2-4) darüber, welcher Stimulus nach einem Tastendruck jeweils erschien. Unmittelbar vor jeder Handlung wurde ein maskierter, d.h., nicht wahrnehmbarer Prime-Reiz präsentiert, der entweder kongruent oder inkongruent mit dem Post-Handlungs-„Effekt” reiz war.

Es wurde vorhergesagt, dass subliminales "Primen" der Repräsentation des PostHandlungs-Reizes vor jeder Handlung zu einer systematischen Überschätzung der 
erlebten Kontrolle über die vermeintlichen Handlungs"effekte“ führte. Wenn mittels Priming keine oder eine inkongruente "Effekt"-Repräsentation induziert würde, wurde ein im Mittel geringer eingeschätztes Kontrollmaß erwartet. Die kritische Idee dieser Vorhersage war es, den Mechanismus, der normalerweise die internalen Vorhersagen von Handlungseffekten berechnet, mit einem externalen Prime, der eine Effektrepräsentation unmittelbar vor einer willentlichen Handlung aktiviert, systematisch "auszutricksen". Die Ergebnisse der vier Experimente bestätigten diese Erwartung. Damit stützten sie die Annahme, dass EffektAntizipationen und ein Vergleichsprozess zwischen antizipierten und wahrgenommenen Handlungskonsequenzen eine Schlüsselrolle im willentlichen Handeln und der damit einhergehenden Erfahrung von Kontrolle spielen. So variierte das Ausmaß erlebter Kontrolle systematisch in Abhängigkeit von der Übereinstimmung zwischen antizipierten und tatsächlichen Handlungskonsequenzen. Bei Übereinstimmung von antizipiertem und tatsächlichem Effekt schätzten Personen im Mittel Handlungseffekte als höher selbst kontrolliert ein als im Fall der Divergenz von antizipiertem und tatsächlichem Effekt. Wie die vorliegenden Ergebnisse zeigten, trat diese Variation sogar dann auf, wenn die Probanden tatsächlich keine Kontrolle über die "Effekt"-reize hatten und, wenn die prä-aktionalen Effektrepräsentationen dem Bewusstsein unzugänglich waren.

Zusammenfassend unterstützen die Ergebnisse Ansätze, die Intentionen und Zielvorstellungen eine indirekte, unbewusste und langfristig wirksame Rolle in der Kausalkette willentlichen Handelns zuschreiben. Diese konzipieren Intentionen als „kognitive Randbedingungen“ (constraints), die das kognitive System eines Handelnden so "konfigurieren“, dass eine erhöhte Bereitschaft zur Ausführung willentlicher Handlungen besteht, sobald geeignete Auslösebedingungen vorliegen (vgl., Goschke, 1996, 2002; Jordan, 2003; Hommel, 2000; Neumann \& Prinz, 1987).

Bezogen auf die vieldiskutierte Frage, ob der bewusste Wille eine Illusion ist (z.B. Wegner, 2002, 2005), implizieren diese Ergebnisse dabei nicht, dass die Erfahrung 
willentlicher Kontrolle grundsätzlich eine Illusion ist (vgl. Goschke \& Walter, 2006; Linser \& Goschke, 2006). Die systematische Modulierbarkeit von Mechanismen wie die Vorhersage von Handlungseffekten und Vergleich von vorhergesagten und tatsächlichen Konsequenzen von Handlungen, steht in Einklang mit der Notwendigkeit, hoch adaptiv zu sein. So lernen wir im Laufe unserer Entwicklung durch kontinuierlich das Handeln begleitende Vergleichsprozesse von vorhergesagten und tatsächlichen Handlungseffekten immer besser zu antizipieren, welche Effekte mit welcher Handlung und unter welchen Bedingungen erzeugt werden (Hoffmann, 1993). Und dabei lernen wir korrekt zu folgern, ob ein Effekt durch uns oder durch eine externe Quelle verursacht war.

\section{Literatur:}

Aarts, H., Custers, R., \& Wegner, D.M. (2005). On the inference of personal authorship: Enhancing experienced agency by priming effect information. Consciousness $\mathcal{E}$ Cognition, 14, 439-458.

Blakemore, S.-J., Wolpert, D.M., \& Frith, C.D. (1998). Central cancellation of self-produced tickle sensation. Nature Neuroscience, 1, 635-640.

Blakemore, S.-J., Wolpert, D.M., \& Frith, C.D. (2000). Why can't you tickle yourself? NeuroReport, 11/11, R11-R16.

Blakemore, S.-J., Wolpert, D.M., \& Frith, C.D. (2002). Abnormalities in the awareness of action. Trends in Cognitive Science, 6/6, 237-242.

Dehaene, S., \& Nacchache, L. (2001). Towards a cognitive neuroscience of consciousness: basic evidence and a workspace framework. Cognition, 79, 1-37.

Eimer, M., \& Schlaghecken, F. (1998). Effects of masked stimuli: Behavioural and electrophysiological evidence. Journal of Experimental Psychology: Human Perception and Performance, 24/6, 1737-1747.

Eimer, M., \& Schlaghecken, F. (2003). Response facilitation and inhibition in subliminal priming. Biological Psychology, 64/1-2, 7-26.

Elsner, B., \& Hommel, B. (2001). Effect anticipation and action control. Journal of Experimental Psychology: Human Perception and Performance, 27/1, 229-240.

Frith, C.D. (2005). The neural basis of hallucinations and delusions. C.R. Biologies, 328, 169-175.

Goschke, T. (1996). Wille und Kognition. Zur funktionalen Architektur der intentionalen Handlungssteuerung. In J. Kuhl, \& H. Heckhausen (eds.), Enzyklopädie der Psychologie, Serie IV, Vol. 4: Motivation, Volition und Handeln, 583-663. Göttingen: Hogrefe.

Goschke, T. (2002). Volition und kognitive Kontrolle. In J. Müsseler, \& W. Prinz (eds.), Allgemeine Psychologie, 271-335. Heidelberg: Spektrum Akademischer Verlag. 
Goschke, T. (2003). Voluntary action and cognitive control from a cognitive neuroscience perspective. In W. Prinz, S. Maasen, \& G. Roth (eds.), Voluntary action: an issue at the Interface of nature and culture, 49-85. Oxford, England: University Press.

Goschke, T. (2004). Vom freien Willen zur Selbstdetermination. Kognitive und volitionale Mechanismen der intentionalen Handlungssteuerung. Psychologische Rundschau, 55/4, 186-197.

Goschke, T., \& Walter, H. (2005). Bewusstsein und Willensfreiheit: Philosophische und empirische Annäherungen. In C. Herrmann, M. Pauen, J. Rieger, \& S. Schicktanz (eds.), Bewusstsein Perspektivenwechsel zwischen den Disziplinen. Stuttgart: UTB.

Haggard, P. (2005). Conscious intention and motor cognition. Trends in Cognitive Science, 9, 290-295.

Hoffmann, J. (1993). Vorhersage und Erkenntnis. Göttingen: Hogrefe.

Hommel, B. (2000) The prepared reflex: Automaticity and control in stimulus-response translation. In S. Monsell, \& J. Driver (eds.). Control of Cognitive Processes: Attention and Performance XVII, 247273. Cambridge, MA: MIT Press.

James, W. (1890). The principles of psychology, Vols. I \& II. New York: Dover Publications, 1950.

Jordan, J.S. (2003). Emergence of self and other in perception and action: an event-control approach. Consciousness $\mathcal{E}$ Cognition, 12/4, 633-46.

Linser, K., \& Goschke, T. (2006). Unconscious modulation of the conscious experience of voluntary control. Cognition, in press.

Lotze, R.H. (1852). Medicinische Psychologie oder die Physiologie der Seele. Leipzig, Germany: Weidmann.

Merikle, P.M., \& Reingold, E.M. (1998). On demonstrating unconscious perception. Journal of Experimental Psychology: General, 127, 304-310.

Merikle, P.M., Smilek, D., \& Eastwood, J.D. (2001). Perception without awareness: Perspectives from cognitive psychology. Cognition, 79, 115-134.

Michotte, A. (1954). The perception of causality. trans. T.R. Miles \& E. Miles. New York. Basic Books, 1963.

Naccache, L., \& Dehaene, S. (2001). Unconscious semantic priming extends to novel unseen stimuli. Cognition, 80, 215-229.

Neumann, O., \& Prinz, W. (1987). Kognitive Antezedenzien von Willkürhandlungen. In P.M. Gollwitzer, H. Heckhausen, \& F.E. Weinert (eds.), Jenseits des Rubikon: Der Wille in den Humanwissenschaften, 195-215. Berlin: Springer.

Prinz, W. (1997). Perception and action planning. European Journal of Cognitive Psychology, 9/2, 129-154.

Prinz, W. (1998). Die Reaktion als Willenshandlung. Psychologische Rundschau, 49/1, 10-20.

Prinz, W. (2000). Kognitionspsychologische Handlungsforschung. Zeitschrift für Psychologie, 208, 32-54.

Sato, A., \& Yasuda, A. (2005). Illusion of sense of self-agency: Discrepancy between the predicted and actual sensory consequences of actions modulates the sense of self-agency, but not the sense of self-ownership. Cognition, 94, 241-255.

Wegner, D.M. (2002). The illusion of conscious will. Cambridge, MA: MIT Press.

Wegner, D.M. (2003). The mind's best trick: How we experience conscious will. Trends in Cognitive Science, 7, 65-69.

Wegner, D.M. (2004). Precis of The Illusion of Conscious Will. Behavioral and Brain Sciences, 27, 649-692.

Wegner, D.M., \& Wheatley, T.P. (1999). Why it feels as if we are doing things: Sources of the experience of will, American Psychologist, 54, 480-492. 
Chapter 7

Appendix 


\section{Appendix A}

\section{Appendix A 1: Control judgment-questionnaire in Exp. 1}

1) Bitte schätzen Sie ein, ob und wenn ja inwieweit Sie durch das Drücken von roter oder blauer Taste beeinflussen konnten, ob die nachfolgenden Pfeile nach links oder rechts zeigten!

Kreuzen Sie an, wie hoch der Einfluss Ihrer Tastendrücke war!

Ich glaube, durch meine Tastendrücke hatte ich.....

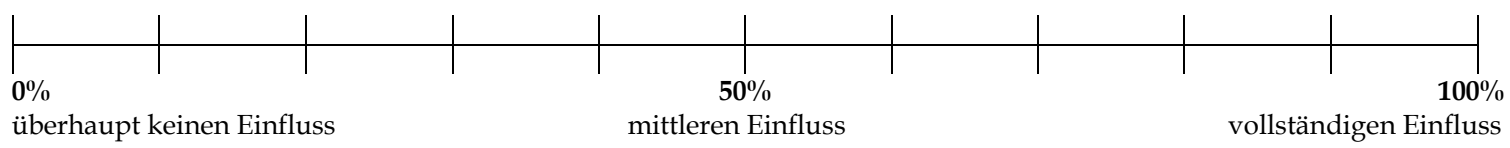

....ob die Pfeile nach links oder rechts zeigten.

2) Hatten Sie den Eindruck, durch eine der beiden Tasten mehr Kontrolle ausüben zu können als durch die andere?

$\square$ nein

$\square$ ja, durch die rote Taste

$\square$ ja, durch die blaue Taste

3) Hatten Sie den Eindruck, dass eine der beiden Pfeilrichtungen besser durch Ihre Tastendrücke beeinflussbar war?

$\square$ nein

$\square$ ja, der Pfeil nach links war in höherem Maße beeinflussbar

$\square$ ja, der Pfeil nach rechts war in höherem Maße beeinflussbar

4) Haben Sie eine Idee, durch welchen Tastendruck welche Pfeilrichtung folgte? Diese Frage brauchen Sie nur zu beantworten, wenn Sie dazu eine "Theorie" haben! 


\section{Appendix A 2: Control judgment-questionnaire in Exp. 2}

1) Bitte schätzen Sie ein, ob und wenn ja inwieweit Sie durch das Drücken von linker und rechter Taste beeinflussen konnten, welcher der beiden Kreise - blau oder gelb - jeweils als nächster auf dem Bildschirm erschien!

Kreuzen Sie an, wie hoch der Einfluss Ihrer Tastendrücke war!

Ich glaube, durch meine Tastendrücke hatte ich.....

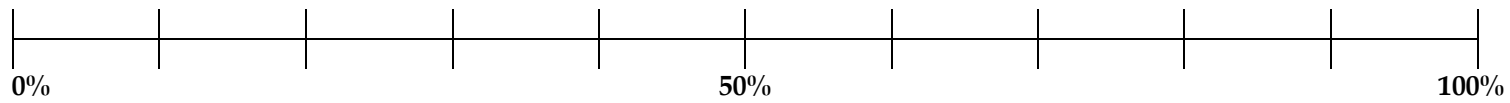

überhaupt keinen Einfluss

mittleren Einfluss

vollständigen Einfluss

....über das Erscheinen von blauem und gelbem Kreis.

2) Hatten Sie den Eindruck, durch eine der beiden Tasten mehr Kontrolle ausüben zu können als durch die andere?

$\square$ nein

$\square$ ja, durch die linke Taste

$\square$ ja, durch die rechte Taste

3) Hatten Sie den Eindruck, dass das Erscheinen von blauem und gelbem Kreis in unterschiedlichem Maße durch Ihre Tastendrücke beeinflussbar war?

$\square$ nein, kein Unterschied in der Beeinflussbarkeit von blauem und gelbem Kreis $\square$ ja, der blaue Kreis war in höherem Maße beeinflussbar

$\square$ ja, der gelbe Kreis war in höherem Maße beeinflussbar

4) Haben Sie eine Idee, durch welchen Tastendruck welcher Kreis erscheint? Diese Frage brauchen Sie nur zu beantworten, wenn Sie dazu eine „Theorie“ haben! 


\section{Appendix A 3: Control judgment-questionnaire in Exp. 3}

1) Bitte schätzen Sie ein, ob und wenn ja inwieweit Sie durch das Drücken von linker und rechter Taste beeinflussen konnten, ob als nächstes Raute oder Quadrat auf dem Bildschirm erschien!

Kreuzen Sie an, wie hoch der Einfluss Ihrer Tastendrücke war!

Ich glaube, durch meine Tastendrücke hatte ich.....

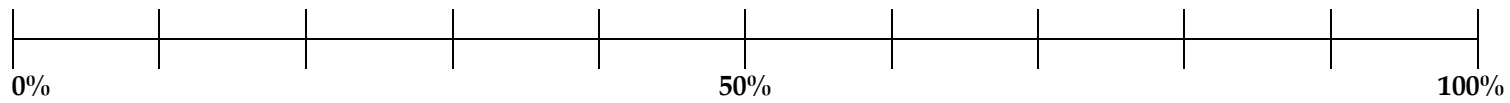

überhaupt keinen Einfluss

mittleren Einfluss

vollständigen Einfluss

....über das Erscheinen von Raute und Quadrat.

2) Hatten Sie den Eindruck, durch eine der beiden Tasten mehr Kontrolle ausüben $\mathrm{zu}$ können als durch die andere?

$\square$ nein

$\square$ ja, durch die linke Taste

$\square$ ja, durch die rechte Taste

3) Hatten Sie den Eindruck, dass das Erscheinen von Raute oder Quadrat in unterschiedlichem Maße durch Ihre Tastendrücke beeinflussbar war?

$\square$ nein, kein Unterschied

$\square$ ja, die Raute war in höherem Maße beeinflussbar

$\square$ ja, das Quadrat war in höherem Maße beeinflussbar

4) Haben Sie eine Idee, durch welchen Tastendruck welches Symbol erscheint? Diese Frage brauchen Sie nur zu beantworten, wenn Sie dazu eine „Theorie“ haben!

Jetzt geht es wieder am PC weiter! 


\section{Appendix A 4: Judgment-questionnaire of "effect"-predictability in Exp. 4}

1) Bitte schätzen Sie ein, wie hoch die Trefferquote Ihrer Vorhersagen für Raute und Quadrat war!

Meine Vorhersagen für Raute und Quadrat waren zutreffend in.....

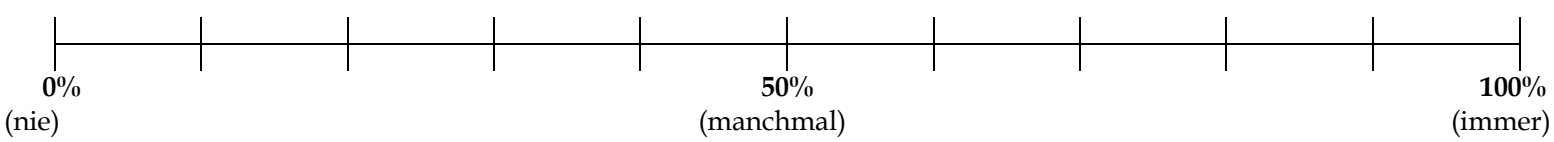

.......aller Fälle.

2) Glauben Sie, für eines der beiden Objekte bessere Vorhersagen getroffen zu haben?

$\square$ nein

$\square$ ja, für die Raute

$\square$ ja, für das Quadrat

3) Hatten Sie den Eindruck, dass das Erscheinen von Raute oder Quadrat in unterschiedlichem Maße durch Ihre Tastendrücke beeinflussbar war?

$\square$ nein, kein Unterschied in der Beeinflussbarkeit von Raute und Quadrat

$\square$ ja, die Raute war in höherem Maße beeinflussbar

$\square$ ja, das Quadrat war in höherem Maße beeinflussbar

5) Sonstige Bemerkungen?

Jetzt geht es wieder am PC weiter! 


\section{Appendix B}

\section{Appendix B 1: Prime identification-questionnaire in Exp. 1}

1) Konnten Sie erkennen, dass vor dem „Mustermix“ noch etwas gezeigt wurde?

$$
\begin{aligned}
& \square \text { ja } \\
& \square \text { nein }
\end{aligned}
$$

2) Konnten Sie erkennen, was vor dem „Mustermix“ gezeigt wurde?

$$
\begin{aligned}
& \square \text { ja, und zwar: } \\
& \square \text { nein }
\end{aligned}
$$

Jetzt geht es wieder am PC weiter! 


\section{Appendix B 2: Prime identification-questionnaire in Exp. 2}

1) Konnten Sie erkennen, dass vor dem Buchstabengemisch noch etwas gezeigt wurde?

$$
\begin{aligned}
& \square \text { ja } \\
& \square \text { nein }
\end{aligned}
$$

3) Konnten Sie erkennen, was vor dem Buchstabengemisch gezeigt wurde?

$$
\begin{aligned}
& \square \text { ja, und zwar: } \\
& \square \text { nein }
\end{aligned}
$$

Jetzt geht es wieder am PC weiter! 


\section{Appendix B 3: Prime identification-questionnaire in Exp. $3+4$}

1) Konnten Sie erkennen, dass vor dem Erscheinen des Sterns noch etwas gezeigt wurde?

$$
\begin{aligned}
& \square \text { ja } \\
& \square \text { nein }
\end{aligned}
$$

4) Konnten Sie erkennen, was vor dem Stern gezeigt wurde?
$\square$ ja, und zwar:
$\square$ nein

Jetzt geht es wieder am PC weiter! 


\section{Erklärung}

Ich versichere, dass ich die vorliegende Arbeit ohne unzulässige Hilfe Dritter und ohne Benutzung anderer als der angegebenen Hilfsmittel angefertigt habe. Die aus fremdem Quellen direkt oder indirekt übernommenen Gedanken sind als solche kenntlich gemacht. Die Arbeit wurde bisher weder im Inland noch im Ausland in gleicher oder ähnlicher Form einer anderen Prüfungsbehörde vorgelegt. Die Arbeit wurde am Institut für Allgemeine Psychologie, Biopsychologie und Methoden der Psychologie der Technischen Universität Dresden unter wissenschaftlicher Betreuung von Prof. Dr. phil. habil. Thomas Goschke erstellt. Die Promotionsordnung der Fakultät Mathematik und Naturwissenschaften vom 20. März 2000 erkenne ich an.

Dresden, 23. Februar 2007

Katrin Linser 


\section{Danksagung}

Mein herzlicher Dank gilt den vielen Menschen, die zum Gelingen dieser Arbeit beigetragen haben.

Der erste Dank geht an Prof. Dr. Thomas Goschke für die Betreuung der Arbeit, die vielen wirklich wertvollen und motivierenden Anregungen, Diskussionen und Beiträge - sowohl zur Dissertation als auch zum gemeinsamen Artikel. In einer so freien Arbeitsatmosphäre promovieren zu können, habe ich sehr genossen.

Prof. Dr. Clemens Kirschbaum und Prof. Dr. Wolfgang Prinz danke ich für ihre Bereitschaft zur Übernahme der Zweitbegutachtung.

Mein Dank gilt außerdem Gesine Dreisbach, Maja Dshemuchadse, Friederike Engst (ihr auch für die spontane Hilfe im Copy-Shop!), Rico Fischer, René Mayer, Stefan Scherbaum, Tino Schmidt und Juliane Wendt-Kürschner, die während meiner Doktorandenzeit als Mitarbeiter am Institut für Allgemeine Psychologie zum Entstehen dieser Arbeit in vielen bereichernden Diskussionen beigetragen haben.

Die Dissertation entstand als Teil des Projektes „Willenshandlungen: Untersuchungen zur Natur und Kultur des Wollens“. Mein Dank geht deshalb an die Volkswagen-Stiftung die das Projekt im Rahmen des Programms "Schlüsselthemen der Geisteswissenschaften" finanziert hat. An dieser Stelle danke ich auch allen Mitarbeitern des Projekts für die anregenden Diskussionen bei Projekttreffen.

Für die Datenerhebung danke ich allen ehemaligen wissenschaftlichen Hilfskräften am Institut, insbesondere Andreas Kalkbrenner, Susanne Diekelmann, Katja Schmidt und Maja Dshemuchadse.

Mein ganz besonderer Dank geht an Robert Barlović, Gesine Dreisbach und Alexander Sack für das Korrekturlesen.

Noch viel mehr als für das Korrekturlesen danke ich Dir, liebster Robert, für all die schöne Zeit während der Fertigstellung dieser Arbeit, davor, darum herum und danach.

Der größte Dank gebührt meinen Eltern Christine und Ullus Linser sowie meiner Tante Margit für die stete Unterstützung nicht nur während meiner Dissertation. 